A Thesis

Entitled

Asymmetric Hydroformylation of Styrene in Supercritical Carbon Dioxide

By

Angela M. Kleman

Submitted as partial fulfillment of the requirements for The Master of Science Degree in Chemical Engineering

Adviser: Dr. Martin A. Abraham

Graduate School

The University of Toledo

May 2005 


\title{
An Abstract of
}

Asymmetric Hydroformylation of Styrene in Supercritical Carbon Dioxide

\author{
Angela M. Kleman
}

Submitted as partial fulfillment of the requirements for The Master of Science Degree in Chemical Engineering

The University of Toledo

May 2005

Hydroformylation reactions in supercritical carbon dioxide provide an environmentally conscious method of producing aldehydes for fine chemical and pharmaceutical products. Asymmetric ligands, such as (R)-BINAP, may be used to provide an enantioselective product. The benefits of producing a selective product include an overall reduction in costs, including those costs associated with separation and disposal of undesired and potentially harmful products. When these reactions are performed in environmentally benign solvents, such as supercritical carbon dioxide $\left(\mathrm{scCO}_{2}\right)$, additional environmental benefits are derived, such as ease of recycling of the solvent and unconverted reactants and elimination of the need for organic solvents.

In this study, rhodium based catalysts were prepared in supercritical carbon dioxide and evaluated for the hydroformylation of styrene to produce 2-phenylpropionaldheyde. Triphenylphosphine and (R)-BINAP were examined as ligands and their effects on the 
reaction were examined. The experiments showed that a catalyst is produced that promotes hydroformylation of styrene in supercritical carbon dioxide and that enantiomeric selectivity could be obtained using (R)-BINAP ligands. 


\section{Acknowledgements}

I would like to thank my adviser, Dr. Martin Abraham, first of all, for taking me on as a graduate student and secondly for all of his guidance, support, and assistance during the course of my research. I would also like to thank Dr. Mark Mason from the Department of Chemistry for his help and insights, as well as sharing his knowledge to help me better understand the chemistry aspect of my research. I would also like to thank Dr. Bruce Poling for his assistance as part of my examination committee.

I would also like to thank Selma Bektesevic for teaching me how to run the reactor, sharing her knowledge and insights, and having so much patience with me throughout the course of my research. I would also like to thank Sandeep Goud for his assistance with the GC/MS. I would also like to thank Nick Kingsley and Dr. Kim from the Department of Chemistry at The University of Toledo. Nick synthesized the rhodium-BINAP catalyst and helped me with NMR and IR spectroscopy. Dr. Kim shared his NMR skills and expertise.

Thank you also to Rob Dunmyer and Don Mockensturm who've been very helpful in helping me get my equipment started and keeping it running.

Also, I would like to thank the faculty and staff of the Department of Chemical and Environmental Engineering for supporting me as I transitioned into chemical engineering. Additionally, I would like to thank the faculty and staff of the Department of Bioengineering for their continuous support throughout my collegiate career.

Thank you also to my parents who have always been supportive of my endeavors everything's worked out OK in the end! 


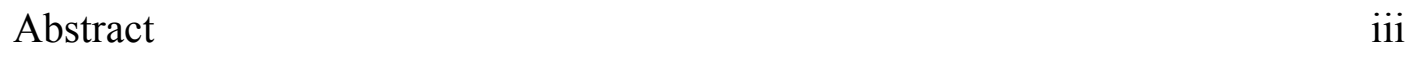

Acknowledgements $\quad \mathrm{v}$

Table of Contents vi

List of Tables \& Figures $\quad$ viii

Chapter One - Introduction 1

1.1 Pollution Prevention 1

1.2 The Reaction 2

1.3 Reactions in supercritical carbon dioxide 3

1.4 Motivation 4

1.5 Research Focus 6

$\begin{array}{ll}\text { Chapter Two - Literature Review } & 7\end{array}$

$\begin{array}{ll}2.1 \text { Hydroformylation } & 7\end{array}$

2.1.1 Homogeneous Catalysis $\quad 8$

2.1.2 Asymmetric Hydroformylation 11

2.1.3 NMR and IR Spectroscopy 13

$\begin{array}{ll}\text { 2.2 Supercritical Carbon Dioxide as a reaction solvent } & 14\end{array}$

$\begin{array}{ll}\text { Chapter Three - Experimental } & 16\end{array}$

$\begin{array}{ll}3.1 \text { Reactor } & 16\end{array}$

$\begin{array}{ll}\text { 3.2 Catalyst Loading } & 18\end{array}$

$\begin{array}{ll}3.3 \text { Reactant Loading } & 18\end{array}$

$\begin{array}{ll}3.4 \text { Experimental Procedure } & 19\end{array}$ 
Chapter 4 - Results and Discussion

4.1 Experiments Conducted

4.2 NMR \& IR Spectroscopy and Catalyst Evaluation

4.2.1 NMR and (R)-BINAP Catalysts 


\section{List of Table \& Figures}

Table/Figure

Page

Figure 1-1. Hydroformylation Reaction.

Figure 2-1. Generally accepted mechanism for the rhodium-catalyzed hydroformylation.

Figure 2-2. (R)-BINAP and (R,S)-BINAPHOS.

Figure 3-1. High pressure batch reactor system.

Figure 3-2. 2-Phenylpropionaldehyde.

Figure 3-3. (R)-BINAP and TPP.

Table 4-1. Reaction specifications.

Figure 4-1. General Reaction Profile.

Figure 4-2. General Reaction Profile, Normalized.

Figure 4-3. Loss of Styrene - Reproducibility.

Figure 4-4. Y Yield of Products - Reproducibility.

Figure 4-5. Solid State ${ }^{31} \mathrm{P}$ MAS NMR spectrum of (R)-BINAP.

Figure 4-6. Solid State ${ }^{31} \mathrm{P}$ MAS NMR spectrum of remaining catalyst residues from experiment $2 \mathrm{G}$.

Figure 4-7. Solid State ${ }^{31} \mathrm{P}$ MAS NMR spectrum of pure triphenylphosphine.

Figure 4-8. Solid State ${ }^{31} \mathrm{P}$ MAS NMR spectrum of remaining catalyst residues from experiment $1 \mathrm{~F}$.

Figure 4-9. IR spectrum of remaining catalyst residues from experiment 10Q. 
Figure 4-10. IR spectrum of remaining catalyst residues from experiment $7 \mathrm{M}$.

Figure 4-11. IR spectrum of remaining catalyst residues from experiment $2 \mathrm{G} . \quad 36$

Figure 4-12. Loss of Styrene at Different Pretreatment Conditions. 38

Figure 4-13. Yield of Products. 38

Figure 4-14. In situ temperature effects. 39

Figure 4-15. Reaction temperature and pressure effects. $\quad 40$

Figure 4-16. Loss of Styrene. $\quad 41$

Figure 4-17. Yield of Products. $\quad 41$

Figure 4-18. Loss of Styrene. $\quad 42$

Figure 4-19. Yield of Product Peak 1. $\quad 43$

Figure 4-20. Yield of Styrene - TPP as a ligand. $\quad 44$

Figure 4-21. Yield of Product Peak 1 - TPP as a ligand. 44

Figure 4-22. Loss of Styrene - Rh:P ratio variances using TPP. 45

Figure 4-23. Yield of Product Peak 1 - Rh:P ratio variances using TPP. $\quad 46$

Figure 4-24. Loss of Styrene - Rh:P ratio variances using TPP. 47

Figure 4-25. Yield of Products - Rh:P ratio variances using TPP. $\quad 47$

Figure 4-26. Loss of Styrene - Comparison of Ligands. 48

Figure 4-27. Product Yield - Comparison of Ligands. 49

Figure 4-28. Loss of Styrene - TPP as a ligand. 50

Figure 4-29. Yield of Products - TPP as a ligand. $\quad 50$

Figure 4-30. Loss of Styrene - BINAP as a ligand. 51 
Figure 4-31. Yield of Products - BINAP as a ligand.

Figure 4-32. Selectivity. $\quad 53$

Figure 4-33. Selectivity Comparison - Solid Catalysts. 54

Figure 4-34. Selectivity of Ligands. 55 


\section{Chapter One}

\section{Introduction}

\section{$\underline{1.1 \text { Pollution Prevention }}$}

The Pollution Prevention Act (PPA), codified as 42 USC 13101, was first passed by Congress in 1990, and "focused industry, government, and public attention on reducing the amount of pollution through cost-effective changes in production, operation, and raw materials use" (EPA, 2005). The Environmental Protection Agency (EPA) notes that source reduction is more desirable than waste management and pollution control; however, source reduction is complicated for several reasons including existing regulations and industrial resources required for compliance (EPA, 2005). This sentiment is echoed by others in the field of green engineering who point out that the maximum opportunity to reduce environmental impact occurs as early in the process design as possible. The EPA also notes that pollution prevention includes practices that increase efficiency in the use of energy, water, and other natural resources, as well as protecting resources via conservation (EPA, 2005).

The concept of improving a process or designing a process to be more environmentally friendly and have minimal negative impacts is referred to as green engineering. This concept is broadened and referred to as sustainable engineering when looking at the holistic impact on the people, the environment, and the benefits received 
over a span of time. Sustainable engineering focuses not only on the reactants being used and the products being created, but also on the origin or destination of these resources, the energy expenditures associated with the processes, and the well-being of the people impacted by the process (Abraham, 2004). While there are few, if any, truly sustainable processes; sustainability is meant as an improvement to the current situation.

\subsection{The Reaction}

Hydroformylation reactions were first discovered by Otto Roelen in 1938 (van Leeuwen, 2000). During the reactions, an olefin reacts in the presence of a catalyst, carbon monoxide, and hydrogen, to produce an aldehyde, as shown in Figure 1.1. In the 1960s, Wilkinson began investigating phosphorus modified rhodium catalysts (van Leeuwen, 2000); these catalysts were to improve the regioselectivity of the hydroformylation reaction towards the formation of the linear product. Wilkinson's research showed that rhodium provided selective hydroformylation under mild conditions in the presence of arylphosphines as a ligand; this lead to further research on hydroformylation and ligand effects (van Leeuwen, 2000).

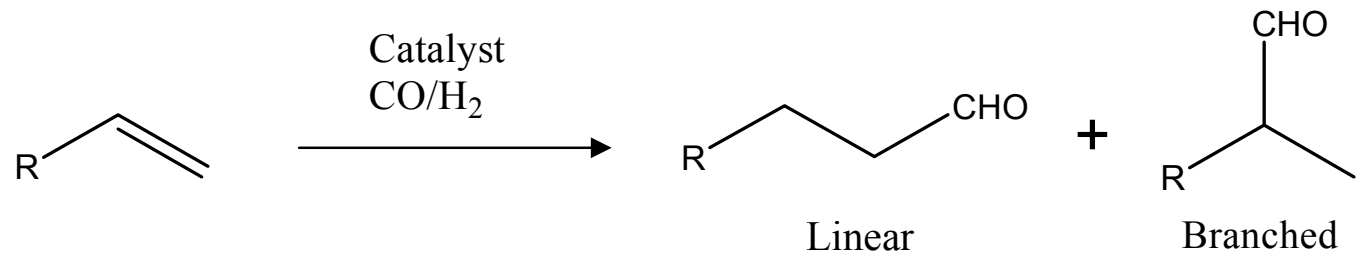

Figure 1-1. Hydroformylation Reaction. 
Providing selectivity to reactions has many benefits for industrial applications. For example, by producing a desired product in excess of an undesired product, separation processes can be reduced and possibly eliminated. In addition to reducing costs associated with separations, this would also reduce costs incurred through disposal of unwanted products. Furthermore, by increasing the yield of the desired product, the ability to produce the end products is greatly enhanced. This ultimately can increase the availability of the finished product.

\subsection{Reactions in supercritical carbon dioxide}

Supercritical carbon dioxide has been extensively studied in efforts to replace organic solvents that have traditionally been used in the hydroformylation reaction (Tack, 2003). Carbon dioxide is naturally abundant; it is non-toxic, readily available in large quantities, and relatively inexpensive. Supercritical carbon dioxide possesses favorable properties of both a liquid and a gas; it has high miscibility with reactant gases, no liquid/gas phase boundary, very low viscosity, very high diffusivity, and high compressibility (Koch \& Leitner, 1998; Tack, 2003). These solvent properties provide a suitable environment for hydroformylation reactions that minimizes their environmental implications, and allows for a more sustainable process to produce aldehydes. Additionally, aldehyde formation is often slower in traditional solvents, such as toluene, than in $\mathrm{scCO}_{2}$ (Koch \& Leitner, 1998). Since carbon dioxide is not consumed by the reaction, it can be recycled and reused for future applications. 


\subsection{Motivation}

Hydroformylation is widely used for large-scale processes, but it has not yet been applied extensively to fine chemical production (van Leeuwen, 2000). Aldehydes are often used in medicinal chemistry as intermediates between the starting components and the end product or pharmaceutical; thus, many benefits can be reaped if hydroformylation can be used to produce the aldehydes needed for fine chemical and pharmaceutical production (Hudson, 2004).

Applying asymmetric hydroformylation processes to fine chemical production can be greatly beneficial. To bring a new pharmaceutical to market, drug companies must provide evidence to the Food and Drug Administration (FDA) that their drug is both safe and effective. If a pharmaceutical is made with racemic mixtures of compounds, the drug company must show that both components of the racemic mixture are non-toxic. The process to ensure a product's safety can be very time consuming and costly, thereby delaying the product's market entry and delaying its benefits to patients. This process can be greatly simplified if the processes used to produce the pharmaceuticals synthesize only the desired enantiomeric aldehyde rather than producing a racemic mixture (Hudson, 2004).

Homogenous asymmetric catalysis is used to produce fine chemicals often used in pharmaceuticals, agrochemicals, flavors, and fragrances (Ojima, 2000). Chiral aldehydes with high enantiomeric purities obtained via asymmetric hydroformylation serve as useful intermediates for pharmaceutical drugs (Ojima, 2000). In particular, the branched aldehydes obtained from the hydroformylation of styrene can be converted to various non-steroidal anti-inflammatory agents (Ojima, 2000). Although the hydroformylation 
reaction used in this research focused on producing products with one chiral center, hydroformylation can also be used to produce products with more than one chiral center. The more complex chemistry using multiple chiral centers can be further enhanced by using specific ligands which target a specific chiral center (Hudson, 2004).

More cost-effective and safer large scale production of aldehydes for pharmaceutical use could provide great economic and health impacts. Asymmetric hydroformylation reactions can be used as a tool for the preparation of a large number of chiral products that can be used as precursors to organic compounds with therapeutic benefits (Castellanos-Paez, et al., 1997).

By synthesizing pharmaceuticals through new pathways, the availability of pharmaceuticals can be greatly increased and the cost can be greatly decreased. By increasing the availability of pharmaceuticals, the standard of living and general health can be greatly improved, especially among people in low and middle income countries. Life expectancies have increased over the years, with the greatest increases being in areas where antibiotics, other medicines, and immunizations are available (The World Bank Group, 2004). Although pharmaceuticals are available to help treat flu, pneumonia, diarrhea, cholera, and malaria, many third world childhood deaths are still attributed to these diseases; additionally, many children in third world countries are not immunized against many deadly, infectious diseases such as diphtheria, measles, polio, tetanus, typhoid, tuberculosis, and whooping cough (The World Bank Group, 2004).

Benefits of enhancing a pharmaceutical's availability are not limited to what improvements can be made in third-world countries; many benefits also exist in developed countries. Medicines play an important role in not only treatment, but also 
prevention. A study at Columbia University found that it is less costly overall to use newer medicines than it is to provide non-drug related health care (Lichtenberg, 2002). By using newer drugs, the need for costly hospitalization, institutionalization, or surgery is reduced (Lichtenberg, 2002).

\section{$\underline{1.5 \text { Research Focus }}$}

The current study examines the enantiomeric hydroformylation of styrene to produce 2-phenylpropionaldehyde; the significance of aldehyde production is that aldehydes are used in many fine chemical and pharmaceutical syntheses, as previously discussed. By performing the reaction using supercritical carbon dioxide and an enantioselective catalyst, a hydroformylation reaction can occur in such a way that minimizes negative environmental impacts and optimizes pharmaceutical benefits. 


\section{Chapter Two}

\section{Literature Review}

\subsection{Hydroformylation}

A German by the name Otto Roelen first described hydroformylation or 'oxo reactions' in a patent filed in 1938; for these reactions, Roelen used a cobalt-catalyzed process (van Leeuwen, 2000). Hydroformylation reactions add one molecule of carbon monoxide and one molecule of hydrogen to an olefin, thereby producing an aldehyde.

While the first generation of hydroformylation catalysts were based on cobalt carbonyls, the second generation of catalysts used rhodium and phosphorus ligands, particularly triphenylphosphine (van Leeuwen, 2000). The major advantage of rhodium catalysts is that the reactions could be carried out in low pressure; cobalt-catalyzed reactions required high pressures to stabilize the catalyst (van Leeuwen, 2000). Additionally, the rhodium catalysts provided better utilization of feed stocks and much faster reactions, which directly correlated to milder conditions noted above (van Leeuwen, 2000). The first rhodium precursors used were simple compounds such as $\mathrm{RhCl}_{3}$ and $\mathrm{Rh} / \mathrm{Al}_{2} \mathrm{O}_{3}$. The rhodium catalysts provided greater aldehyde formation than the cobalt catalysts and reduced the undesired hydrogenation reaction, hence the cobalt catalysts were replaced with rhodium catalysts in the mid 1970s (van Leeuwen, 2000). 
Wilkinson and his colleagues have made significant contributions to rhodium catalyzed hydroformylation (van Leeuwen, 2000). Using $\mathrm{RhCl}\left(\mathrm{PPh}_{3}\right)_{3}$, Wilkinson, et al. found that substitution at the aromatic ring affected the reaction rate (van Leeuwen, 2000). Wilkinson's group also determined that phosphine ligand variations had a minimal affect on rate and selectivity at the conditions used, $70{ }^{\circ} \mathrm{C}$ and 100 bar (about 1470 psig) (van Leeuwen, 2000). A generally accepted mechanism for rhodiumcatalyzed hydroformylation is summarized in Figure 2.1.

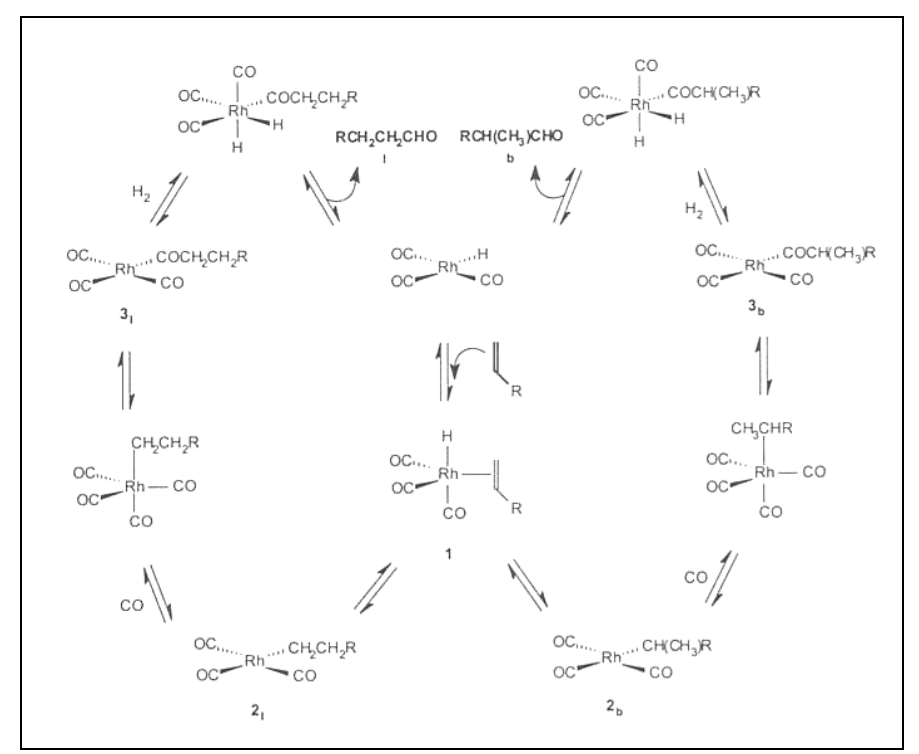

Figure 2-1. Generally accepted mechanism for the rhodium-catalyzed hydroformylation. (Van Leeuwen, 2000)

\subsubsection{Homogeneous Catalysis}

Homogeneous catalysis is defined as a catalytic reaction in which the catalyst and the reactants are in the same phase. Since the catalyst is dissolved in the medium, each molecule of a particular structure acts like any other molecule (Satterfield, 1991); therefore, not only do homogeneous reactions in supercritical fluids dissolve the organic substrates, they can lead to longer catalyst lifetimes relative to gas-phase heterogeneous catalysis (DeSimone \& Tumas, 2003). 
Homogeneous reactions require the reclamation of highly expensive and often specialized catalysts (Aresta, 2003). Extensive research has enabled researchers to control the stereoelectronic environment around the transition-metal center via ligand design; this has led to significant developments in homogeneously catalyzed reactions over the past 30 years (DeSimone \& Tumas, 2003).

Phosphorus ligands are the only ligands used in hydroformylation in addition to carbon monoxide (van Leeuwen, 2000). The performance of the hydroformylation catalyst can be greatly affected by the phosphorus ligands present in the reaction (Bunten, et al., 2002). Modified phosphorus ligands sometimes form very selective catalysts (van der Slot, et al., 2002).

Triphenylphosphine is one of the most commonly used ligands in industry. Dickson (1985) reported that co-oxidation of triphenylphosphine and terminal alkenes produces rhodium catalysts, among which, $\mathrm{RhCl}\left(\mathrm{PPh}_{3}\right)_{3}$ was observed to be the most effective catalyst. During the 1970s, Celanese, Union Carbide Corporation, and Mitsubishi Chemical Corporation used triphenylphosphine for ligand-modified processes (van Leeuwen, 2000).

Under hydroformylation conditions, a rhodium carbonyl hydride, $\left[\mathrm{HRh}(\mathrm{CO})_{3}\right]_{2}$, is produced (van Leeuwen, 2000). This rhodium carbonyl hydride is the active catalytic species of the reaction (van Leeuwen, 2000). Additionally, Bensaid reported that free phosphines play an important role in transformation of catalyst precursors into the presumed catalytically active complexes, the rhodium carbonyl hydrides (2002). Bensaid also notes that systems in which the excess quantity of free phosphine is greater than ten-fold, the hydroformylation reactions are inhibited (2002). 
Hydroformylation research has focused on developing new ligands to obtain highly active and selective catalysts (van der Slot, et al., 2002). Ligand modifications are the most effective way to influence the selectivity of rhodium-catalyzed reactions (Reinius \& Krause, 2000). For this reason, it is important to understand the structure-activity relationships so that a ligand can be designed specifically to favor the desired products. The influence of the ligands is primarily due to the electronic and the steric effects (van Leeuwen, 2000); however, the dominant effect is believed to vary depending on the stability of the catalyst complex.

Reinius and Krause observed regiocontrol during the hydroformylation of styrene with an in situ formed rhodium-phosphorus complex (2000); they also state that the factors that most greatly affected regioselectivity were the substrate and the modifying ligand. Ali, et al. (2005) noted that high catalytic activity occurred during a reaction in which $\mathrm{Rh}_{6}(\mathrm{CO})_{16}$ was used as a rhodium complex. The activity was likely due to protonation of the rhodium carbonyl intermediates and stabilization of an active catalytic intermediate (Ali, et al., 2005). Advanced knowledge of the correlation between central atoms and ligands has greatly improved the activity and selectivity (Ali, et al., 2005).

Although the ligand sometimes provides much desired selectivity, it can often slow the rate of reaction (van der Slot, et al., 2002). The general trend is that the greater the phosphorus loading, the greater the inhibition of the reaction. Ideally, a ligand would provide selectivity and not affect the activity of the reaction.

Phosphite ligands were examined in the 1960s, but triphenylphosphine (TPP) continued to be the catalyst of choice; the interest in phosphite ligands arose again in the 1980s because Bryant et al. made bulky monophosphites with better stability and they 
were found to give very high rates (van Leeuwen, 2000). Eastman's BISBI is an example of a diphosphine ligand that became very popular for rhodium hydroformylation (van Leeuwen, 2000).

The regioselectivity of the reaction, which is the ratio of linear to branched products, depends on the substrate being used. When styrene, a vinyl substrate, is used, the branched aldehyde should be produced in abundance (van Leeuwen, 2000). In a system in which the unmodified rhodium-based precursors were used between $20^{\circ} \mathrm{C}$ and $100{ }^{\circ} \mathrm{C}$, van Leeuwen states that the formation of the linear aldehyde during styrene hydroformylation increased as temperature increased (2000). Van Leeuwen did not note selectivity changes for a phosphorus modified rhodium-based system (2000). Additional research by Matsuda et al. (2001) reports that enantioselectivity can be increased by decreasing the pressure while maintaining a constant temperature. Balsells and Walsh (2000) note that enantioselectivity can also be controlled by the use of diastereomers.

The partial pressures of carbon monoxide and hydrogen during the reaction also affect regioselectivity, but only when the reaction is carried out at high temperatures $\left(100^{\circ} \mathrm{C}\right)$ (van Leeuwen, 2000). Van Leeuwen notes that for styrene hydroformylation at $100{ }^{\circ} \mathrm{C}$, an equimolar mixture of $\mathrm{CO}$ and $\mathrm{H}_{2}$ at 170 bar ( $\left.\sim 2500 \mathrm{psig}\right)$ would give a branched to linear ratio of 80 to 20 (2000).

\subsubsection{Asymmetric Hydroformylation}

Many hydroformylation reactions on pro-chiral alkenes provide two enantiomeric products that are generally equimolar. Asymmetric hydroformylation, however, provides an enantiomeric excess of one enantiomer relative to the production of the other 
enantiomer. Asymmetric hydroformylation has historically been done using transitionmetal complexes, primarily those using rhodium and platinum (Castellanos-Paez, et al., 1997). Additionally Wilkinson's catalyst was used for asymmetric hydrosilylation of ketones; since this catalyst provided asymmetric products, research grew in the area of using rhodium complexes with chiral phosphine ligands (Ojima, 2000). During the 1970s, several chiral phosphine-rhodium catalysts were used that provided low-tomoderate enantioselectivity (Ojima, 2000).

Asymmetric hydroformylation used to transform substrates into aldehydes can be used on substrates with one or more chiral center (Ojima, 2000). Styrene is extensively studied for asymmetric hydroformylation reactions because it has a high reactivity and high selectivity for yielding branched aldehydes (Ojima, 2000).

Rhodium-BINAP complexes are often studied for their enantioselective hydrogenation abilities (Bunten, et al., 2002); although other ligands have been used to successfully perform asymmetric hydroformylation reactions. Chiral diphosphite ligands have been used in asymmetric hydroformylation of styrene; a regioselectivity of branched:linear $=98: 2$ was observed using this ligand (Ojima, 2000). A Rh-BINAPHOS complex supported on a highly cross-linked polymer was found to also provide high regioselectivity and enantioselectivity when styrene is used as the substrate (Ojima, 2000). 

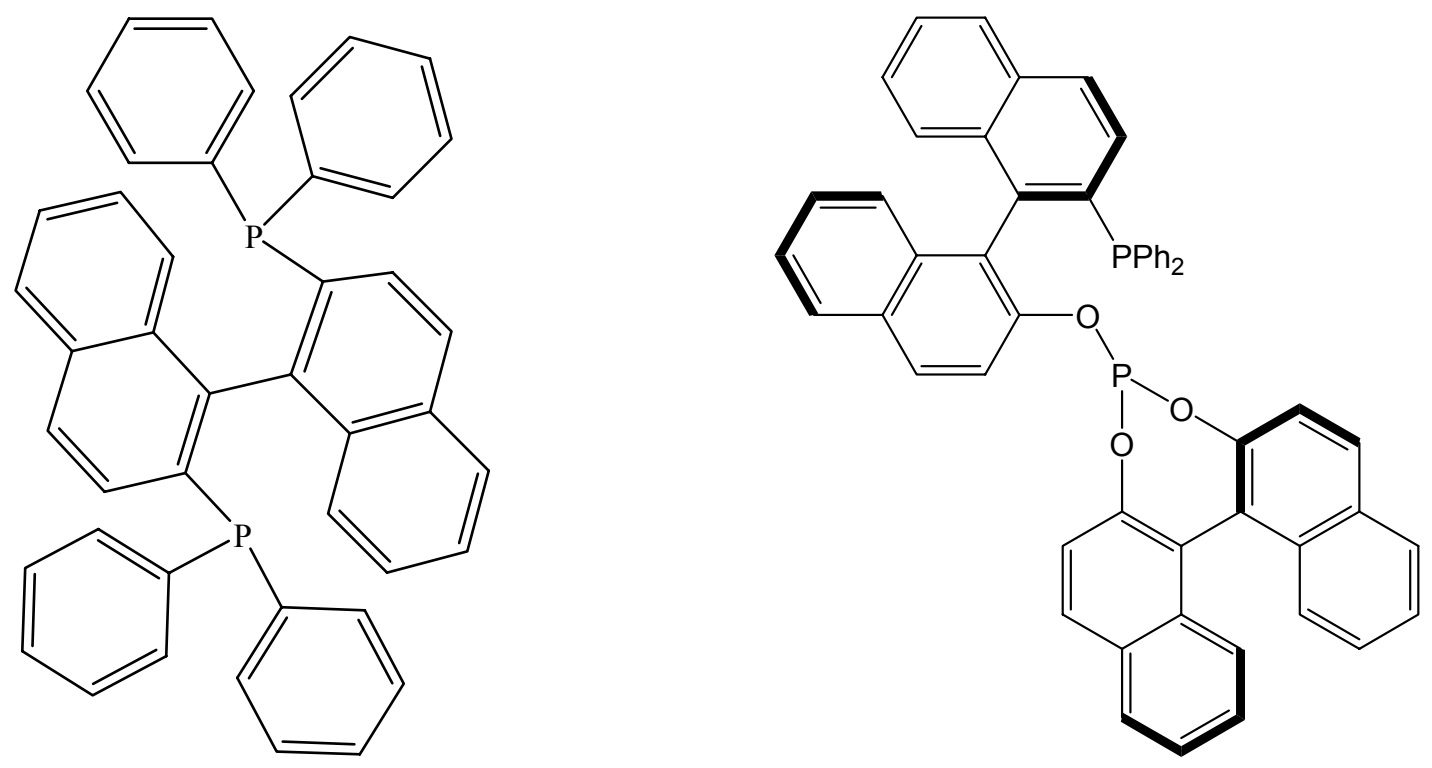

Figure 2-2. (R)-BINAP and (R,S)-BINAPHOS. (R)-BINAP ligand is shown on the left and $(\mathrm{R}, \mathrm{S})-\mathrm{BINAPHOS}$ is shown on the right.

\subsubsection{NMR and IR Spectroscopy}

Various ${ }^{31} \mathrm{P}$ NMR data can be found for rhodium phosphine complexes. Quin and Verkade (1994) reported doublets at 61.6 and $46.1 \mathrm{ppm}$, with $J_{\mathrm{RhP} 1}=189$ and $J_{\mathrm{RhP} 2}=205$ $\mathrm{Hz}$ for $[\mathrm{CIRh}(\mathrm{P} \sim \mathrm{O})(\mathrm{PO})]$. Quin and Verkade (1994) also reported $\delta \mathrm{P}-\mathrm{Rh}$ with the following values: $26.5,29.3,25.3$, and $25.5 \mathrm{ppm}$; thereby giving $\delta \mathrm{P}-\mathrm{Rh}$ a range in the mid-to high twenties (ppm). Quin and Verkade (1994) also reported values for ${ }^{1} J_{\mathrm{RhP} 1}$ equal to $104,100,134$, and $111 \mathrm{~Hz}$; thereby giving an acceptable range of 100 to $134 \mathrm{~Hz}$ for values of ${ }^{1} J_{\mathrm{RhP} 1}$.

Bunten, et al. (2002) reported doublets found in Rhodium-BINAP complexes at 50, 46.1, 24.9, and $48.6 \mathrm{ppm}$; singlets were found in oxidized Rhodium-BINAP complexes at 28.1 and $29.3 \mathrm{ppm}$. Values of $J_{\mathrm{RhP}}$ were also reported at $195,163,128$, and $175 \mathrm{~Hz}$ for compounds using BINAP as a ligand (Bunten, et al., 2002). 
Various IR frequencies of carbonyl groups can be found throughout the literature. Van der Slot, et al. (2002) reported a value for $v_{\mathrm{CO}}\left(\mathrm{cm}^{-1}\right)$ of 1978 for triphenylphosphine when used with $\mathrm{RhCl}(\mathrm{CO})\left(\mathrm{PPh}_{3}\right)_{2}$. Bunten, et al. reported values for similar active catalysts at $v_{\mathrm{CO}}$ of 1978 and $2018 \mathrm{~cm}^{-1}$ (2002). Van Leeuwen reports rhodium hydride signals for similar active catalysts ranging from 1996 to $2093 \mathrm{~cm}^{-1}$ (2000).

\section{$\underline{2.2 \text { Supercritical Carbon Dioxide as a reaction solvent }}$}

The interest in supercritical fluids is justified on several bases; supercritical fluids (Akgerman, 1997):

(1) reduce environmental problems associated with commonly used organic solvents,

(2) provide a less expensive means of separation with respect to energy costs, and

(3) provide a means of achieving necessary separations that can adapt to emerging industrial needs.

Supercritical carbon dioxide has many advantages over traditionally used solvents. According to Koch and Leitner (1998), "Supercritical carbon dioxide is an environmentally benign reaction medium for highly efficient rhodium-catalyzed hydroformylation reactions." Many advantages are associated with using $\mathrm{scCO}_{2}$ for metal-catalyzed chemical synthesis because of its "gas-like" properties: high miscibility with reactant gases, no liquid/gas phase boundary, very low viscosity, very high diffusivity, and high compressibility (Koch \& Leitner, 1998; Tack, 2003). Another advantage of $\mathrm{scCO}_{2}$ is that it is nonflammable, which is an advantage that it has when compared to conventional organic solvents used in hydroformylation reactions (Liu, et al., 2003). Additionally, carbon dioxide can be separated from product gases and reused; 
absorption, cryogenic distillation, adsorption, and membranes provide means of separating $\mathrm{CO}_{2}$ from other gases used in the synthesis (Liu, et al., 2003).

Homogeneous catalysis in $\mathrm{scCO}_{2}$ has been extensively studied; these reactions provide equal, if not better regioselectivity in hydroformylation reactions (Aresta, 2003). Higher reaction rates are obtained when using $\mathrm{scCO}_{2}$ as a reaction medium for rhodiumcatalyzed hydroformylation, with a reaction rate increase at least 5 times that obtained when using toluene as a reaction medium (Koch \& Leitner, 1998). Additionally, phosphorus donor ligands have been used for hydroformylation in $\mathrm{scCO}_{2}$ when the ligands are soluble in the supercritical fluid (Koch \& Leitner, 1998).

Palo and Erkey (2000) reported that the electron withdrawing effect of fluoroalkyl moieties increases the activity of the rhodium hydroformylation catalysts when the form of the catalysts is $\mathrm{HRh}(\mathrm{CO}) \mathrm{L}_{3}$, with $\mathrm{L}$ being the ligand; Palo and Erkey's research focused on evaluating the effect of ligand modifications for rhodium-catalyzed homogeneous hydroformylation in $\mathrm{scCO}_{2}(2000)$.

Akgerman has made many contributions in the area of supercritical fluids. Akgerman (1997) reported that using supercritical fluids yields better selectivity to desired compounds, which eliminates costly separations of products and minimizes waste accumulation due to undesired product formation. Akgerman (1993) also reported that advantages of using $\mathrm{scCO}_{2}$ in catalytic reactions also include "ease of solvent recovery, elimination of residual solvent in the extracted medium, lower pressure drops, and enhanced mass transfer rates." Akgerman and associates have also conducted research in areas of supercritical fluids, including supported rhodium catalysis (Kani, et al., 2004; Kani, et al., 2002). 


\section{Chapter Three}

\section{Experimental}

\section{$\underline{3.1 \text { Reactor }}$}

Hydroformylation of styrene in supercritical carbon dioxide was used to evaluate various methods of in situ catalyst preparation with variations in rhodium to phosphorus ratios. The $300 \mathrm{~mL}$ reactor (Figure 3.1) was manufactured by Autoclave Engineers; it is operable to $5400 \mathrm{psig}(37.2 \mathrm{MPa})$ at $344{ }^{\circ} \mathrm{C}$, as described in previous works (Tadd 2001, Tack 2003). To ensure safety, the reactor was equipped with a 5000 psig rupture disc and was operated with a Lexan shield surrounding the reactor. The reactor used an Omega Type K thermocouple and a Sensotech pressure transducer for temperature and pressure indication, respectively.

The reactor was heated using a clamp-on ceramic heating jacket supplied by Industrial Heater Corporation. Temperature control was provided by a Partlow 1160+ PID controller in conjunction with a type $\mathrm{K}$ thermocouple placed in the reactor. 


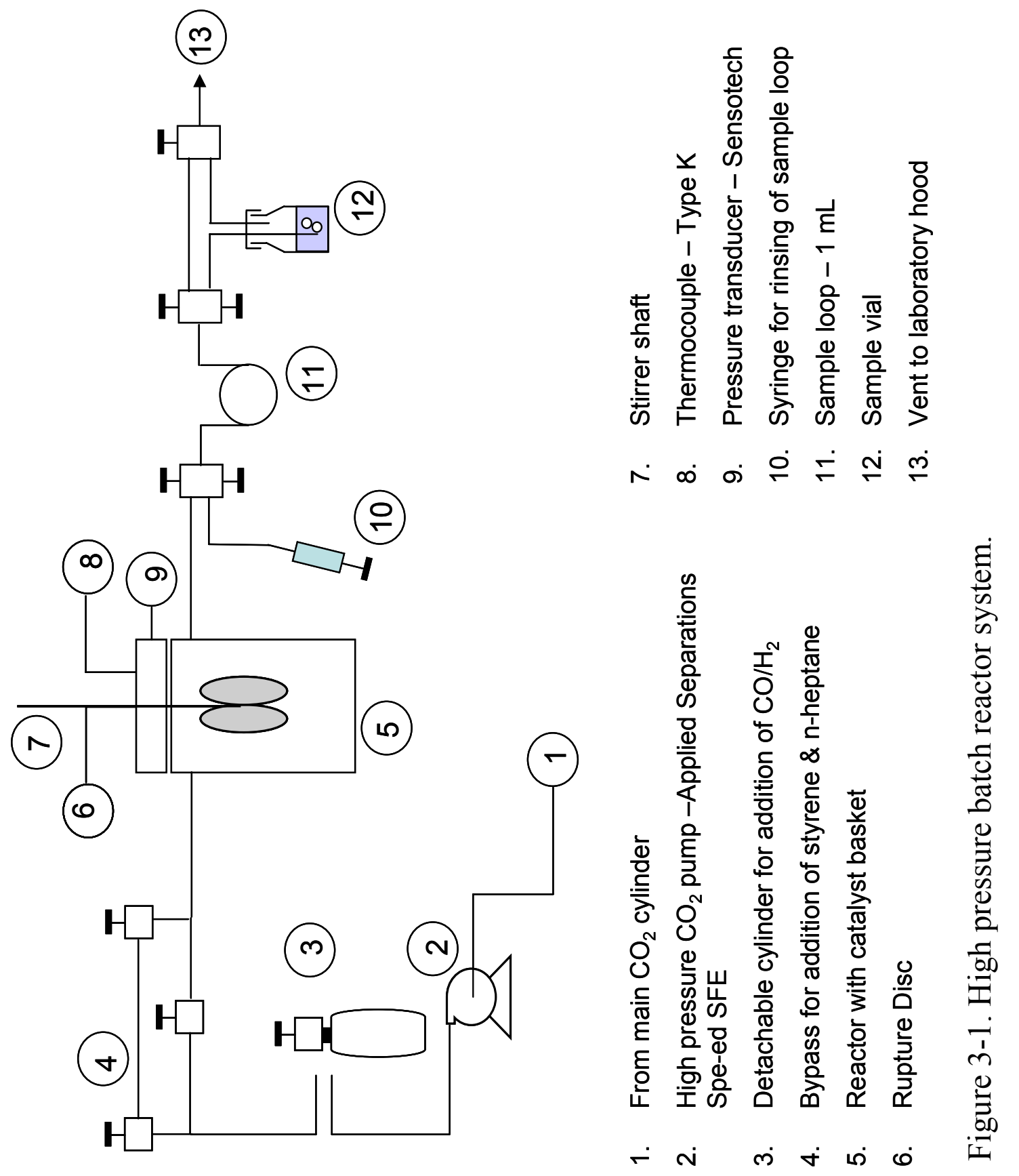




\subsection{Catalyst Loading}

The catalysts used in all experiments were solids in the form of flakes or powder. A $5 \mu \mathrm{m}$ nylon mesh material (Spectrum Labs) was created by cutting two small rectangles of mesh; three of the rectangle's edges were fused together using a variable wattage soldering iron. A measured amount of catalyst or catalyst precursors was added to the pouch through the open end; the remaining edge was then soldered to secure the catalyst inside the pouch and prevent disbursement throughout the reactor.

The catalyst envelope was then clamped between two heavy gauge screens mounted on discs located on the stirring shaft. The screens and discs were configured so that two catalyst envelopes could be used during reactions, however only one catalyst envelope was used during any reaction.

\section{$\underline{3.3 \text { Reactant Loading }}$}

An equimolar mixture of carbon monoxide and hydrogen was added to a sample cylinder (Whitey) from a gas cylinder (AirGas); the sample cylinder was pressurized to 1400 psig. The sample cylinder was then weighed and its contents brought into equilibrium with the sealed reaction vessel. The sample cylinder was then weighed to determine the weight of the carbon monoxide and hydrogen added to the reactor. The reactor was then heated to the desired temperature.

Experimental variances occurred after the desired temperature was obtained; these variances are noted in the results and discussion section of this work. The first variance is that the reactor was maintained at the pressure obtained by adding only carbon monoxide and hydrogen to the vessel; the contents of the reactor were held at this 
pressure and temperature for 24 hours to allow in situ catalyst formation to occur. The second variance is that carbon dioxide was added to the reactor using a high pressure liquid pump (Applied Separations Spe-ed SFE). This increased the pressure inside the vessel to obtain supercritical conditions; the contents of the reactor were then held at this elevated pressure and temperature for 24 hours to allow in situ catalyst formation to occur.

Prior to the experiment, a known amount of styrene and n-heptane was added to the bypass section (item 4 in Figure 3-1). After the 24 hour in situ catalyst preparation period, the high pressure liquid pump was used to push $\mathrm{CO}_{2}$ through the bypass line, thereby forcing the styrene and $n$-heptane from the bypass line into the reaction vessel. The pump was turned off when the reaction pressure was achieved.

\subsection{Experimental Procedure}

In preparation for an experimental run, the reaction vessel was disassembled and thoroughly cleaned using acetone and ethyl acetate. After cleaning, the reaction vessel was reassembled. The sample loop was flushed with ethyl acetate to remove any remaining reactants or products. The pressure transducer was also rinsed using acetone and allowed to air dry.

After sealing the reactor with the catalyst envelope attached to the stir column as previously described, the system was then powered on so that the system pressure and temperature could be observed. The heating jacket was set to provide a temperature slightly greater than room temperature, so as to minimize temperature fluctuation affects during pressurization. The reaction vessel was flushed using $\mathrm{CO}_{2}$ with a maximum 
pressure no greater than $500 \mathrm{psig}$. The $\mathrm{CO}_{2}$ was purged from the reaction vessel via the sample loop and discharged into the hood; the purging allowed the pressure inside the reactor to drop to atmospheric pressure.

The sample cylinder containing an equimolar mixture of carbon monoxide and hydrogen was connected to the system and its contents brought into equilibrium with the contents of the reaction vessel. The temperature of the heating jacket was then incrementally increased until the desired temperature was obtained; this process was carefully observed so as to minimize overshoot, with a maximum overshoot no greater than $10^{\circ} \mathrm{C}$ above the desired temperature.

After heating to the desired temperature, carbon dioxide was added in select experiments so that the reaction vessel was brought to an elevated pressure. To allow for in situ catalyst preparation, the contents of the reactor were maintained at the given temperature and pressure with mixing for 24 hours. At the conclusion of the 24 hour period, the reactor was pressurized using liquid $\mathrm{CO}_{2}$ to obtain a pressure approximately 500 psig lower than the desired reaction pressure. The reaction system was then allowed to stabilize, normally requiring no greater than $1 / 2$ hour to achieve stability. After achieving stability, the styrene and n-heptane present in the bypass were pushed into the reactor using liquid $\mathrm{CO}_{2}$; this process continued until the desired reaction pressure was achieved, usually requiring no greater than 3 minutes to obtain desired pressure. The start of the experiment is marked from the time the contents of the bypass line began being flushed into the reactor.

Sampling began at 15 minutes; additional samples were taken generally at $30,45,60$, 75, 90, and 120 minutes with hourly samplings occurring for the next 4 hours of the 
experiment. If additional samples were needed, they were taken at the 9 hour mark and then every 6 or 12 hours thereafter.

Following the reaction, the contents were purged into the ventilation hood and the power to the system terminated. The system was allowed to cool to ambient temperature before disassembling. The catalyst pouch was removed and placed in a sample vial; the contents collected on the bottom of the reactor were removed via pipette and put into sample vials for later analysis using GC/MS. The cleaning procedure described previously was used to prepare the reactor for the next experimental run.

\section{$\underline{3.5 \text { Analytical Methods }}$}

The reaction's progress, the utilization of styrene and the production of products, was monitored by taking samples for analysis by gas chromatography. Products were identified using a Hewlett-Packard 6980 gas chromatograph and a 5973 mass selective detector. A chiral Supelco Beta Dex ${ }^{\mathrm{TM}} 225$ column $(30 \mathrm{~m}$ x $0.25 \mathrm{~mm}$ x $0.25 \mu \mathrm{m}$ film, column number 16651-018) was used to achieve separation of the styrene reactant and the enantiomeric products. A temperature ramp was used, with an initial temperature $40^{\circ} \mathrm{C}$ for 5 minutes, then increasing $10{ }^{\circ} \mathrm{C}$ per minute until a temperature of $85{ }^{\circ} \mathrm{C}$ was reached; the total time needed to complete a sample's analysis was 39.5 minutes. Samples were collected from the reactor by expansion through $1 \mathrm{~mL}$ of ethyl acetate in a $5 \mathrm{~mL}$ screw cap vial. The sample was bubbled through the solvent. The organic components were trapped in the liquid solvent while the $\mathrm{CO}, \mathrm{H}_{2}$, and $\mathrm{CO}_{2}$ escaped; therefore, these components were not quantified. 
The contents of the sample were quantitatively measured; this was accomplished by using known mixtures of the reactants and products and comparing the samples' contents to the internal standard, n-heptane. Mass spectrometry was used to identify the components. Gas chromatography was used to obtain absorbance measurements of the components in the reaction sample; the absorbance measurements were compared to the calibrations to quantify the amount of each component in the sample. Most reactions were terminated when full conversion of styrene was obtained, and the time required to achieve full conversion varied. Calibration curves were constructed in which the areas observed were converted to mole ratios. The standardization curves exhibited a linear fit. The slopes were assumed to be response factors, $R_{f}$, which would allow the concentrations in the reactor to be quantified by using the observed area ratios of the samples.

$$
\begin{aligned}
& \frac{A_{A}}{A_{S}}=R_{f}\left(\frac{N_{A}}{N_{S}}\right) \\
& N_{A}=\frac{1}{R_{f}}\left(\frac{A_{A}}{A_{S}}\right) N_{S}
\end{aligned}
$$

The internal standard, n-heptane, was used because it would not react with either the reactants or the products of the reaction.

The known samples used in producing the calibrations were prepared using purchased materials of high purity. The products from the reaction, 2-phenylpropionaldehyde, shown in Figure 3-2, are enantiomers and were purchased in a mixture, which is believed to be racemic. Both enantiomeric products were obtained from the analysis; however, no effort was made to identify the individual enantiomers because the separate enantiomers were not found to be commercially available. 


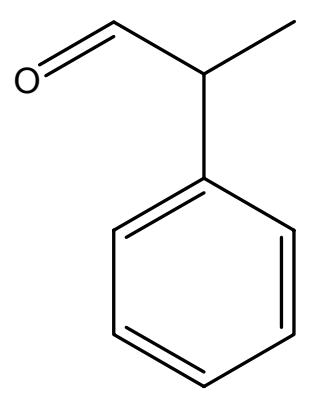

Figure 3-2. 2-Phenylpropionaldehyde. 2-Phenylpropionaldehyde is the enantiomeric product produced by the hydroformylation reaction.

\section{$\underline{3.6 \text { Catalysts }}$}

Most of the catalysts used were produced in the reaction vessel. These catalysts were made during a pretreatment process in which the $\left[\mathrm{RhCl}\left(\mathrm{C}_{8} \mathrm{H}_{12}\right)\right]_{2}$ and the phosphorus component, either (R)-BINAP or triphenylphosphine, were placed in a mesh envelope, the envelope sealed and affixed to the stir bar, and put into the reactor with mixing at a specified temperature, pressure, and mixture of $\mathrm{CO}$, and $\mathrm{H}_{2}$, or $\mathrm{CO}, \mathrm{H}_{2}$, and $\mathrm{CO}_{2}$. $\left[\mathrm{RhCl}\left(\mathrm{C}_{8} \mathrm{H}_{12}\right)\right]_{2}$ was prepared in the Department of Chemistry at The University of Toledo; the procedure for synthesis can be found in Inorganic Syntheses (Giordano \& Crabtree, 1990). The (R)-BINAP, was purchased from Strem Chemicals; its purity is 98\%. The triphenylphosphine was purchased from Aldrich Chemical Company, Inc.; its purity is $99 \%$. Figure 3-3 shows the chemical structure of each ligand used in the experiments. 

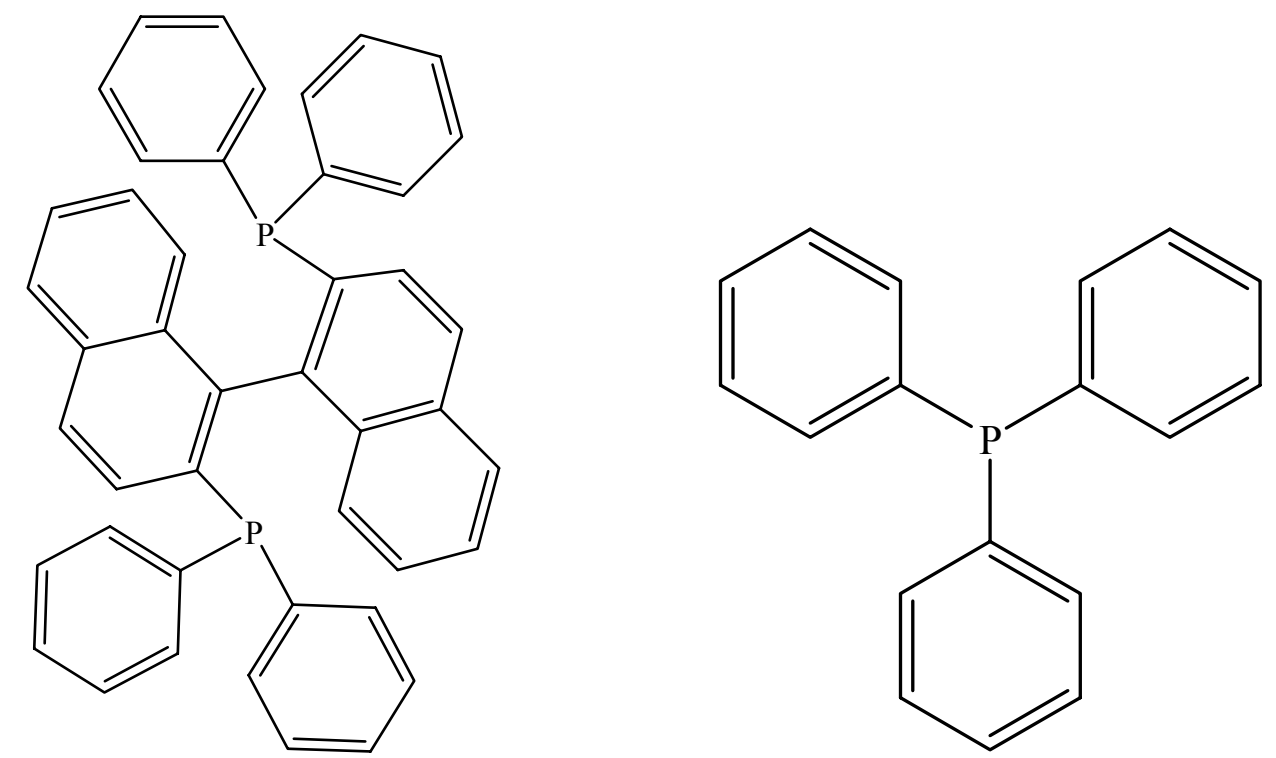

Figure 3-3. (R)-BINAP and TPP. (R)-(+)-2,2'-Bis(diphenylphosphino)-1,1'-binaphthyl is shown on the left and triphenylphosphine on the right.

Other catalysts used were prepared by Nick Kingsley of the Department of Chemistry at The University of Toledo. These catalysts included: Wilkinson's Catalyst, a solid catalyst with a Rh:P ratio of $1: 3$, a solid catalyst with a $\mathrm{Rh}: \mathrm{P}$ ratio of $2: 1$, and a solid rhodium-BINAP complex. The catalysts that were prepared by Nick Kingsley were characterized by ${ }^{31} \mathrm{P}$ solid state NMR spectroscopy. The preparation and characterization of the solid catalysts with $\mathrm{Rh}: \mathrm{P}$ ratios of $1: 3$ and $2: 1$ can be found in the dissertation by Marteel (2003). The preparation method for the solid rhodium-BINAP complex, $\mathrm{C}_{96} \mathrm{H}_{80} \mathrm{Cl}_{2} \mathrm{P}_{4} \mathrm{Rh}_{2}$, can be found in the supplemental materials of an article by Bunten, et al. (2002). The preparation of Wilkinson's catalyst can be found in The Journal of the American Chemical Society (Gassman, et al., 1985).

After the reaction was completed, the mesh envelope was opened and the catalyst was removed. The catalysts were analyzed using solid state phosphorus $\left({ }^{31} \mathrm{P}\right) \mathrm{NMR}$, liquid state phosphorus $\left({ }^{31} \mathrm{P}\right) \mathrm{NMR}$, liquid state proton $\left(\mathrm{H}^{1}\right) \mathrm{NMR}$, and IR spectroscopy, all of which occurred with the assistance and supervision of Dr. Yong-Wah Kim from the 
Department of Chemistry at The University of Toledo. Working with the constraint of having very small amounts of catalyst, some of the catalysts were not able to be analyzed after the reaction. All obtained spectroscopy outputs can be found in Appendix A. 


\section{Chapter 4}

\section{Results and Discussion}

\subsection{Experiments Conducted}

Table 4-1 shows the experiments that were conducted over the course of my research. The components used include the following compounds: $\left[\mathrm{RhCl}\left(\mathrm{C}_{8} \mathrm{H}_{12}\right)\right]_{2}$, triphenylphosphine (TPP), and (R)-(+)-2,2'-Bis(diphenylphosphino)-1,1'-binaphthyl (BINAP). The atomic ratio of rhodium to phosphorus is noted, as it was varied for experiments to determine its effects on selectivity.

The catalysts were placed in the reactor for a 24 hour period prior to injecting styrene and n-heptane into the reactor. The purpose of this pretreatment period was to allow the catalyst time to undergo an in situ reaction in which the two components of the catalyst would react to make a homogeneous soluble catalyst; although several experiments noted in Table 4-1 show that only one catalyst component was used, the in situ preparation period was used in all experiments to maintain uniformity throughout the experiments. Additionally, for the pretreatments in which the pressure was 650 psig, only carbon monoxide and hydrogen were present in the reactor; whereas, for the pretreatments in which the pressure was 2000 psig, carbon dioxide was present in the reactor in addition to carbon monoxide and hydrogen. When the reactions were performed, carbon monoxide, hydrogen, and carbon dioxide were present in the reactor. 
Table 4-1. Reaction specifications.

\begin{tabular}{|c|c|c|c|c|c|c|}
\hline \multirow[b]{2}{*}{$\begin{array}{l}\text { Rxn. } \\
\text { Code }\end{array}$} & \multirow[b]{2}{*}{ Components } & \multirow[b]{2}{*}{$\begin{array}{l}\text { Rh:P } \\
\text { Ratio }\end{array}$} & \multicolumn{2}{|c|}{$\begin{array}{c}\text { Pretreatment } \\
\text { Conditions }\end{array}$} & \multicolumn{2}{|c|}{$\begin{array}{c}\text { Reaction } \\
\text { Conditions }\end{array}$} \\
\hline & & & $\begin{array}{l}\text { Temp. } \\
\left({ }^{\circ} \mathrm{C}\right)\end{array}$ & $\begin{array}{c}\text { Pressure } \\
\text { (psig) }\end{array}$ & $\begin{array}{l}\text { Temp. } \\
\left({ }^{\circ} \mathrm{C}\right)\end{array}$ & $\begin{array}{c}\text { Pressure } \\
\text { (psig) }\end{array}$ \\
\hline $1 \mathrm{~F}$ & {$\left[\mathrm{RhCl}\left(\mathrm{C}_{8} \mathrm{H}_{12}\right)\right]_{2} \& \mathrm{TPP}$} & $1: 8$ & 90 & 650 & 90 & 2500 \\
\hline $2 \mathrm{G}$ & {$\left[\mathrm{RhCl}\left(\mathrm{C}_{8} \mathrm{H}_{12}\right)\right]_{2} \&$ BINAP } & $1: 4$ & 90 & 650 & 90 & 2500 \\
\hline $3 \mathrm{H}$ & {$\left[\mathrm{RhCl}\left(\mathrm{C}_{8} \mathrm{H}_{12}\right)\right]_{2}$} & N/A & 90 & 650 & 90 & 2500 \\
\hline $4 \mathrm{~J}$ & Wilkinson's Catalyst & $1: 3$ & 90 & 650 & 90 & 2500 \\
\hline $5 \mathrm{~K}$ & Solid Catalyst - TPP & $1: 3$ & 90 & 650 & 90 & 2500 \\
\hline $6 \mathrm{~L}$ & {$\left[\mathrm{RhCl}\left(\mathrm{C}_{8} \mathrm{H}_{12}\right)\right]_{2} \& \mathrm{TPP}$} & $1: 34$ & 50 & 2000 & 75 & 3000 \\
\hline $7 \mathrm{M}$ & {$\left[\mathrm{RhCl}\left(\mathrm{C}_{8} \mathrm{H}_{12}\right)\right]_{2} \& \mathrm{TPP}$} & $1: 8$ & 50 & 2000 & 90 & 2500 \\
\hline $8 \mathrm{~N}$ & {$\left[\mathrm{RhCl}\left(\mathrm{C}_{8} \mathrm{H}_{12}\right)\right]_{2} \& \mathrm{TPP}$} & $1: 34$ & 50 & 2000 & 90 & 2500 \\
\hline 9P & {$\left[\mathrm{RhCl}\left(\mathrm{C}_{8} \mathrm{H}_{12}\right)\right]_{2} \& \mathrm{TPP}$} & $1: 8$ & 50 & 2000 & 75 & 3000 \\
\hline $10 \mathrm{Q}$ & {$\left[\mathrm{RhCl}\left(\mathrm{C}_{8} \mathrm{H}_{12}\right)\right]_{2} \& \mathrm{TPP}$} & $1: 8$ & 90 & 2000 & 90 & 2500 \\
\hline $11 \mathrm{R}$ & {$\left[\mathrm{RhCl}\left(\mathrm{C}_{8} \mathrm{H}_{12}\right)\right]_{2} \& \mathrm{TPP}$} & $1: 2$ & 90 & 650 & 90 & 2500 \\
\hline $12 \mathrm{~S}$ & {$\left[\mathrm{RhCl}\left(\mathrm{C}_{8} \mathrm{H}_{12}\right)\right]_{2} \&$ BINAP } & $1: 4$ & 90 & 650 & 90 & 2500 \\
\hline $13 \mathrm{~T}$ & $\mathrm{C}_{96} \mathrm{H}_{80} \mathrm{Cl}_{2} \mathrm{P}_{4} \mathrm{Rh}_{2}$ (BINAP) & $1: 2$ & 90 & 650 & 90 & 2500 \\
\hline $14 \mathrm{U}$ & {$\left[\mathrm{RhCl}\left(\mathrm{C}_{8} \mathrm{H}_{12}\right)\right]_{2} \& \mathrm{TPP}$} & $1: 8$ & 90 & 2000 & 75 & 3000 \\
\hline
\end{tabular}

Throughout the course of the reactions, the yields of styrene and products were monitored. Figure 4-1 shows the decrease in styrene and the formation of two enantiomeric products with time. 


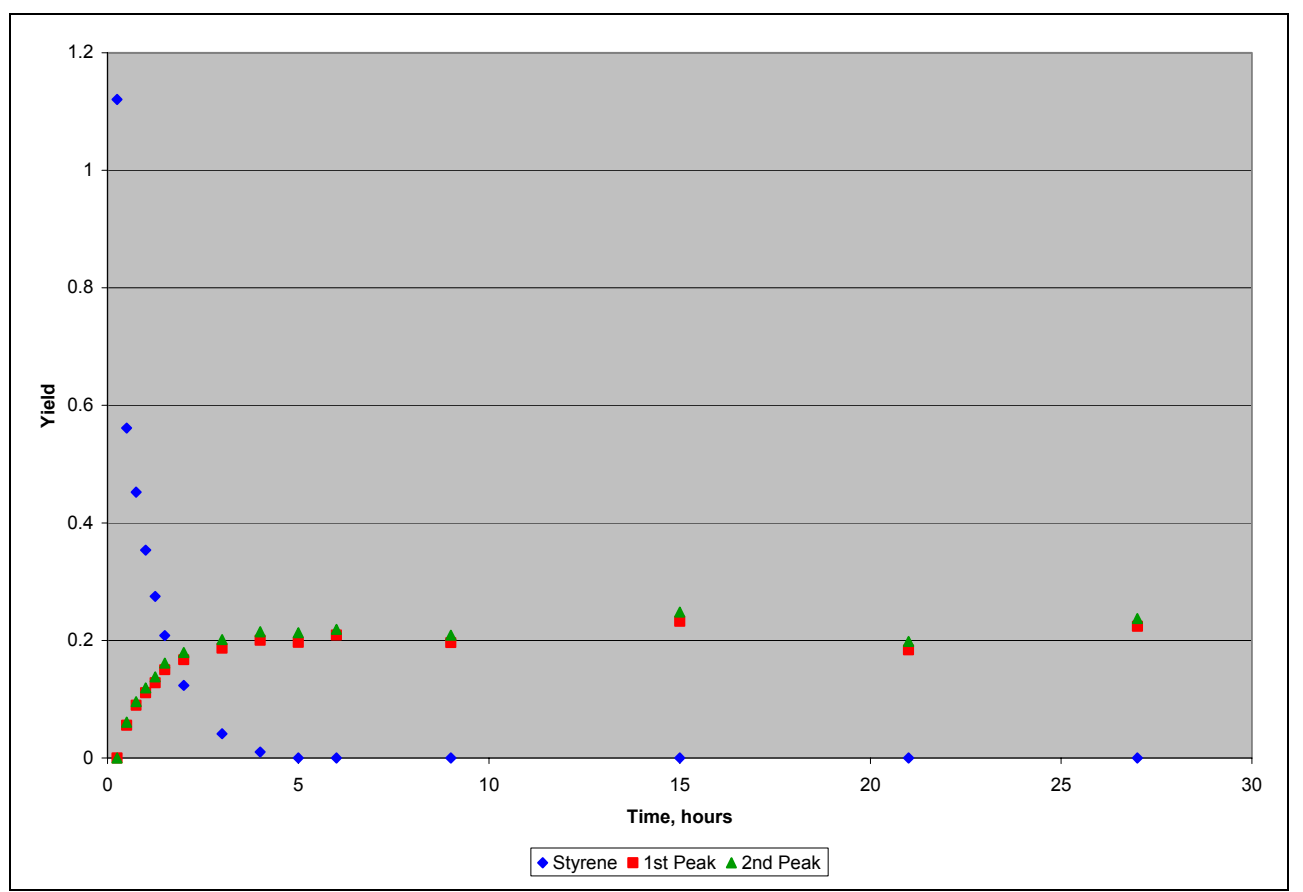

Figure 4-1. General Reaction Profile. The experiment shown in the graph above is experiment $8 \mathrm{~N}$.

The yield was calculated using the calibration obtained from direct injection of standards into the GC. The styrene yield is the amount of reactant remaining in the reactor relative to the initial amount of styrene injected into the reactor. The yields obtained through the calibrations did not provide a justified mass balance, most likely due to the method used for sample calibration. The calibrations were obtained by mixing known quantities in a vial and running these known samples through the GC/MS. Unlike the reaction samples, the known samples were not sampled through the reactor. Since the known samples did not go through the sampling procedure, the error is believed to be associated with differences in the way n-heptane, styrene, and products were removed from the reactor and dissolved into the ethyl acetate solvent.

In order to provide consistent data for comparison purpose, a normalized yield was used for the data analysis. The normalized yield was calculated using the following equation: 


$$
y_{n, i}=\frac{y_{i}}{y_{s}+y_{p 1}+y_{p 2}} \text {, }
$$

where $y_{n, i}$ is the normalized yield of component $i, y_{i}$ is the yield of component $i$, and $y_{s}$ is the yield of styrene, and $y_{p 1}$ and $y_{p 2}$ are the yields of the 2-phenylpropionaldehyde enantiomers.. The data shown in Figure 4-1 is reproduced in terms of the normalized yield in Figure 4-2, which demonstrates that the normalization process was simply a scaling factor.

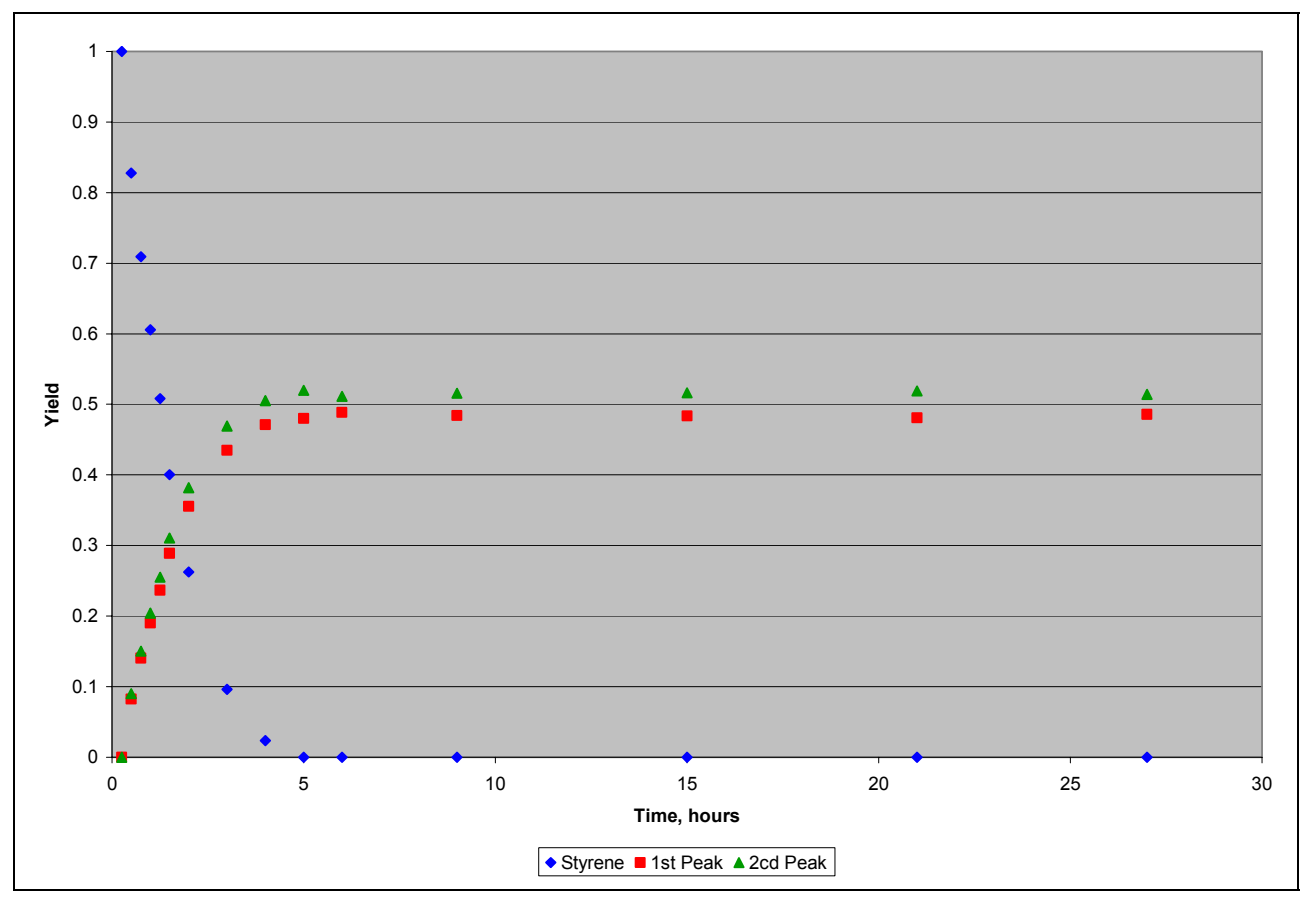

Figure 4-2. General Reaction Profile, Normalized. The experiment shown in the graph above is experiment $8 \mathrm{~N}$.

For the purposes of easily displaying data, the graphs displaying product peak data show the first product peak and do not show the second product peak. Since the reactions did not show large enantioselectivity towards either product, the first product peak was arbitrarily chosen to simplify comparisons among reactions.

Replicate experiments ( $2 \mathrm{G}$ and $12 \mathrm{~S}$ ) were performed to examine the reproducibility of the experiments. The experiments were conducted with the following conditions: 
$\mathrm{Rh}: \mathrm{P}$ ratio of $1: 4$, pretreatment conditions of $90{ }^{\circ} \mathrm{C}$ and $650 \mathrm{psig}$, and reaction conditions of $90{ }^{\circ} \mathrm{C}$ and 2500 psig. Figures $4-3$ and $4-4$ show the reproducibility of the experiments for both reactant conversion and product formation.

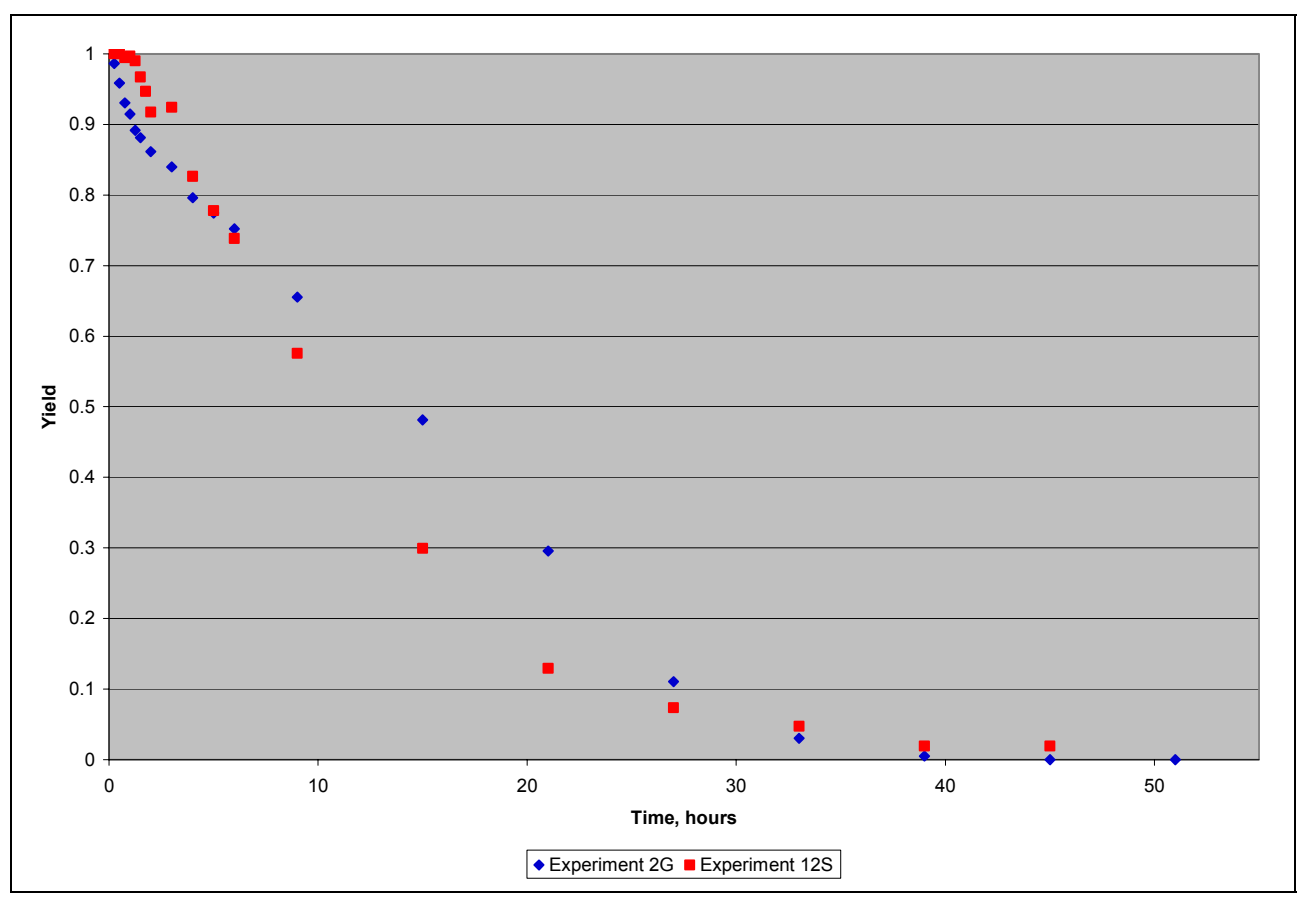

Figure 4-3. Loss of Styrene - Reproducibility. The yield profiles of styrene appear to be very similar, indicating that the reaction is repeatable.

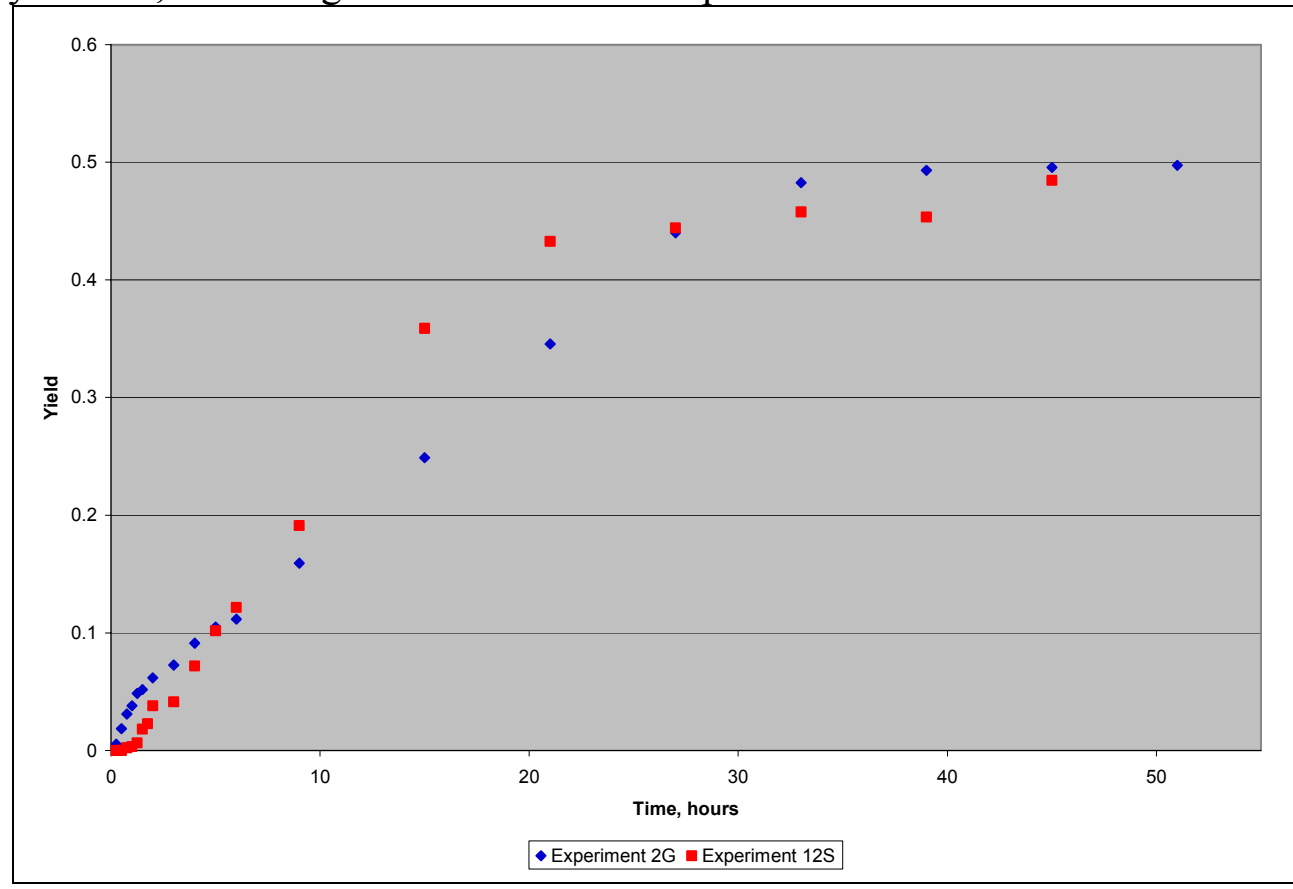

Figure 4-4. Yield of Products - Reproducibility. The yield profiles of the first product peak appear to be very similar, again indicating that the reaction is repeatable. 
By confirming that this reaction is reproducible, we demonstrate validity of the results obtained from each individual experiment.

\subsection{NMR \& IR Spectroscopy and Catalyst Evaluation}

Since in situ preparation of catalysts in supercritical fluids is a developing technology, there was a concern that the pretreatment conditions used in the reactions would not synthesize the catalysts. Therefore, NMR and IR spectroscopy were used to analyze the catalysts remaining in the envelopes after the reactions were completed; all NMR and IR evaluations were conducted in the analytical laboratories of the Department of Chemistry at The University of Toledo. Solid state phosphorus $\left({ }^{31} \mathrm{P}\right)$ NMR, liquid state phosphorus $\left({ }^{31} \mathrm{P}\right) \mathrm{NMR}$, liquid state proton $\left(\mathrm{H}^{1}\right) \mathrm{NMR}$, and IR were used to examine the catalysts. Two rhodium hydride peaks should be present on the $\left({ }^{31} \mathrm{P}\right)$ NMR data and one carbonyl peak should be present on the IR data if an active catalyst was formed and catalysts remaining in the pouch.

\subsubsection{NMR and (R)-BINAP Catalysts}

Figure 4-5 and Figure 4-6 show the NMR spectra of pure (R)-BINAP and the catalyst remaining in the envelope after reaction $2 \mathrm{G}$, in which $\left[\mathrm{RhCl}\left(\mathrm{C}_{8} \mathrm{H}_{12}\right)\right]_{2}$ and (R)-BINAP were used to make a catalyst in situ. The catalysts prepared from (R)-BINAP do not

show either a rhodium hydride or a carbonyl peak; the ${ }^{31} \mathrm{P}$ NMR spectrum of pure (R)BINAP shows peaks at the same locations as the catalyst that was attempted to be made in situ. This suggests that the catalyst from experiment $2 \mathrm{G}$ does not vary from the (R)BINAP, and that no rhodium-phosphine catalyst was formed during the in situ 
preparation. However, since the analytical methods were conducted on the catalyst remaining in the pouch, we cannot conclude that catalyst was not made in situ because the reaction profiles discussed later in this chapter indicate that a catalyst was present. Bunten, et al. (2002) reported that a $J_{\mathrm{RhP}}$ equal to $163 \mathrm{~Hz}$ and doublets at $46 \mathrm{ppm}$ were found for the Rhodium-BINAP complex that should have been formed in experiments $2 \mathrm{G}$ and 12S. The $J_{\mathrm{RhP}}$ shown in Figure $4-5$ is $146 \mathrm{~Hz}$ with the doublet occurring near -12.8 ppm; these would indicate that the Rhodium-BINAP complex was not formed inside the reactor. A possible explanation for this is that the catalyst was solubilized during either pretreatment or reaction and was transported outside of the catalyst envelope; this explanation is supported by the fact that no catalyst visibly remained in the catalyst envelope at the end of experiment 13T, which used a solid catalyst made with BINAP.

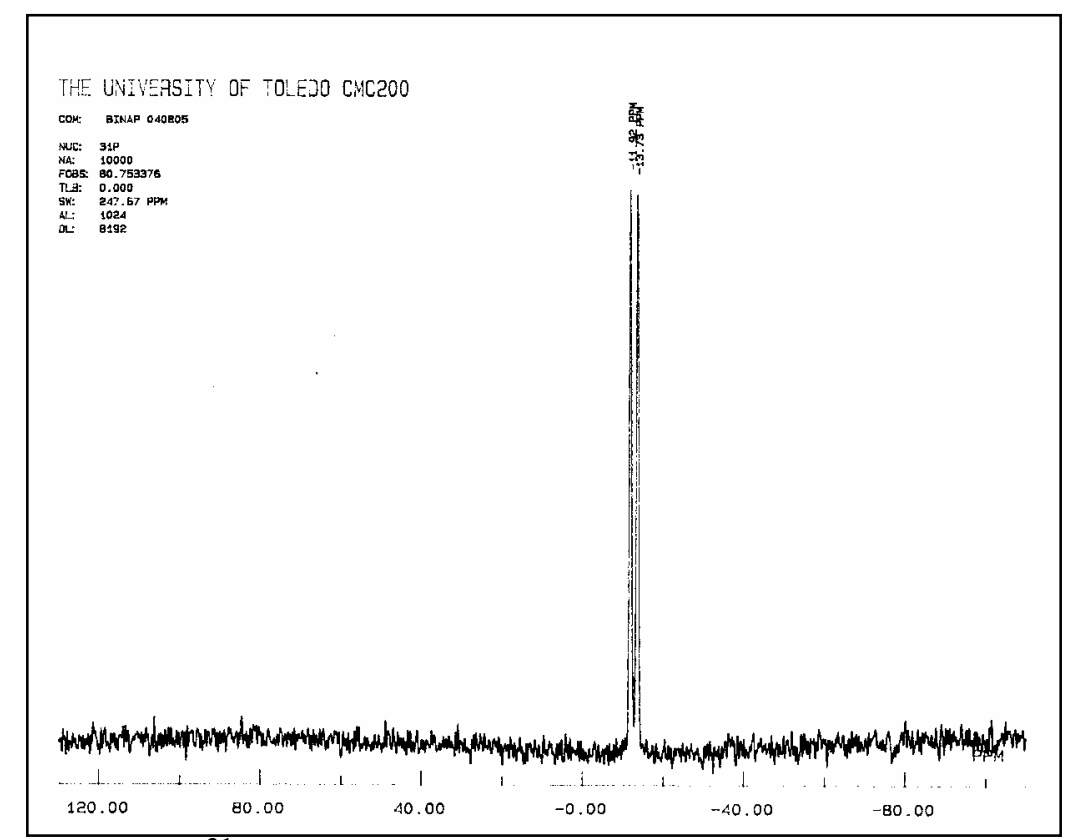

Figure 4-5. Solid State ${ }^{31}$ P MAS NMR spectrum of (R)-BINAP. Peaks are shown at 11.9 and -13.7 ppm. 


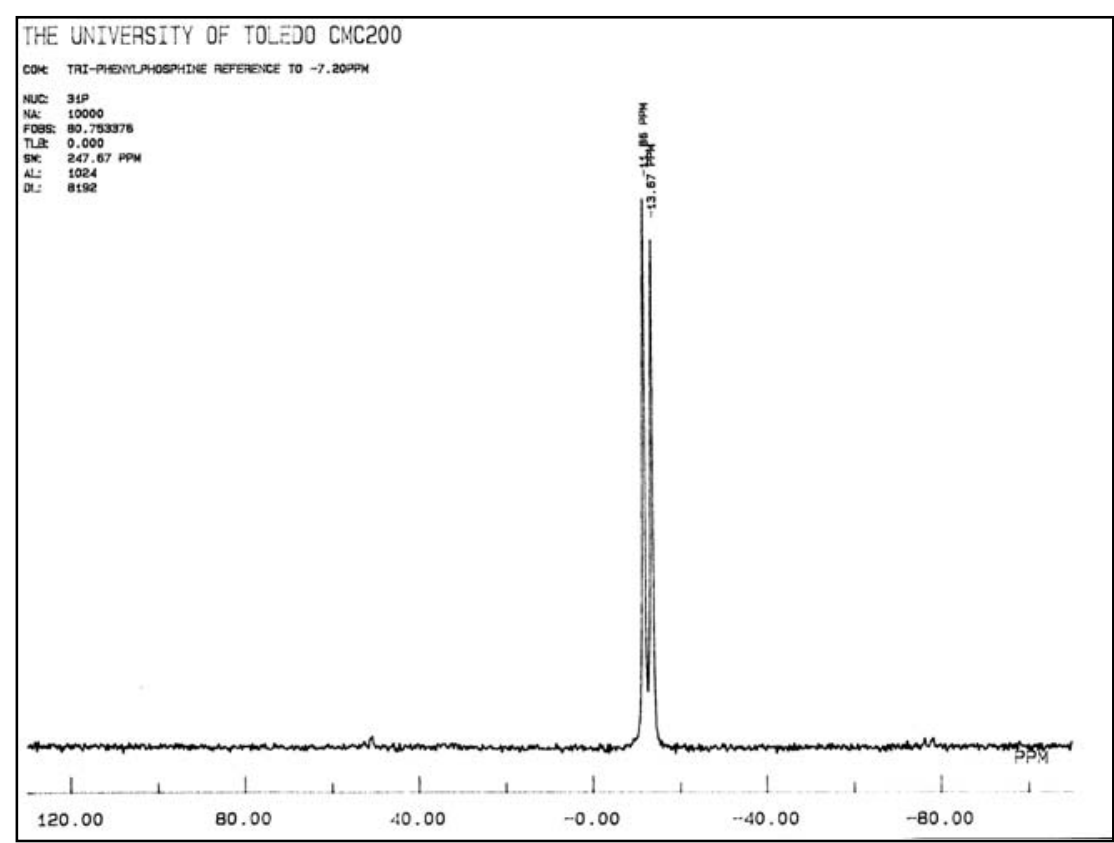

Figure 4-6. Solid State ${ }^{31}$ P MAS NMR spectrum of remaining catalyst residues from experiment 2G. Peaks are shown at -11.8 and $-13.6 \mathrm{ppm}$.

\subsubsection{NMR and Triphenylphosphine Catalysts}

Figure 4-7 and Figure 4-8 show the NMR spectra of pure triphenylphosphine and the catalyst remaining in the envelope after reaction $1 \mathrm{~F}$, in which $\left[\mathrm{RhCl}\left(\mathrm{C}_{8} \mathrm{H}_{12}\right)\right]_{2}$ and $\mathrm{TPP}$ were used to make a catalyst in situ. With the peaks of TPP and the catalyst formed in situ being at different locations, it is believed that catalyst was formed from triphenylphosphine and $[\mathrm{RhCl}(\operatorname{cod})]_{2}$ during the in situ pretreatment conditions. However, for the catalysts in which a Rh:P ratio of 1:34 was used, no catalyst remained in the envelopes to analyze. With triphenylphosphine's melting point of $79-81{ }^{\circ} \mathrm{C}$ at atmospheric pressure, it is believed that the triphenylphosphine melted during the pretreatment and became uniformly dispersed throughout the reaction vessel. Additionally, the $J_{\mathrm{RhP}}$ value for the data in Figure 4-7 is $107.4 \mathrm{~Hz}$; this is within the range 
reported to have rhodium-phosphorus coupling. Therefore, it can be concluded that the catalysts using TPP for ligands were able to be made during in situ pretreatment.

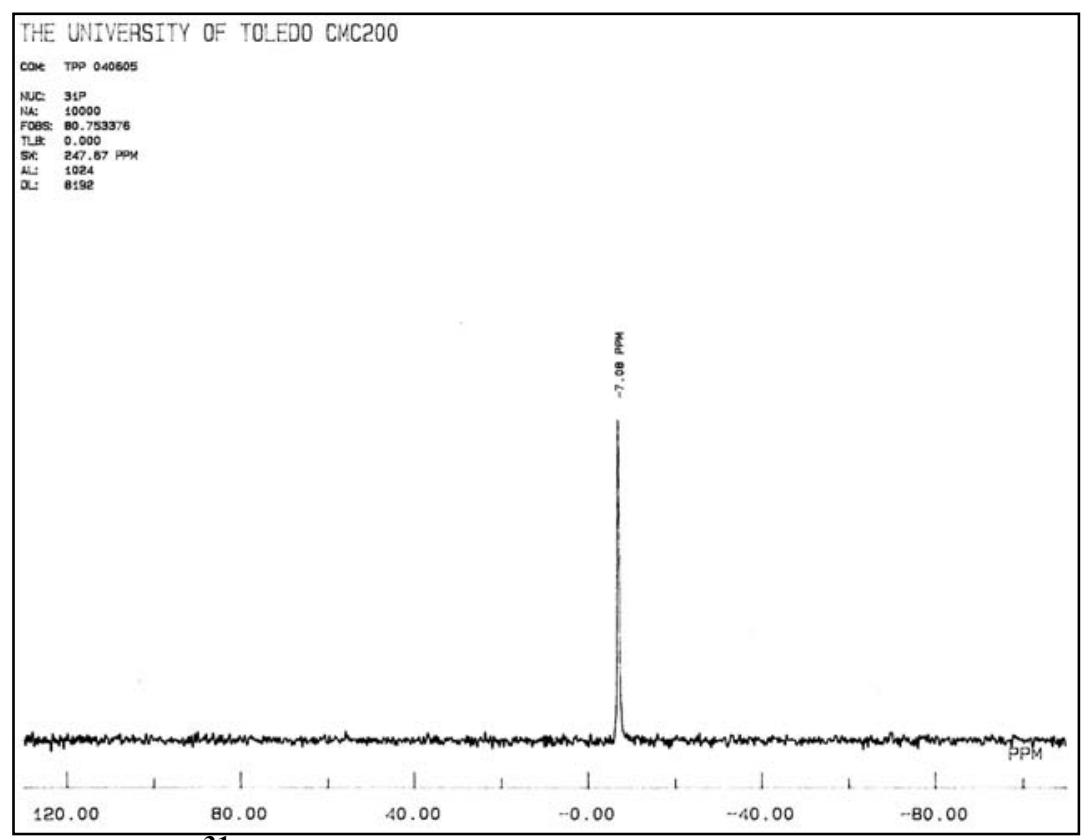

Figure 4-7. Solid State ${ }^{31} \mathrm{P}$ MAS NMR spectrum of pure triphenylphosphine. A peak is shown at $-7.1 \mathrm{ppm}$.

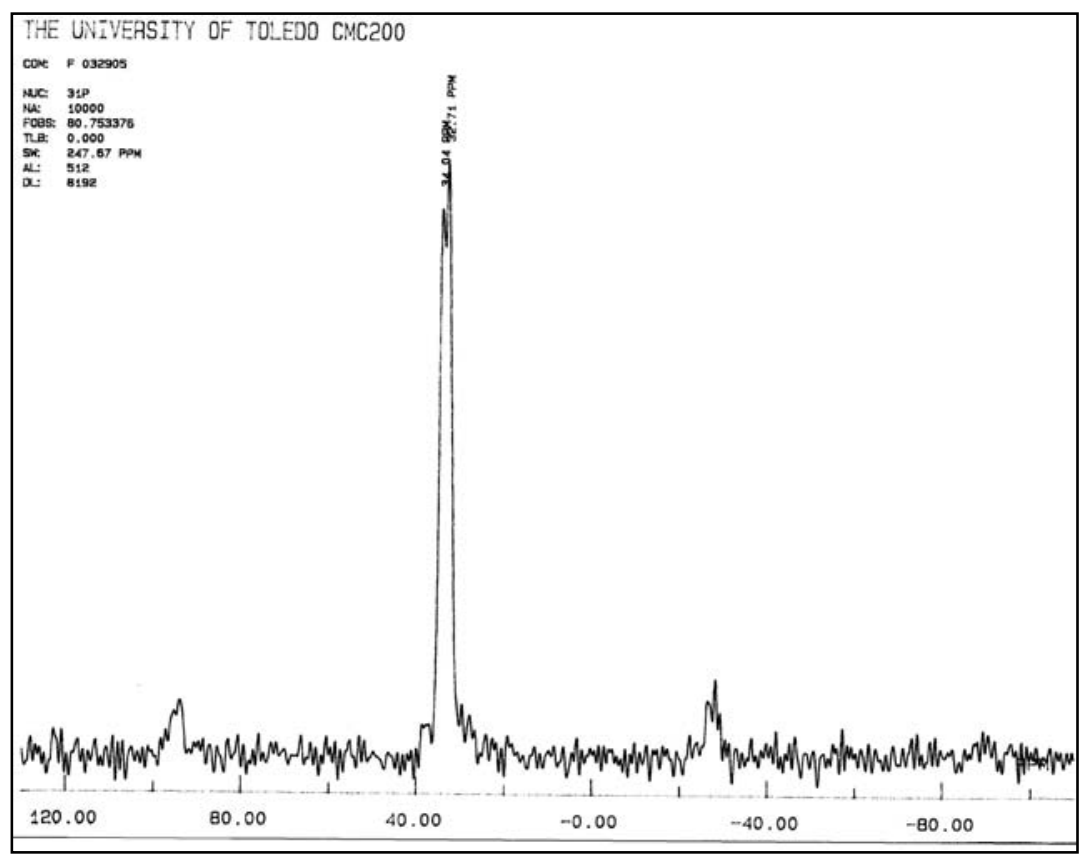

Figure 4-8. Solid State ${ }^{31} \mathrm{P}$ MAS NMR spectrum of remaining catalyst residues from experiment 1F. Peaks are shown at 34.0 and $32.7 \mathrm{ppm}$. 


\subsubsection{Infrared Spectroscopy}

IR literature reports that a peak between 1978 an $2093 \mathrm{~cm}^{-1}$ may indicate rhodiumhydride presence; therefore, peaks found in the following IR graphs within or near that range are believed to be rhodium-hydride peaks. The findings of the NMR showed that the catalysts using TPP as a ligand formed a catalyst; the IR data reflects these findings.

Experiments $10 \mathrm{Q}$ and $7 \mathrm{M}$ used triphenylphosphine as a ligand and experiment $2 \mathrm{G}$ used BINAP as a ligand. Catalyst recovered from experiment 10Q following reaction showed a peak at $1965 \mathrm{~cm}^{-1}$, catalyst recovered from experiment $7 \mathrm{M}$ showed a peak at $1965 \mathrm{~cm}^{-1}$, whereas catalyst recovered from experiment $2 \mathrm{G}$ showed no peak within or near the given range.

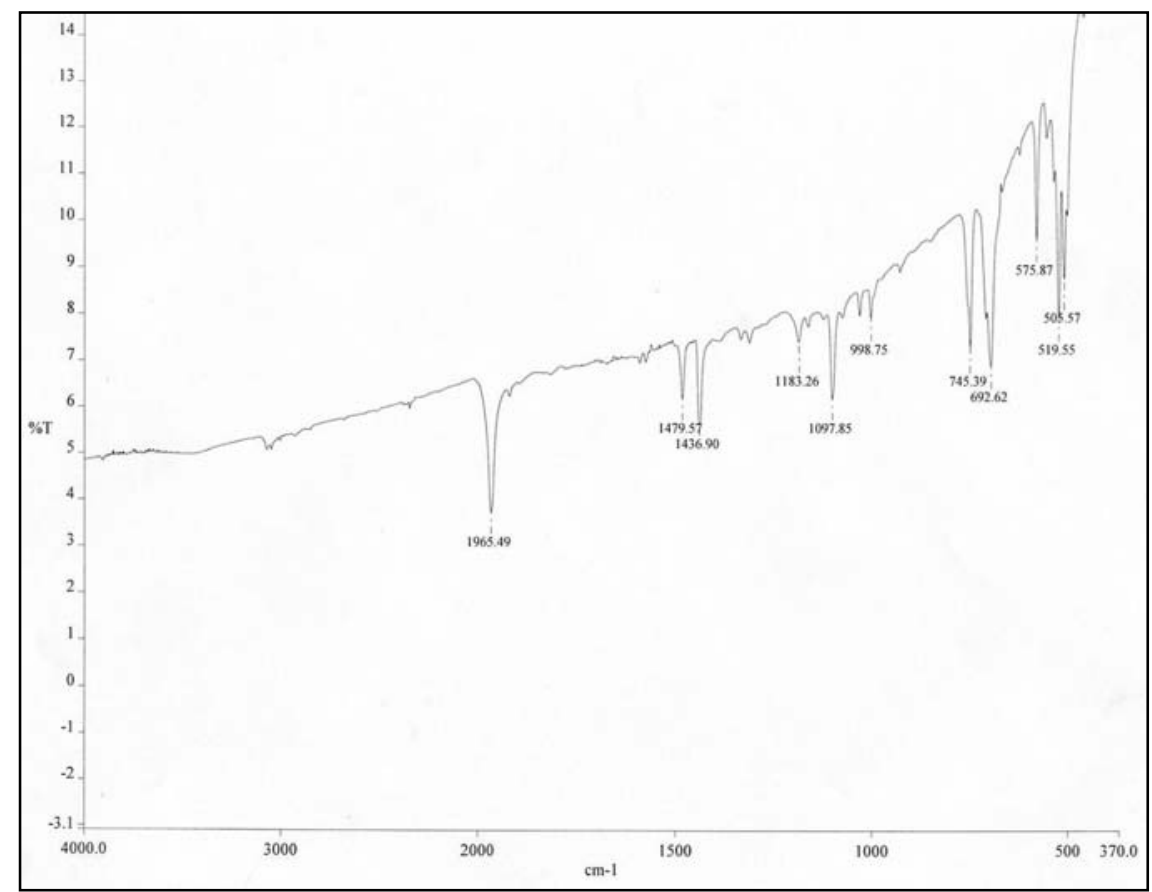

Figure 4-9. IR spectrum of remaining catalyst residues from experiment 10Q. A rhodium-hydride peak is shown at $1965 \mathrm{~cm}^{-1}$. 


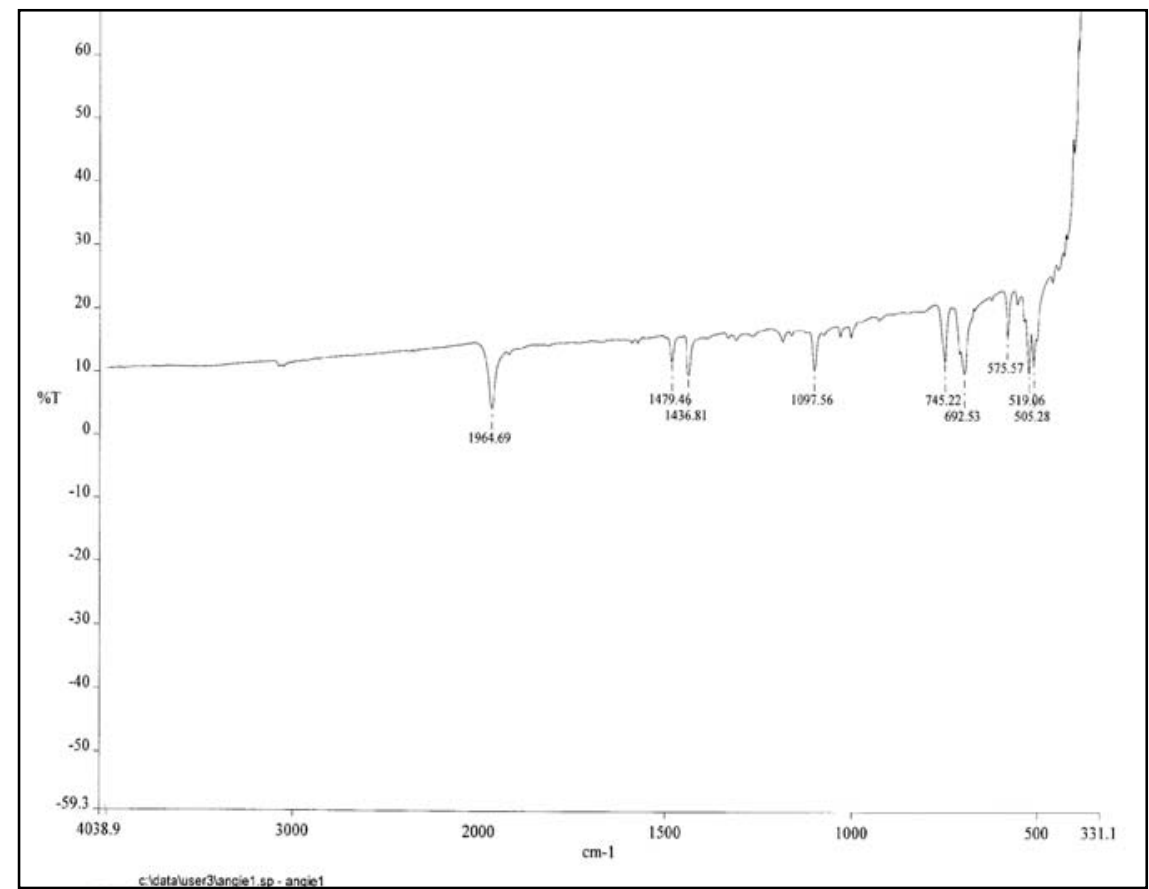

Figure 4-10. IR spectrum of remaining catalyst residues from experiment $7 \mathrm{M}$. A rhodium-hydride peak is shown at $1965 \mathrm{~cm}^{-1}$.

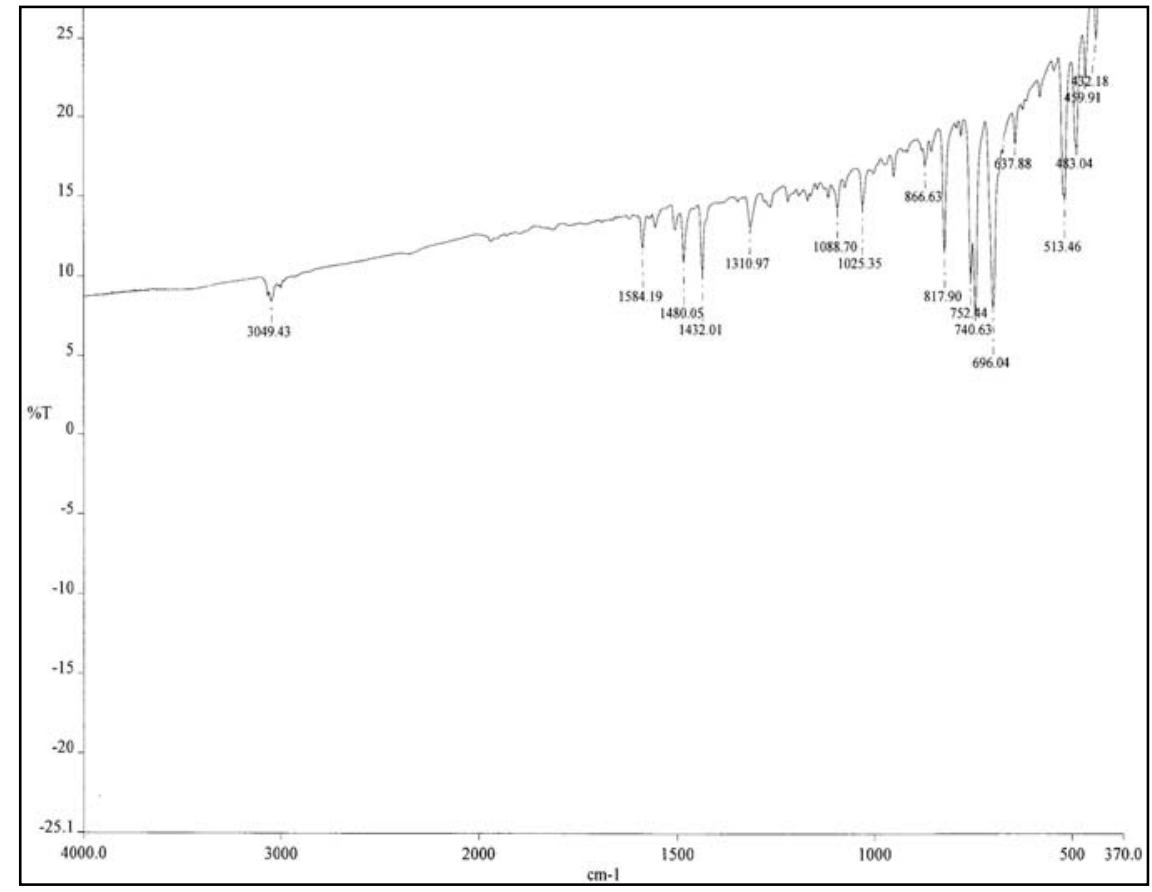

Figure 4-11. IR spectrum of remaining catalyst residues from experiment 2G. A rhodium-hydride peak is not shown within the expected range. 


\section{$\underline{4.3 \text { Effect of Pretreatment Conditions }}$}

Figures 4-12 and 4-13 describe yields over a range of catalyst pretreatment variables. Experiments $1 \mathrm{~F}\left(90{ }^{\circ} \mathrm{C} \& 650 \mathrm{psig}\right), 7 \mathrm{M}\left(50{ }^{\circ} \mathrm{C} \& 2000 \mathrm{psig}\right)$, and $10 \mathrm{Q}\left(90{ }^{\circ} \mathrm{C} \& 2000\right.$ psig) were conducted using $\left[\mathrm{RhCl}\left(\mathrm{C}_{8} \mathrm{H}_{12}\right)\right]_{2}$ and TPP, a $\mathrm{Rh}: \mathrm{P}$ ratio of $1: 8$, reaction conditions of $90{ }^{\circ} \mathrm{C}$ and $2500 \mathrm{psig}$, and variable in situ preparation conditions. These graphs show that the experiment using a higher pretreatment pressure provided a faster rate of reaction when comparing experiments with $90{ }^{\circ} \mathrm{C}$ pretreatment temperatures. Additionally, among the reactions with the pretreatments at higher pressures, the reaction with the catalyst prepared at the lower temperature provided a faster rate of reaction. The reactions had similar yields, but the rate of reaction varied. The fastest reaction resulted in a maximum yield of products in less than 5 hours. As the catalyst pretreatment conditions moved away from the critical conditions of $\mathrm{CO}_{2}$, a successively poorer catalyst was formed. The presence of $\mathrm{CO}_{2}$ during pretreatment may have provided a solvent environment in which the catalyst precursors effectively interacted, thereby creating a good catalyst. However, in the absence of $\mathrm{CO}_{2}$, the catalyst formation reaction is slow and a poor quality catalyst is produced. 


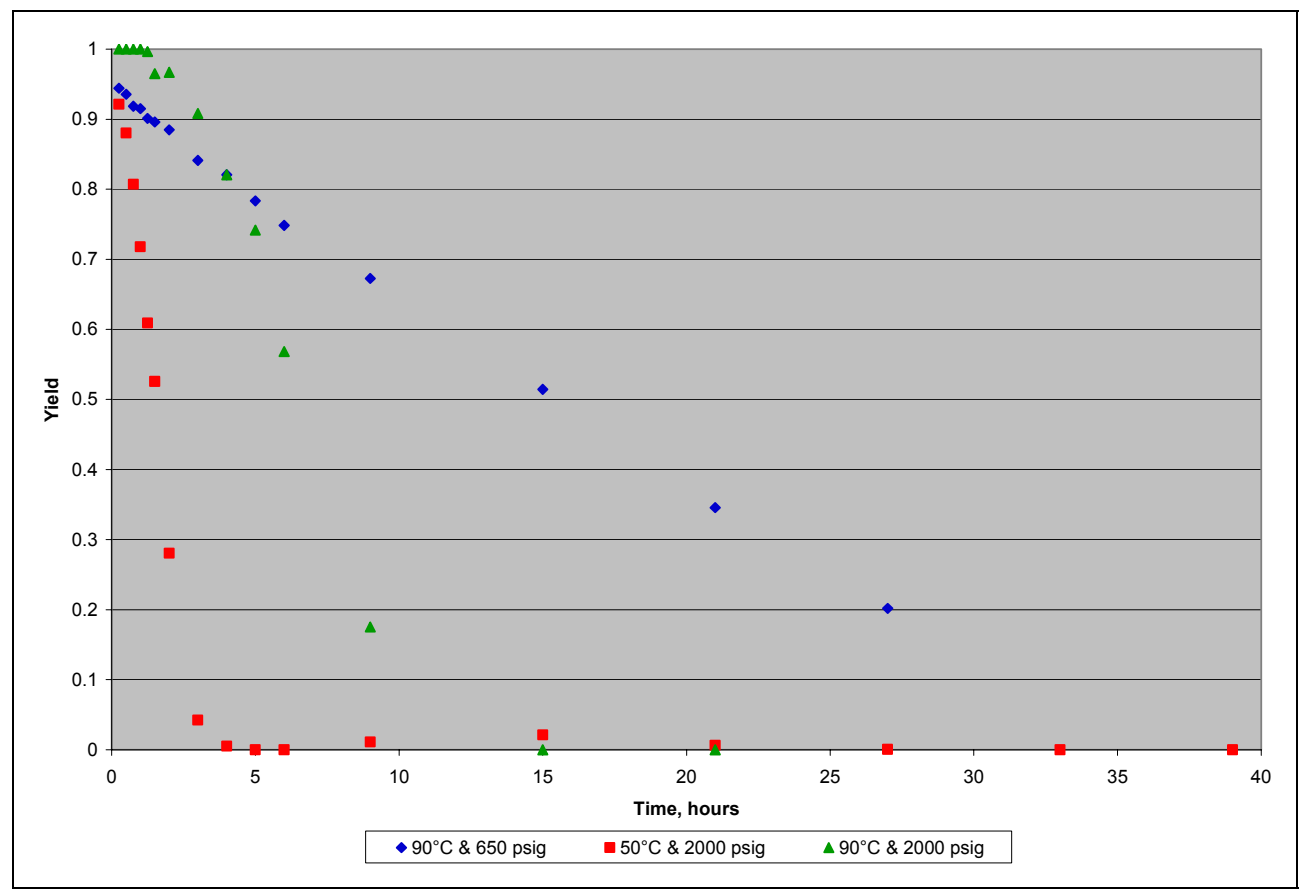

Figure 4-12. Loss of Styrene at Different Pretreatment Conditions. Conditions: $\left[\mathrm{RhCl}\left(\mathrm{C}_{8} \mathrm{H}_{12}\right)\right]_{2} \& \mathrm{TPP}, \mathrm{Rh}: \mathrm{P}$ ratio $=1: 8$, reaction conditions $=90{ }^{\circ} \mathrm{C} \& 2500$ psig; Variable: in situ pretreatment conditions.

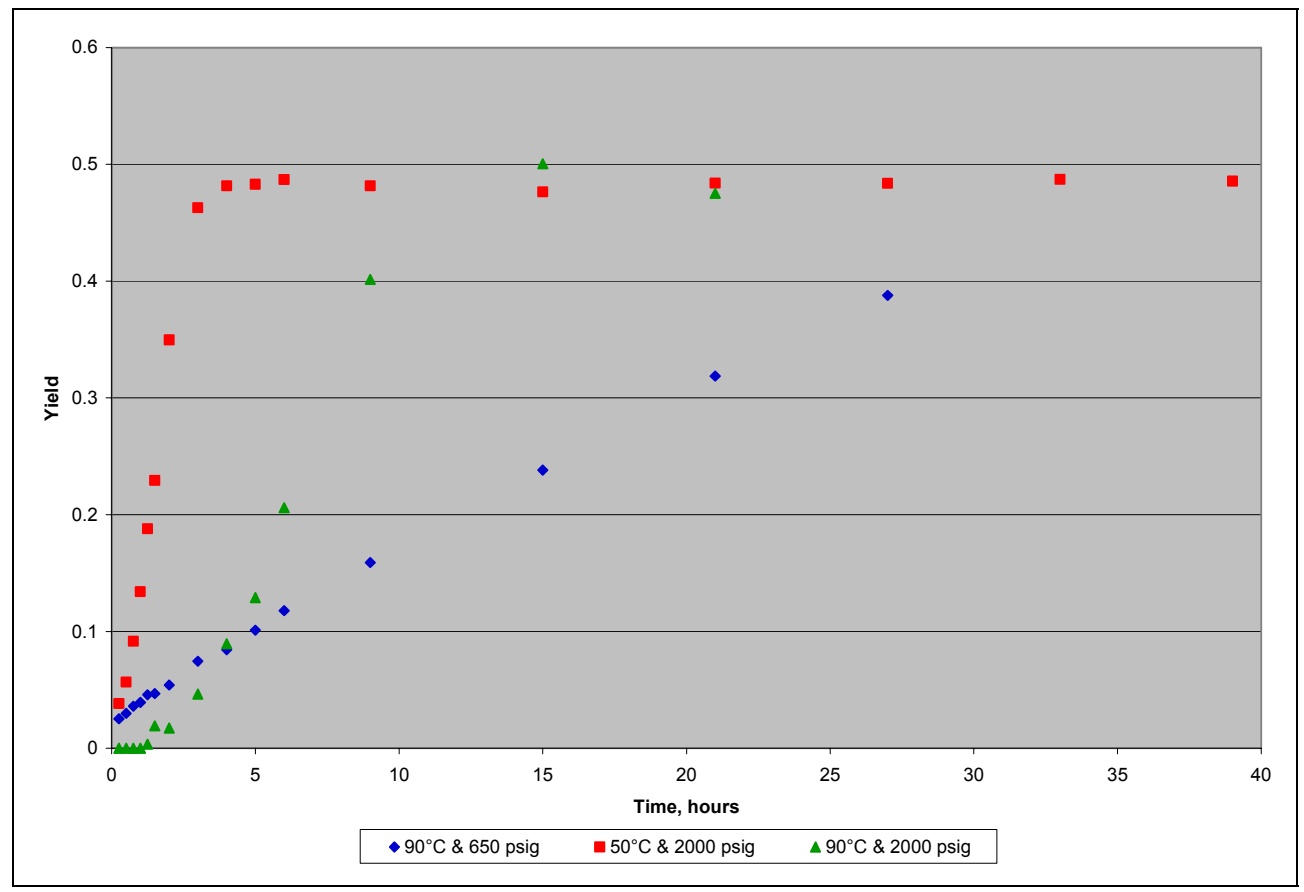

Figure 4-13. Yield of Products. Conditions: $\left[\mathrm{RhCl}\left(\mathrm{C}_{8} \mathrm{H}_{12}\right)\right]_{2} \& \mathrm{TPP}, \mathrm{Rh}: \mathrm{P}$ ratio $=1: 8$, reaction conditions $=90^{\circ} \mathrm{C} \& 2500$ psig; Variable: in situ pretreatment conditions. 
By comparing experiments $9 \mathrm{P}\left(50{ }^{\circ} \mathrm{C}\right)$ and $14 \mathrm{U}\left(90^{\circ} \mathrm{C}\right)$ the effects of pretreatment temperature can be observed. Both reactions used $\left[\mathrm{RhCl}\left(\mathrm{C}_{8} \mathrm{H}_{12}\right)\right]_{2}$ and TPP, a $\mathrm{Rh}: \mathrm{P}=1: 8$, pretreatment pressure of $2000 \mathrm{psig}$, and reaction conditions of $75^{\circ} \mathrm{C}$ and $3000 \mathrm{psig}$. The reaction in which the catalyst was prepared at the lower in situ temperature had a much lower yield than the catalyst prepared at the higher temperature, consistent with the results shown in Figure 4-13. Additionally, the pretreatment temperature for the slower reaction was greater than the reaction temperature; however it is not clear why this influenced the catalyst performance.

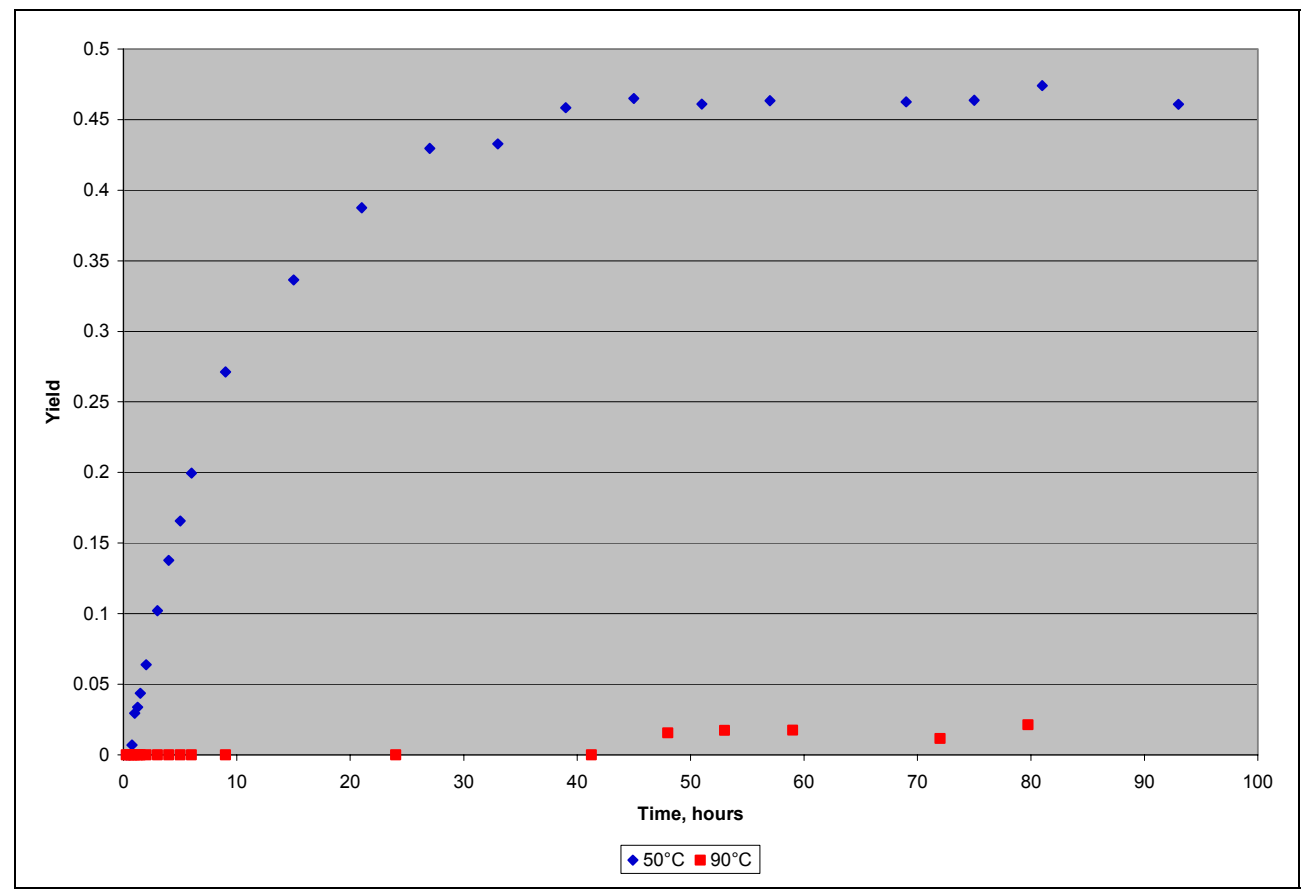

Figure 4-14. In situ temperature effects. Conditions: $\left[\mathrm{RhCl}\left(\mathrm{C}_{8} \mathrm{H}_{12}\right)\right]_{2} \& \mathrm{TPP}, \mathrm{Rh}: \mathrm{P}=$ $1: 8$, pretreatment pressure $=2000 \mathrm{psig}$, reaction conditions $=75^{\circ} \mathrm{C} \& 3000$ psig; Variable: in situ temperature.

\subsection{Effects of Temperature and Pressure during Reaction}

Figure 4-15 compares experiments $10 \mathrm{Q}\left(90^{\circ} \mathrm{C} \& 2500 \mathrm{psig}\right)$ and $14 \mathrm{U}\left(75^{\circ} \mathrm{C} \& 3000\right.$ psig) which use $\left[\mathrm{RhCl}\left(\mathrm{C}_{8} \mathrm{H}_{12}\right)\right]_{2}$ and TPP, a $\mathrm{Rh}: \mathrm{P}=1: 8$, and pretreatment conditions of 
$90^{\circ} \mathrm{C}$ and $2000 \mathrm{psig}$; the variables being examined are the reaction temperature and pressure. The reaction with the lower reaction temperature and higher reaction pressure has a much lower yield than the reaction conducted at the higher temperature, as would be expected.

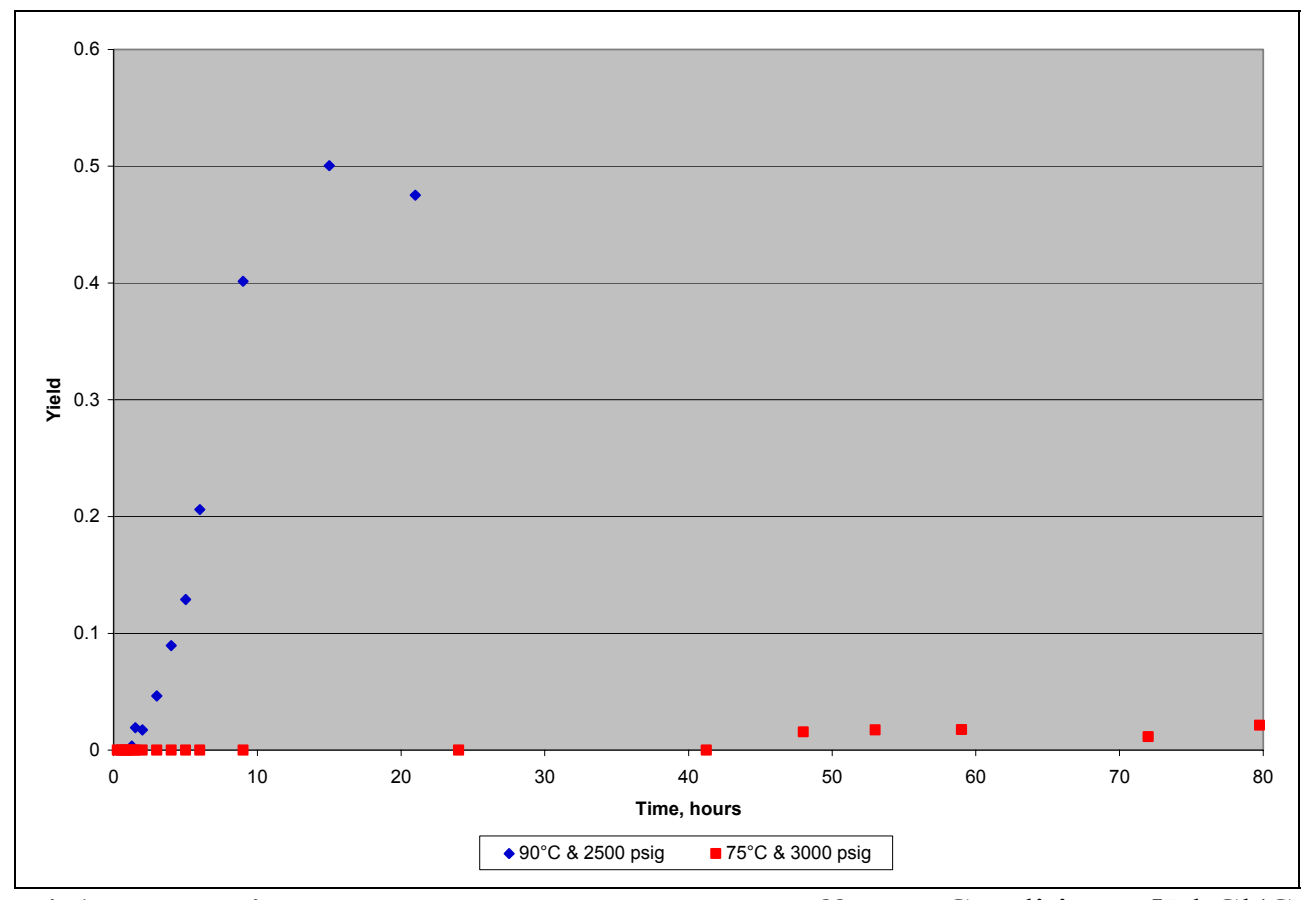

Figure 4-15. Reaction temperature and pressure effects. Conditions: $\left[\mathrm{RhCl}\left(\mathrm{C}_{8} \mathrm{H}_{12}\right)\right]_{2}$ $\& \mathrm{TPP}, \mathrm{Rh}: \mathrm{P}=1: 8$, pretreatment conditions of $90{ }^{\circ} \mathrm{C} \& 2000$ psig; Variables: reaction temperature and pressure.

The effect of reaction temperature and pressure are again seen in Figures 4-16 and 417; experiments $6 \mathrm{~L}\left(75^{\circ} \mathrm{C} \& 3000 \mathrm{psig}\right)$ and $8 \mathrm{~N}\left(90{ }^{\circ} \mathrm{C} \& 2500 \mathrm{psig}\right)$ use $\left[\mathrm{RhCl}\left(\mathrm{C}_{8} \mathrm{H}_{12}\right)\right]_{2}$ and TPP, a $\mathrm{Rh}: \mathrm{P}=1: 34$, and pretreatment conditions of $50{ }^{\circ} \mathrm{C}$ and 2000 psig. The reaction at $90{ }^{\circ} \mathrm{C}$ goes to completion and has a much faster rate of reaction than the reaction at the lower temperature. The reaction at $90{ }^{\circ} \mathrm{C}$ also shows a product yield near 0.5 in less than 15 hours whereas the reaction at $75{ }^{\circ} \mathrm{C}$ shows a product yield less than 0.1 at more than 80 hours. Since styrene is still present in the reaction at $75{ }^{\circ} \mathrm{C}$, it is 
unknown what the maximum product yield may be when full conversion of styrene is obtained.

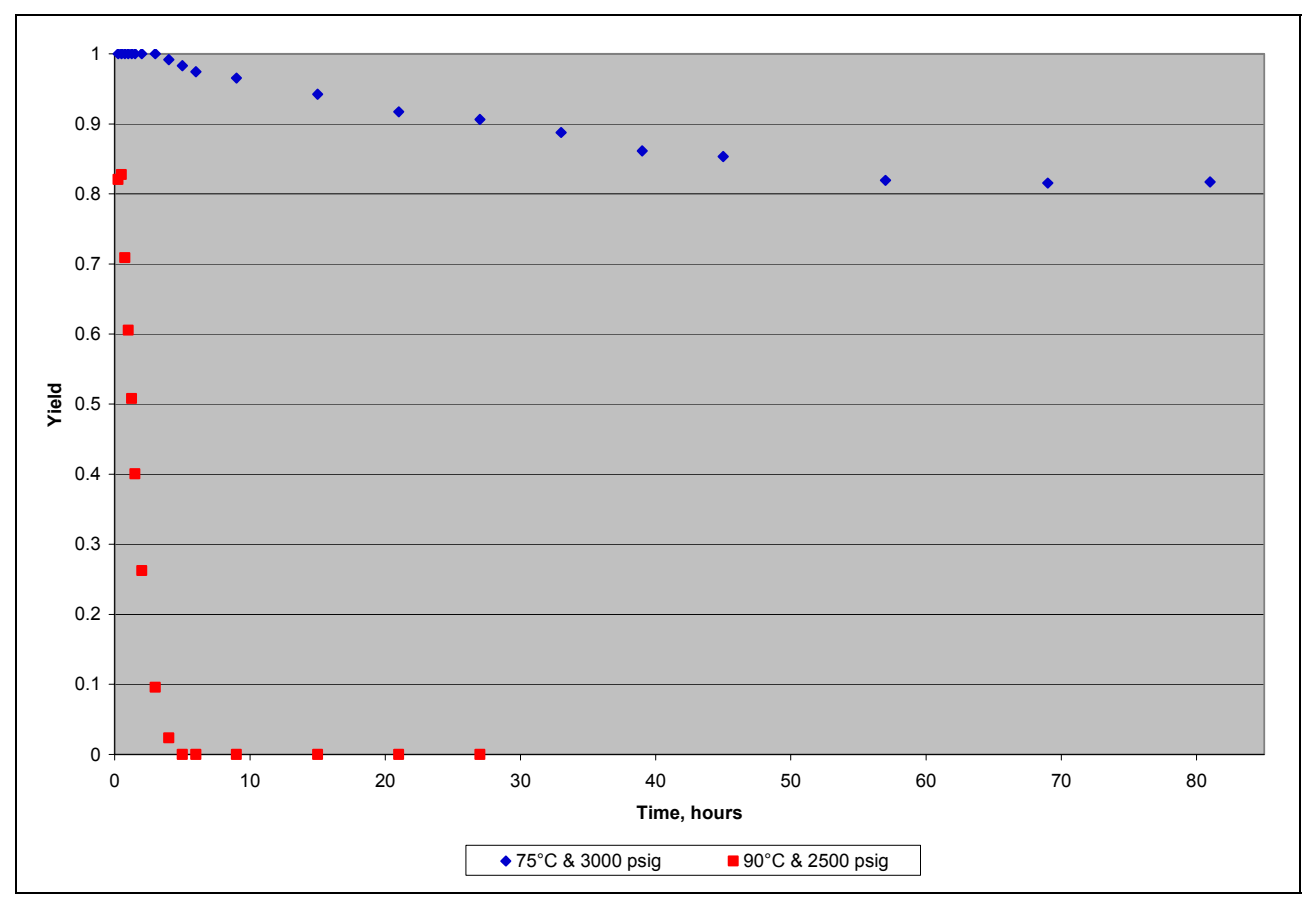

Figure 4-16. Loss of Styrene. Conditions: $\left[\mathrm{RhCl}\left(\mathrm{C}_{8} \mathrm{H}_{12}\right)\right]_{2}$ and TPP, $\mathrm{Rh}: \mathrm{P}=1: 34$, pretreatment conditions of $50{ }^{\circ} \mathrm{C} \& 2000$ psig; Variables: reaction temperature and pressure.

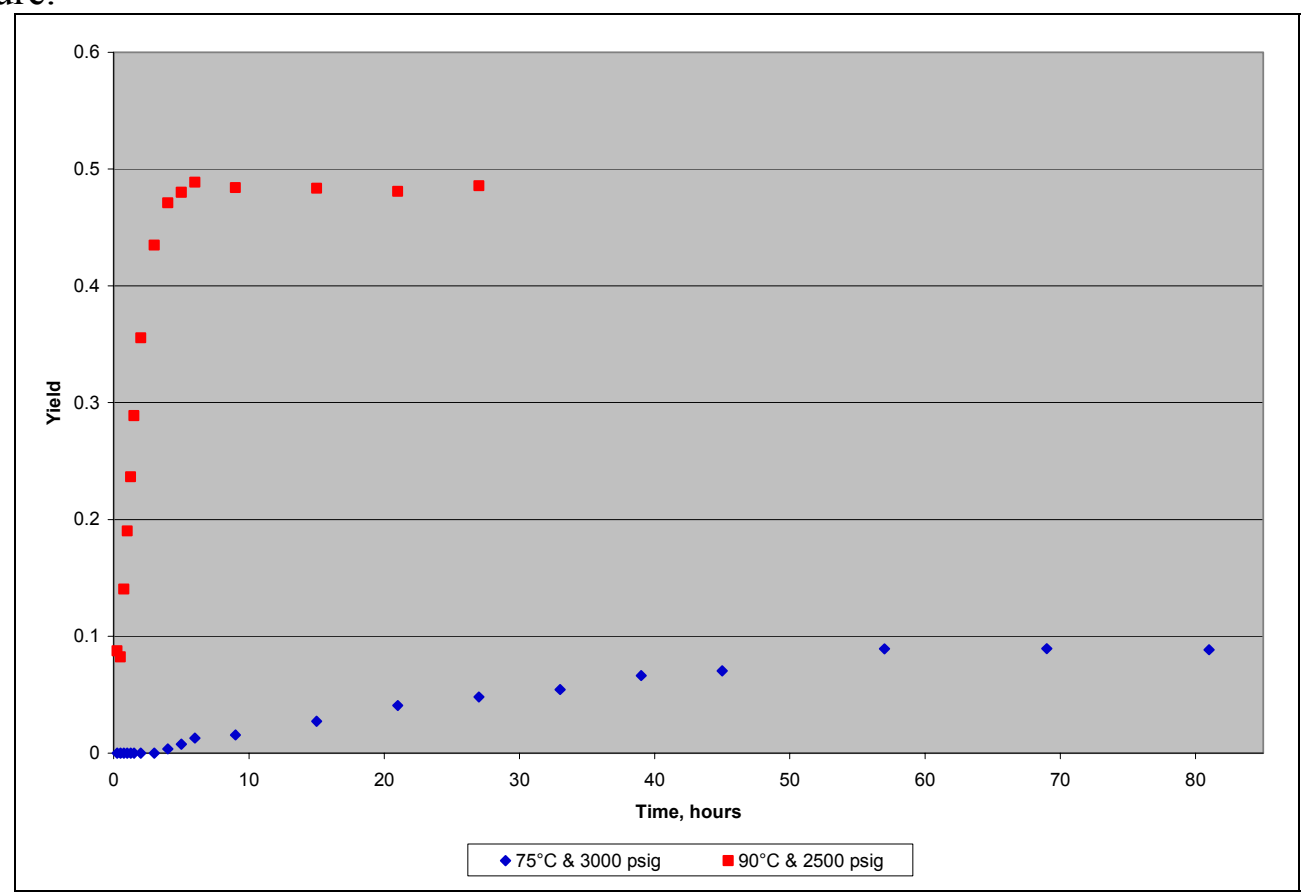

Figure 4-17. Yield of Products. Conditions: $\left[\mathrm{RhCl}\left(\mathrm{C}_{8} \mathrm{H}_{12}\right)\right]_{2}$ and TPP, $\mathrm{Rh}: \mathrm{P}=1: 34$, pretreatment conditions of $50{ }^{\circ} \mathrm{C} \& 2000$ psig; Variables: reaction temperature and pressure. 
Figures 4-18 and 4-19 compare the effect of reaction temperature and pressure on the yield of styrene and products; experiments $7 \mathrm{M}\left(90{ }^{\circ} \mathrm{C} \& 2500 \mathrm{psig}\right)$ and $9 \mathrm{P}\left(75^{\circ} \mathrm{C} \&\right.$ 3000 psig) use $\left[\mathrm{RhCl}\left(\mathrm{C}_{8} \mathrm{H}_{12}\right)\right]_{2}$ and $\mathrm{TPP}$, a $\mathrm{Rh}: \mathrm{P}=1: 8$, and pretreatment conditions of $50^{\circ} \mathrm{C}$ and 2000 psig. The reaction at $90{ }^{\circ} \mathrm{C}$ goes to completion much faster than the reaction at the lower temperature. The reaction at $90{ }^{\circ} \mathrm{C}$ obtained a yield near 0.5 in less than 10 hours, whereas the reaction at the lower temperature required more time to obtain a similar yield.

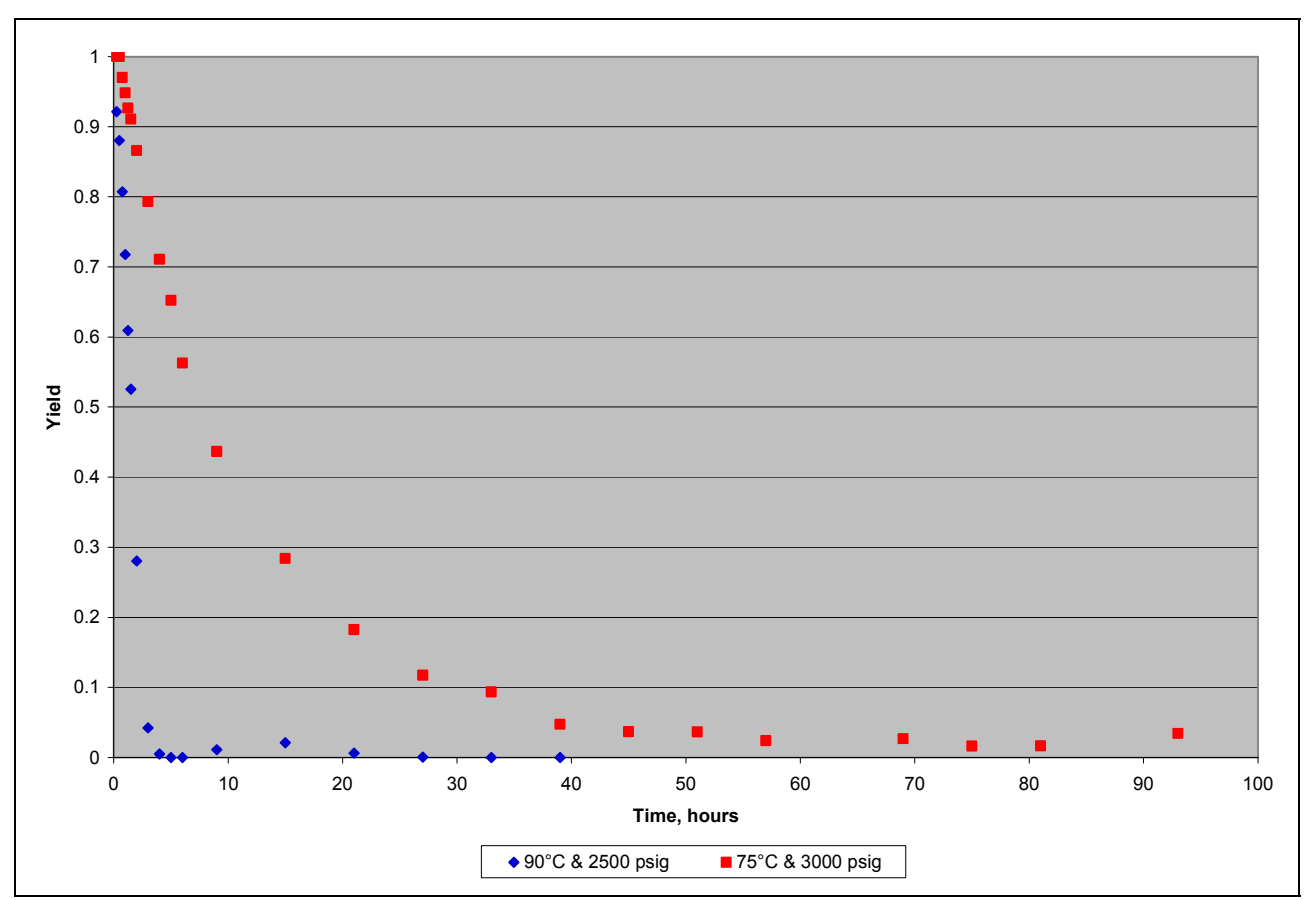

Figure 4-18. Loss of Styrene. Conditions: $\left[\mathrm{RhCl}\left(\mathrm{C}_{8} \mathrm{H}_{12}\right)\right]_{2}$ \& $\mathrm{TPP}, \mathrm{Rh}: \mathrm{P}=1: 8$, pretreatment conditions of $50{ }^{\circ} \mathrm{C} \& 2000$ psig; Variables: reaction temperature and pressure. 


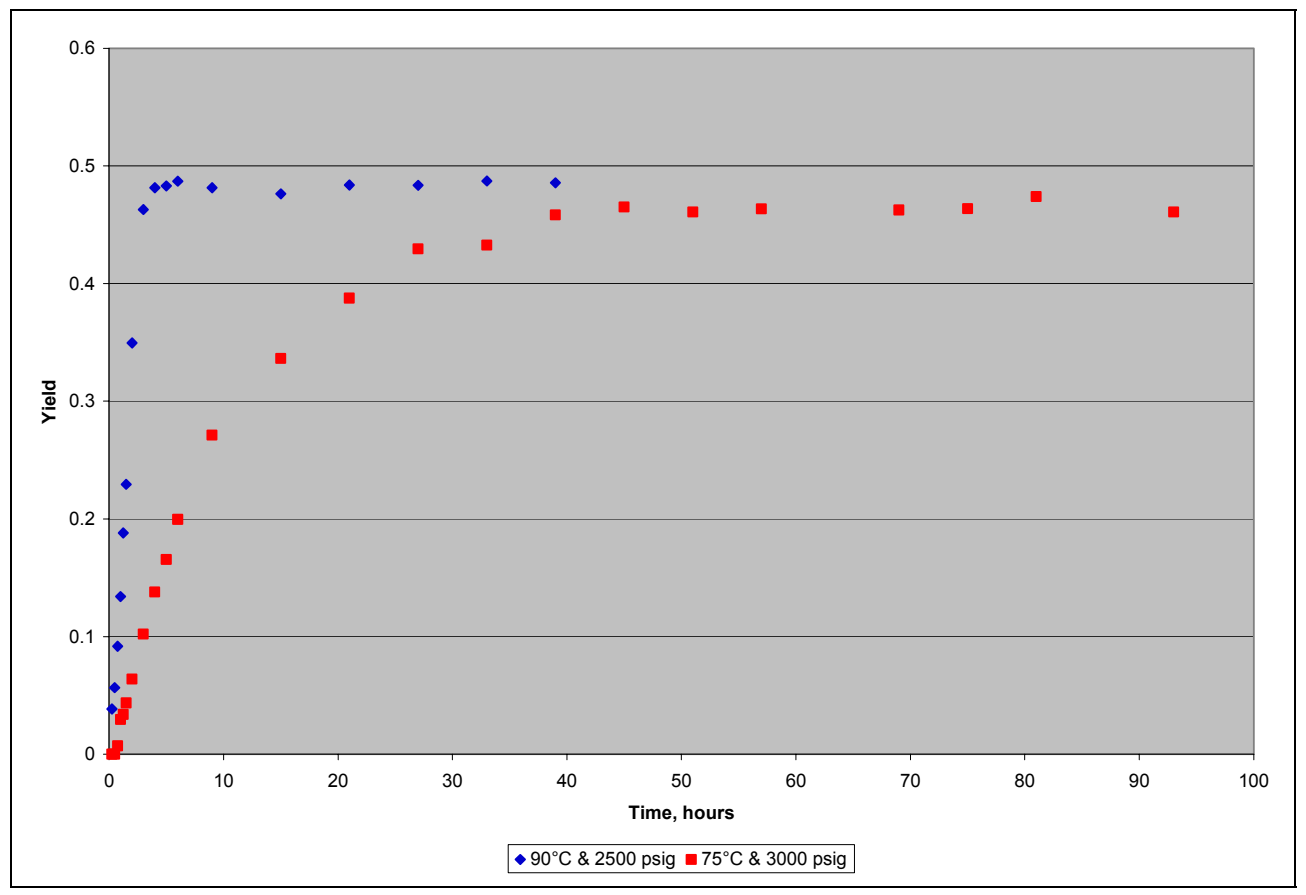

Figure 4-19. Yield of Product Peak 1. The reaction at $90{ }^{\circ} \mathrm{C}$ obtained a yield near 0.5 in less than 10 hours, whereas the reaction at the lower temperature required more time to obtain a similar yield.

\section{$\underline{4.5 \text { Effects of Rhodium to Phosphorus Ratios }}$}

The presence of phosphines during hydroformylation reactions is believed to slow the rate at which products are produced (Bensaid, 2002); however, selectivity increases as the amount of phosphorus per rhodium increases. In order to understand these effects during reaction in supercritical $\mathrm{CO}_{2}$, a series of experiments were performed in which the $\mathrm{Rh}: \mathrm{P}$ ratio was varied under otherwise identical conditions.

The experiments shown, Experiments $1 \mathrm{~F}(1: 8), 11 \mathrm{R}(1: 2)$, and $3 \mathrm{H}\left(\left[\mathrm{RhCl}\left(\mathrm{C}_{8} \mathrm{H}_{12}\right)\right]_{2}\right.$ only) compare the Rh:P ratios among catalysts using $\left[\mathrm{RhCl}\left(\mathrm{C}_{8} \mathrm{H}_{12}\right)\right]_{2}$ and $\mathrm{TPP}$, in situ preparation conditions of $90{ }^{\circ} \mathrm{C}$ and $650 \mathrm{psig}$, and reaction conditions of $90{ }^{\circ} \mathrm{C}$ and 2500 psig. The reaction with the greatest phosphorus loading had the slowest reaction rate. Additionally, in the experiment using only $\left[\mathrm{RhCl}\left(\mathrm{C}_{8} \mathrm{H}_{12}\right)\right]_{2}$, a time lag is observed before 
the aldehyde product is initially observed, indicating the importance of the phosphorus ligand in the performance of the catalyst.

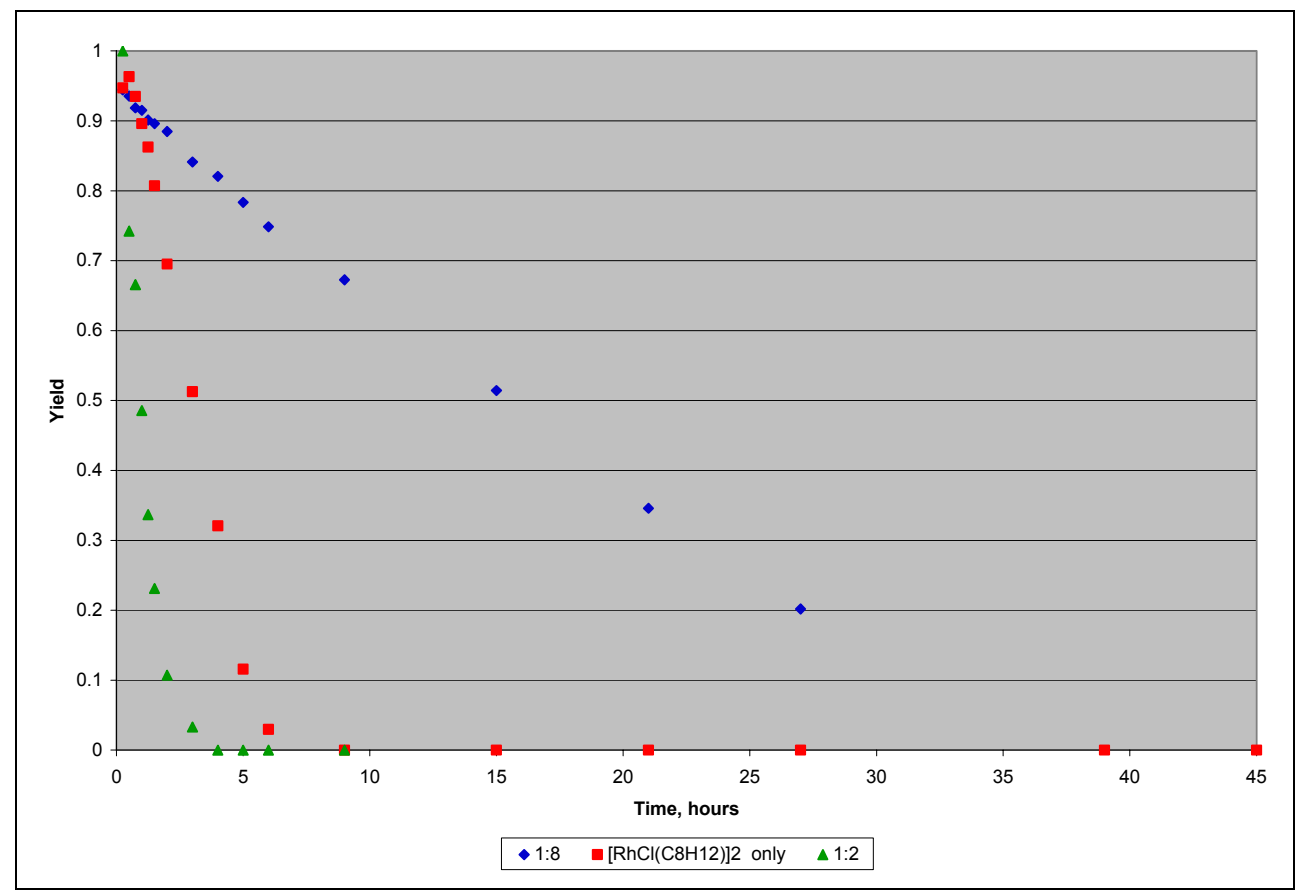

Figure 4-20. Yield of Styrene - TPP as a ligand. Conditions: $\left[\mathrm{RhCl}\left(\mathrm{C}_{8} \mathrm{H}_{12}\right)\right]_{2} \&$ TPP, in situ pretreatment $=90{ }^{\circ} \mathrm{C} \& 650 \mathrm{psig}$, reaction conditions $=90{ }^{\circ} \mathrm{C} \& 2500$ psig; Variable: $\mathrm{Rh}: \mathrm{P}$ ratio.

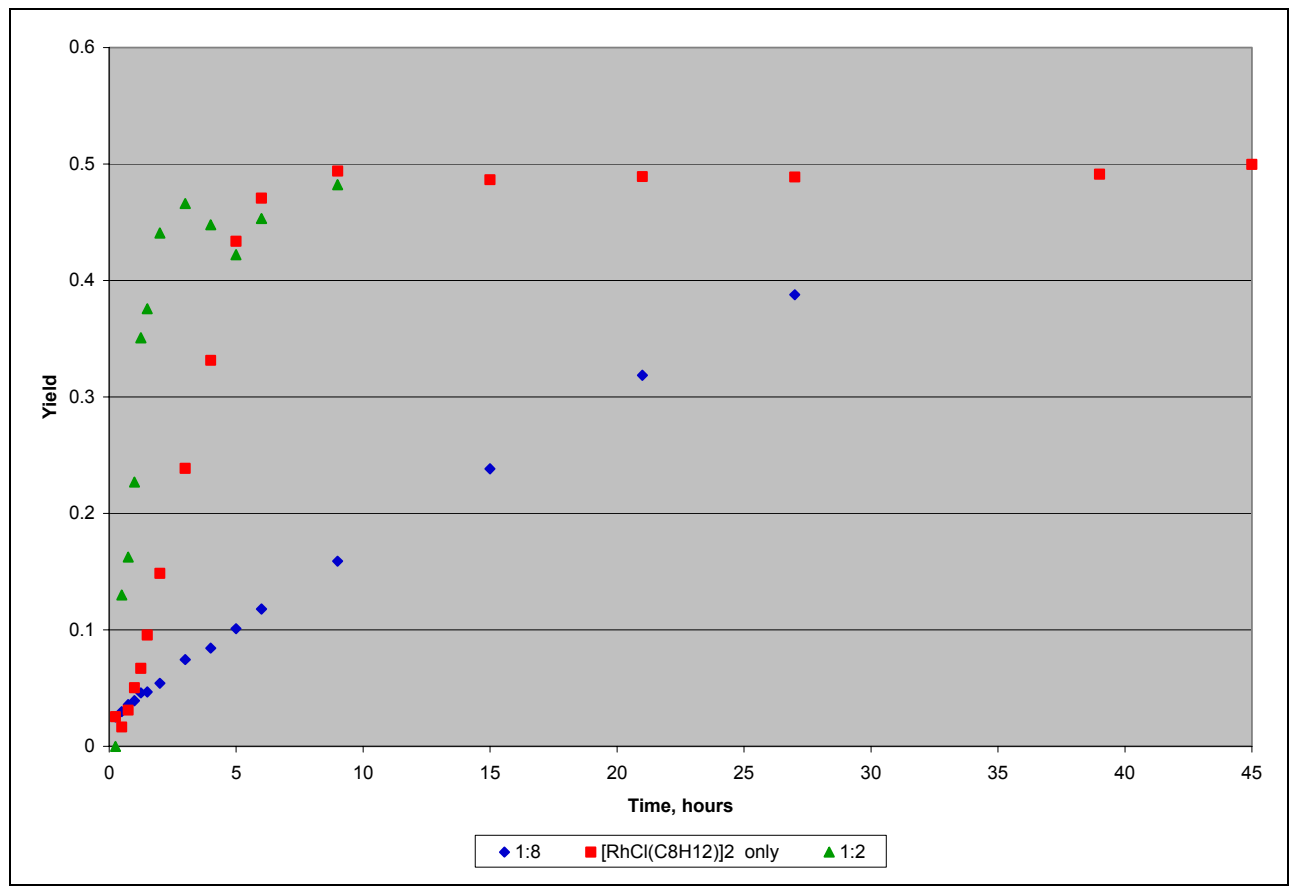

Figure 4-21. Yield of Product Peak 1 - TPP as a ligand. Conditions: $\left[\mathrm{RhCl}\left(\mathrm{C}_{8} \mathrm{H}_{12}\right)\right]_{2}$ \& TPP, in situ pretreatment $=90{ }^{\circ} \mathrm{C} \& 650 \mathrm{psig}$, reaction conditions $=90{ }^{\circ} \mathrm{C} \& 2500$ psig; Variable: Rh:P ratio. 
Additional comparisons using experiments 6L (1:34) and 9P (1:8) further illustrate the effects of Rh:P ratio variances. These experiments used $\left[\mathrm{RhCl}\left(\mathrm{C}_{8} \mathrm{H}_{12}\right)\right]_{2}$ and TPP, in situ preparation conditions of $50{ }^{\circ} \mathrm{C}$ and $2000 \mathrm{psig}$, and reaction conditions of $75^{\circ} \mathrm{C}$ and 3000 psig. The results are shown in Figure 4-22 for conversion of styrene, and Figure 423 for the yield of product 1 . The catalyst in which $\mathrm{Rh}: \mathrm{P}=1: 8$ provided the faster rate of reaction; this reaction provided nearly complete conversion at 50 hours whereas the experiment in which $\mathrm{Rh}: \mathrm{P}=1: 34$, was not near complete conversion, even after 80 hours.

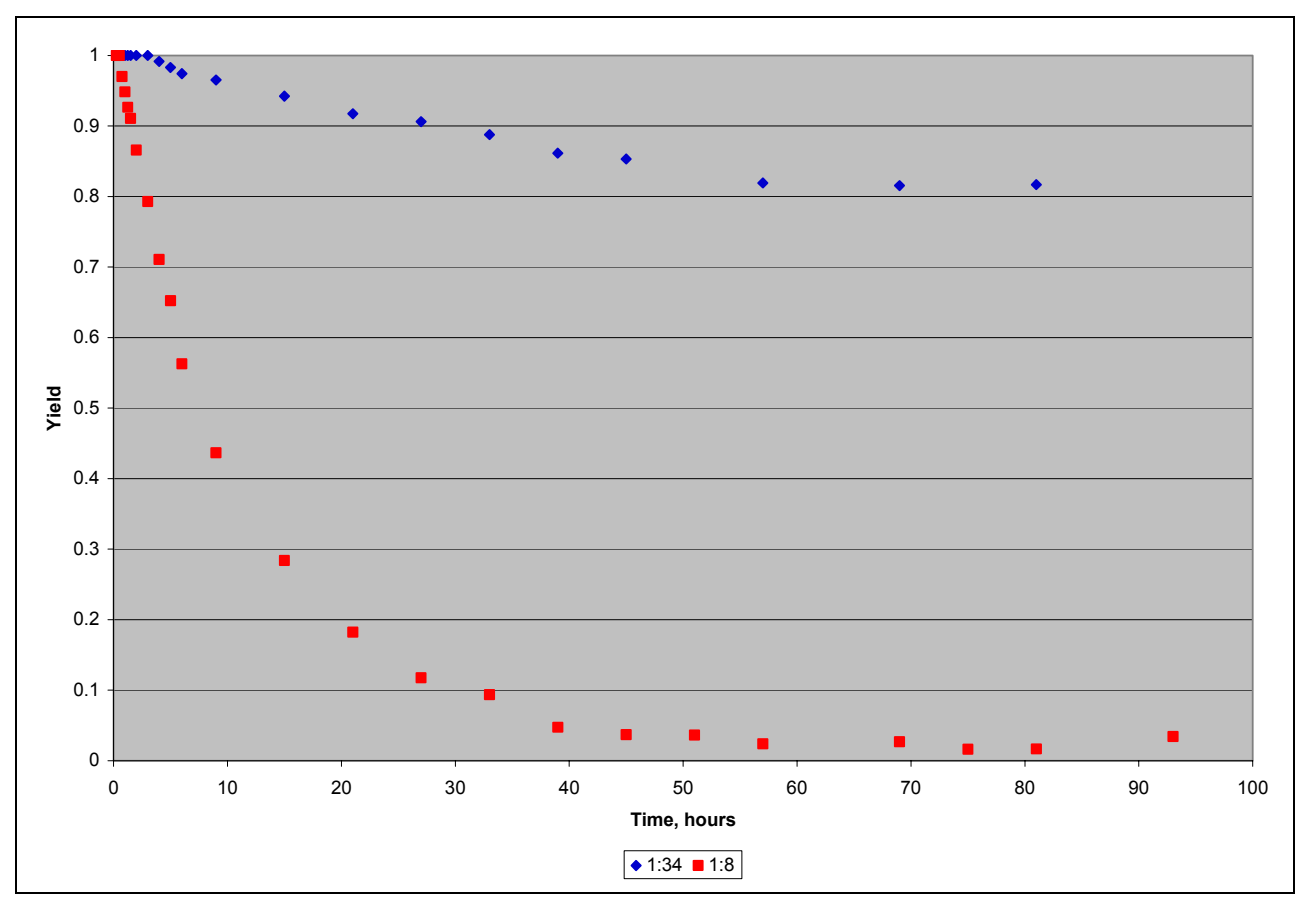

Figure 4-22. Loss of Styrene - Rh:P ratio variances using TPP. Conditions: $\left[\mathrm{RhCl}\left(\mathrm{C}_{8} \mathrm{H}_{12}\right)\right]_{2} \& \mathrm{TPP}$, in situ pretreatment $=50{ }^{\circ} \mathrm{C} \& 2000 \mathrm{psig}$, reaction conditions $=$ $75^{\circ} \mathrm{C} \& 3000$ psig; Variable: Rh:P ratio. 


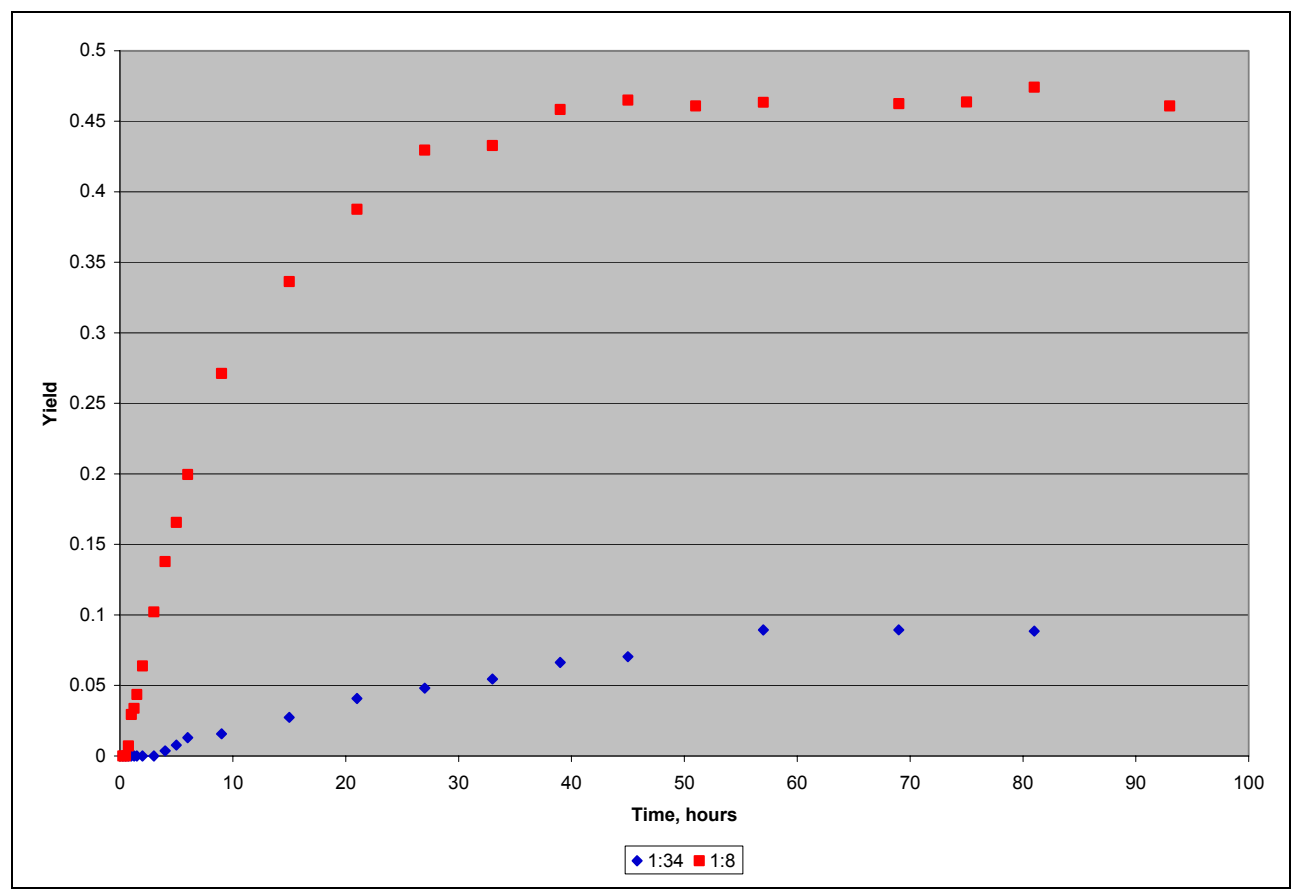

Figure 4-23. Yield of Product Peak 1 - Rh:P ratio variances using TPP. Conditions: $\left[\mathrm{RhCl}\left(\mathrm{C}_{8} \mathrm{H}_{12}\right)\right]_{2} \& \mathrm{TPP}$, in situ pretreatment $=50{ }^{\circ} \mathrm{C} \& 2000$ psig, reaction conditions $=$ $75^{\circ} \mathrm{C} \& 3000$ psig; Variable: Rh:P ratio.

Experiments $7 \mathrm{M}(1: 8)$ and $8 \mathrm{~N}(1: 34)$ used $\left[\mathrm{RhCl}\left(\mathrm{C}_{8} \mathrm{H}_{12}\right)\right]_{2}$ and $\mathrm{TPP}$, in situ preparation conditions of $50{ }^{\circ} \mathrm{C}$ and $2000 \mathrm{psig}$, and reaction conditions of $90{ }^{\circ} \mathrm{C}$ and 2500 psig, as shown in Figures 4-24 and 4-25. As seen, with these pretreatment conditions and at this range of $\mathrm{Rh}: \mathrm{P}$ ratio, the additional phosphorus had no effect on either the conversion or product yield. Although it is not clear why this should occur, it is possible that the formation of catalyst during the 24 -hour pretreatment period at $90{ }^{\circ} \mathrm{C}$ and without added solvent was rate-limiting, and thus, the additional phosphorus ligands were not incorporated into the active catalyst. These experiments appear to provide similar yields of both styrene and products. 


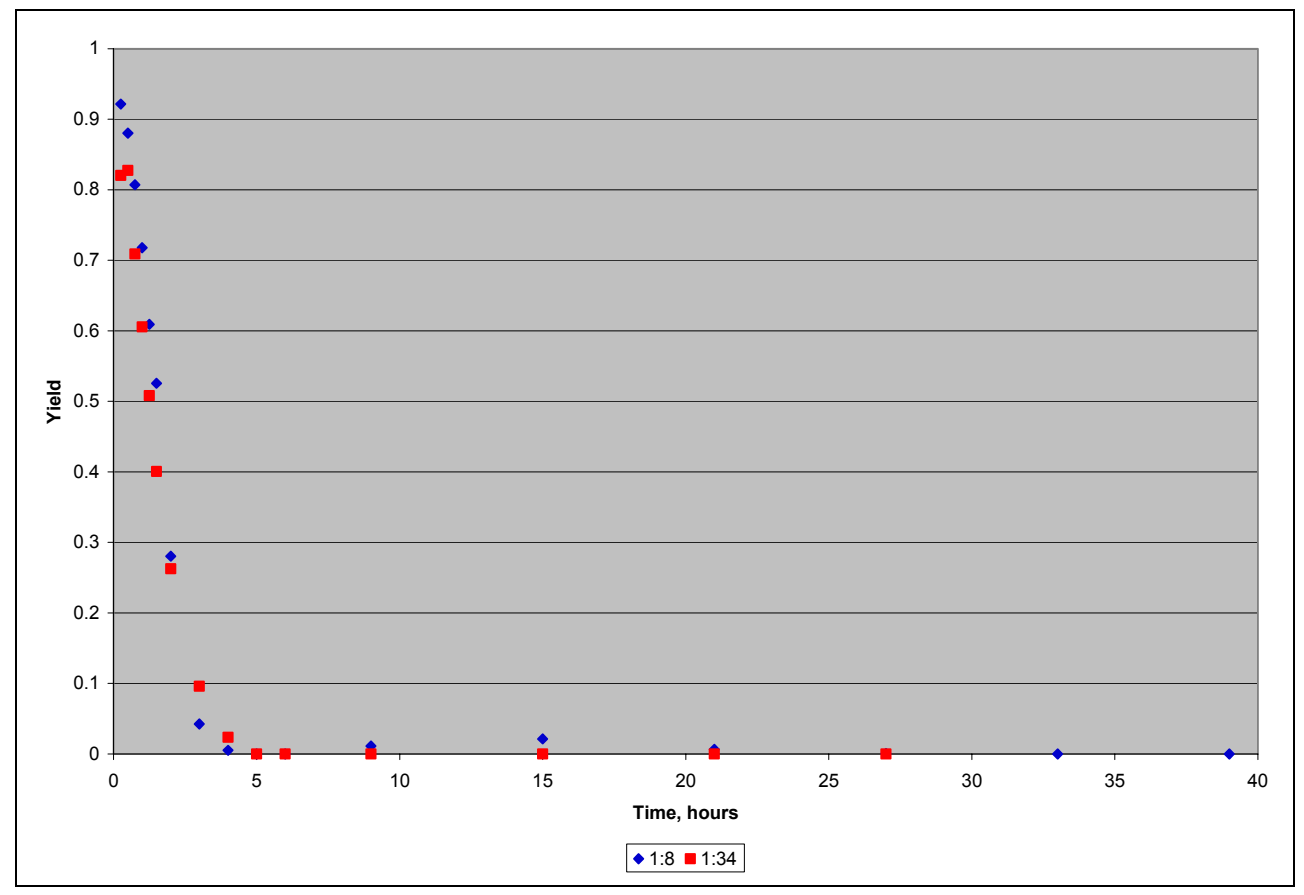

Figure 4-24. Loss of Styrene - Rh:P ratio variances using TPP. Conditions: $\left[\mathrm{RhCl}\left(\mathrm{C}_{8} \mathrm{H}_{12}\right)\right]_{2} \& \mathrm{TPP}$, in situ pretreatment $=50{ }^{\circ} \mathrm{C} \& 2000 \mathrm{psig}$, reaction conditions $=$ $90{ }^{\circ} \mathrm{C} \& 2500$ psig; Variable: Rh:P ratio.

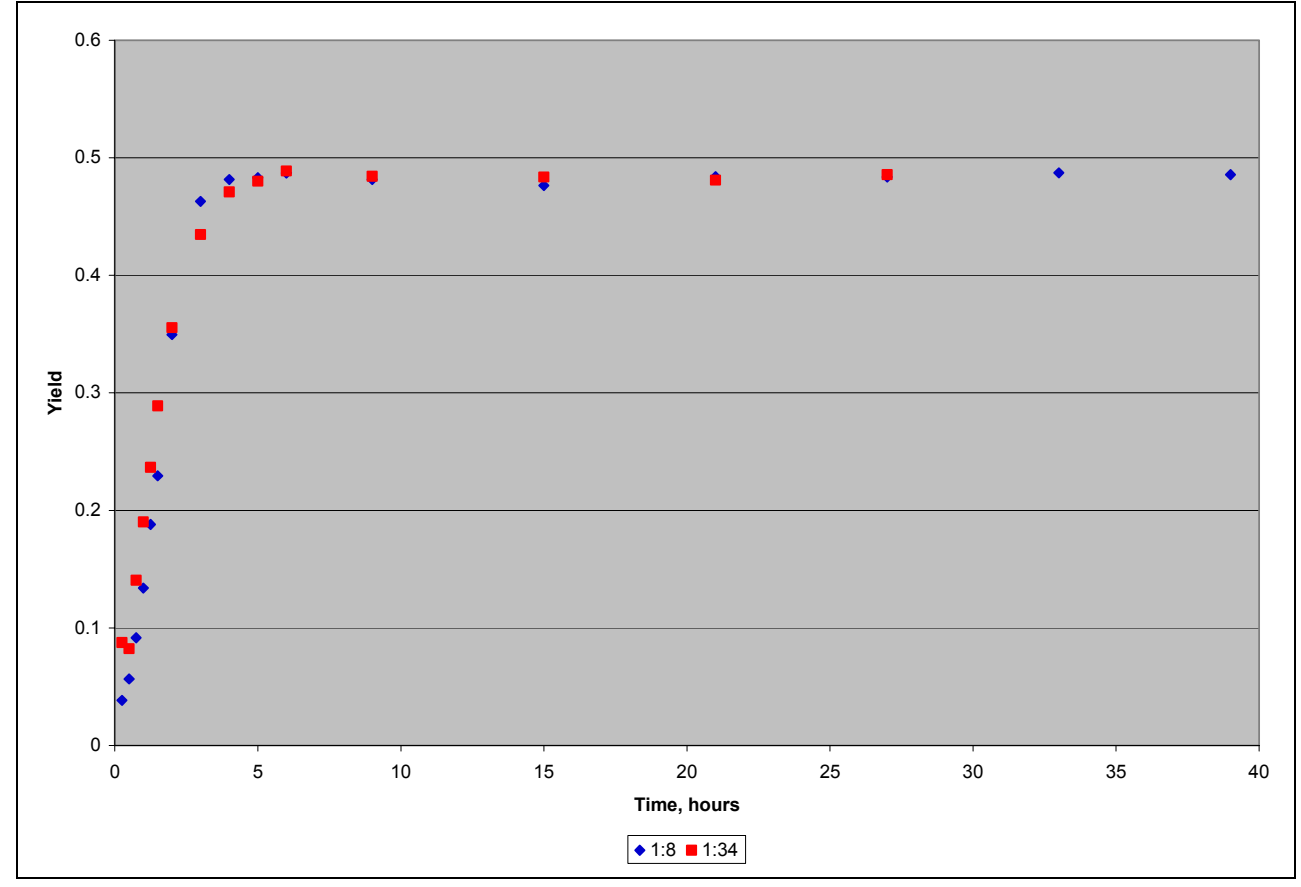

Figure 4-25. Yield of Products - Rh:P ratio variances using TPP. Conditions: $\left[\mathrm{RhCl}\left(\mathrm{C}_{8} \mathrm{H}_{12}\right)\right]_{2} \& \mathrm{TPP}$, in situ pretreatment $=50{ }^{\circ} \mathrm{C} \& 2000$ psig, reaction conditions $=$ $90{ }^{\circ} \mathrm{C} \& 2500$ psig; Variable: $\mathrm{Rh}: \mathrm{P}$ ratio. 


\section{$\underline{4.6 \text { Comparing Catalysts }}$}

Figures 4-26 and 4-27 compare experiments 1F (TPP), 2G (BINAP), and 3H (No Phosphorus), in order to evaluate the effects of ligand on catalyst performance. The reactions were conducted with pretreatment conditions of $90{ }^{\circ} \mathrm{C}$ and $650 \mathrm{psig}$, reaction conditions of $90{ }^{\circ} \mathrm{C}$ and 2500 psig, and $\mathrm{Rh}: \mathrm{P}$ ratios of $1: 8,1: 4$, and 1:0, respectively. Despite the difference in Rh:P ratios, the reactions using the phosphine ligands have very similar reaction profiles.

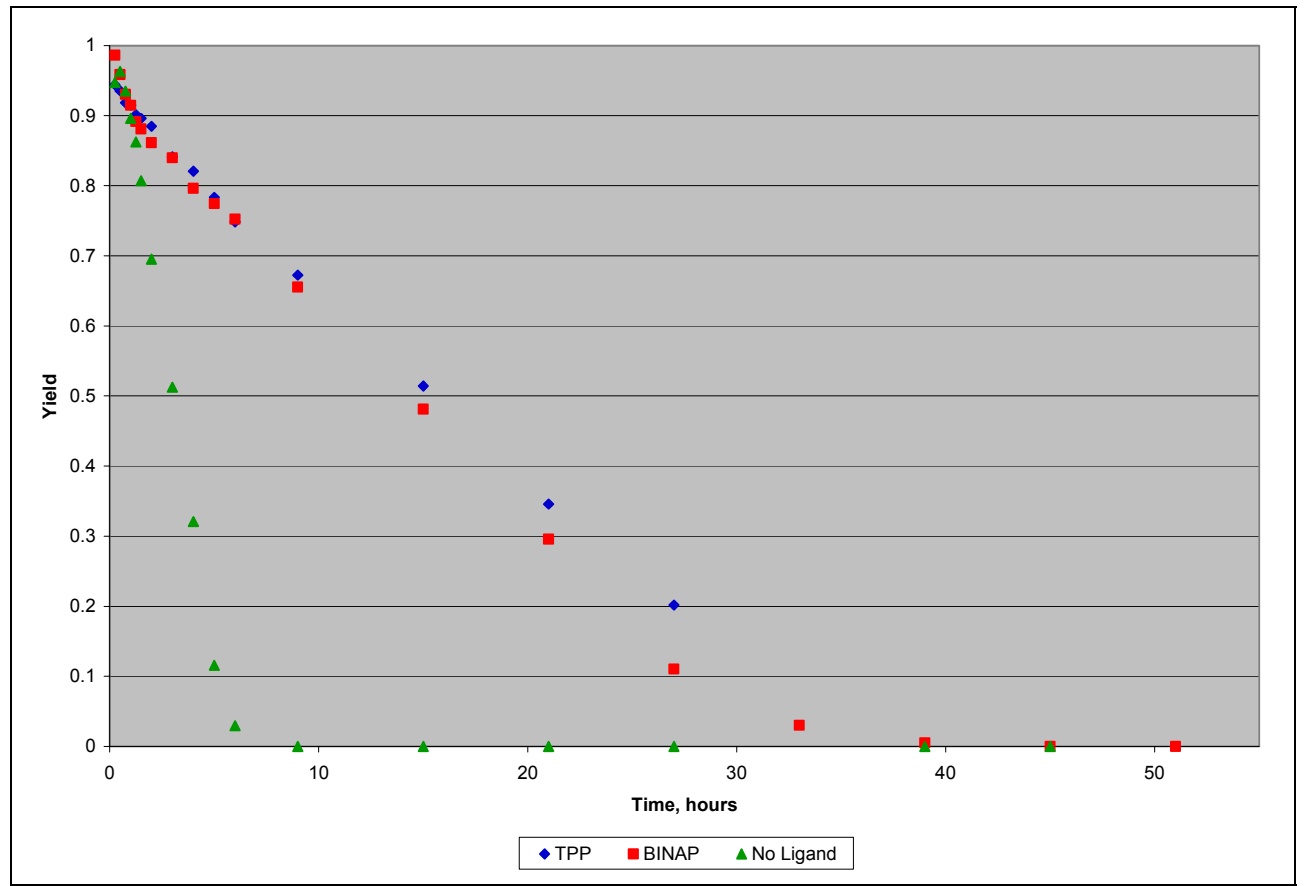

Figure 4-26. Loss of Styrene - Comparison of Ligands. Conditions: $\left[\mathrm{RhCl}\left(\mathrm{C}_{8} \mathrm{H}_{12}\right)\right]_{2}$, pretreatment conditions $=90{ }^{\circ} \mathrm{C} \& 650$ psig, reaction conditions $=90{ }^{\circ} \mathrm{C} \& 2500 \mathrm{psig}$; Variables: ligands \& $\mathrm{Rh}: \mathrm{P}$ ratios. 


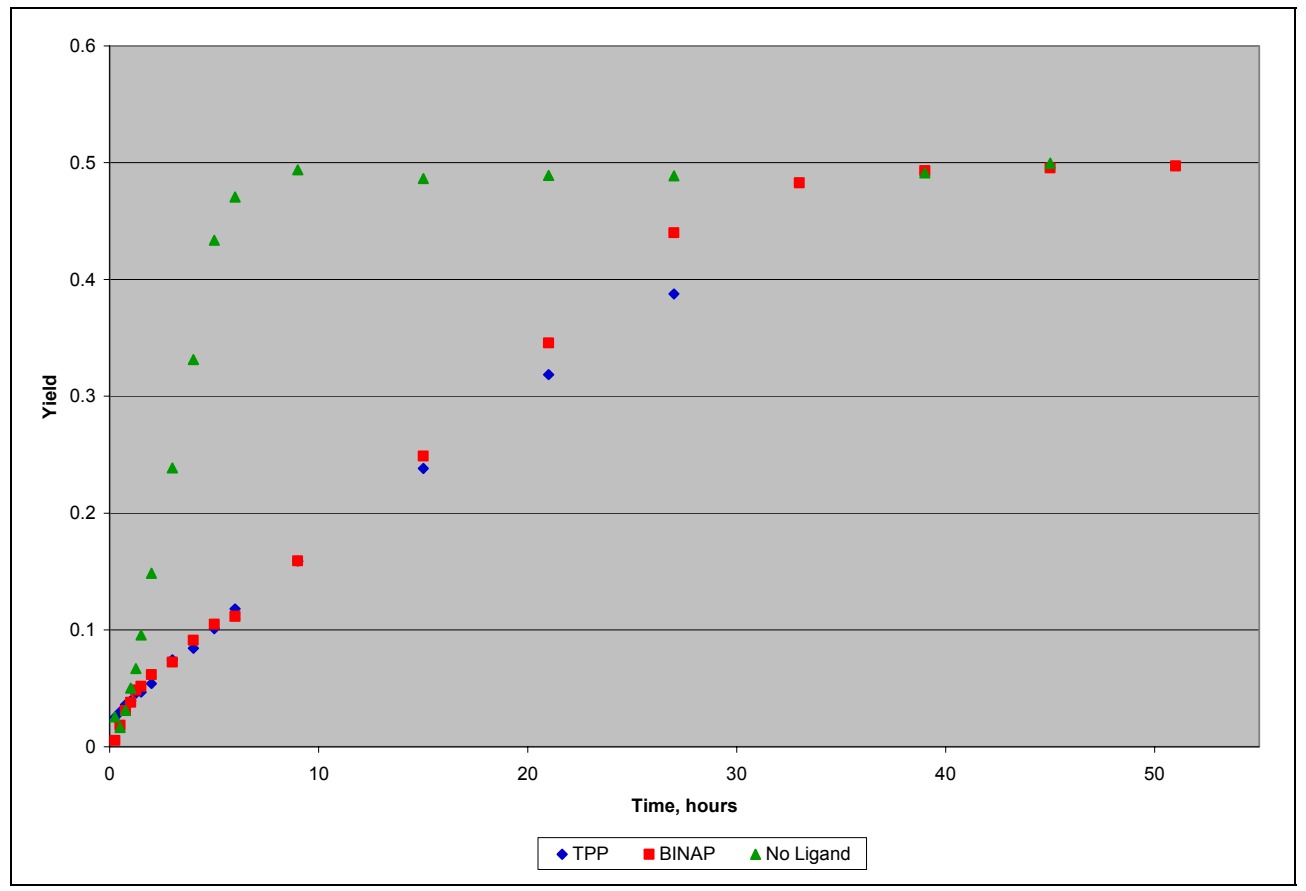

Figure 4-27. Product Yield - Comparison of Ligands. Conditions: $\left[\mathrm{RhCl}\left(\mathrm{C}_{8} \mathrm{H}_{12}\right)\right]_{2}$, pretreatment conditions $=90{ }^{\circ} \mathrm{C} \& 650 \mathrm{psig}$, reaction conditions $=90{ }^{\circ} \mathrm{C} \& 2500 \mathrm{psig}$; Variables: ligands \& Rh:P ratios.

Figure 4-28 and Figure 4-29 compare the yields obtained from catalysts with the lowest atomic ratios, pretreatment conditions of $90{ }^{\circ} \mathrm{C}$ and $650 \mathrm{psig}$, and reaction conditions of $90{ }^{\circ} \mathrm{C}$ and 2500 psig; these graphs show results from experiments $4 \mathrm{~J}$ (Wilkinson's catalyst produced in the laboratory), 5K (Wilkinson's catalyst immobilized on a silica support), and $11 \mathrm{R}\left(\left(\left[\mathrm{RhCl}\left(\mathrm{C}_{8} \mathrm{H}_{12}\right)\right]_{2} \& \mathrm{TPP}\right)\right.$. Wilkinson's catalysts and the immobilized catalyst have $\mathrm{Rh}: \mathrm{P}$ ratios of $1: 3$; the experiment in which the catalyst was made in situ has a Rh:P ratio of 1:2. The catalyst made in situ performed somewhat better than the two catalysts produced in the laboratory, both of which performed similarly. The product yield data shows a similar trend. 


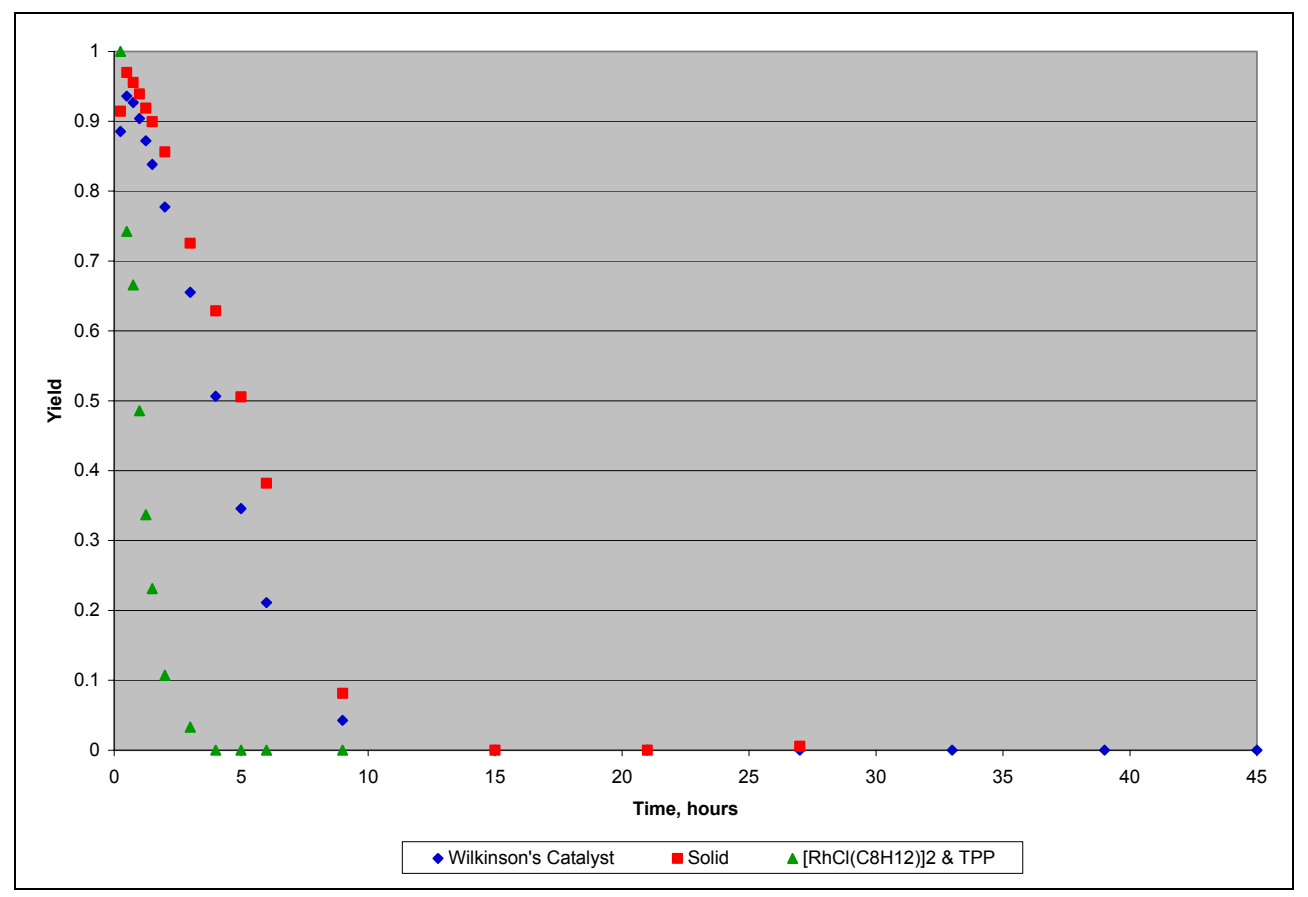

Figure 4-28. Loss of Styrene - TPP as a ligand. Conditions: pretreatment $=90{ }^{\circ} \mathrm{C} \&$ 650 psig, reaction conditions $=90{ }^{\circ} \mathrm{C} \& 2500$ psig; Variables: catalyst and $\mathrm{Rh}: \mathrm{P}$ ratio.

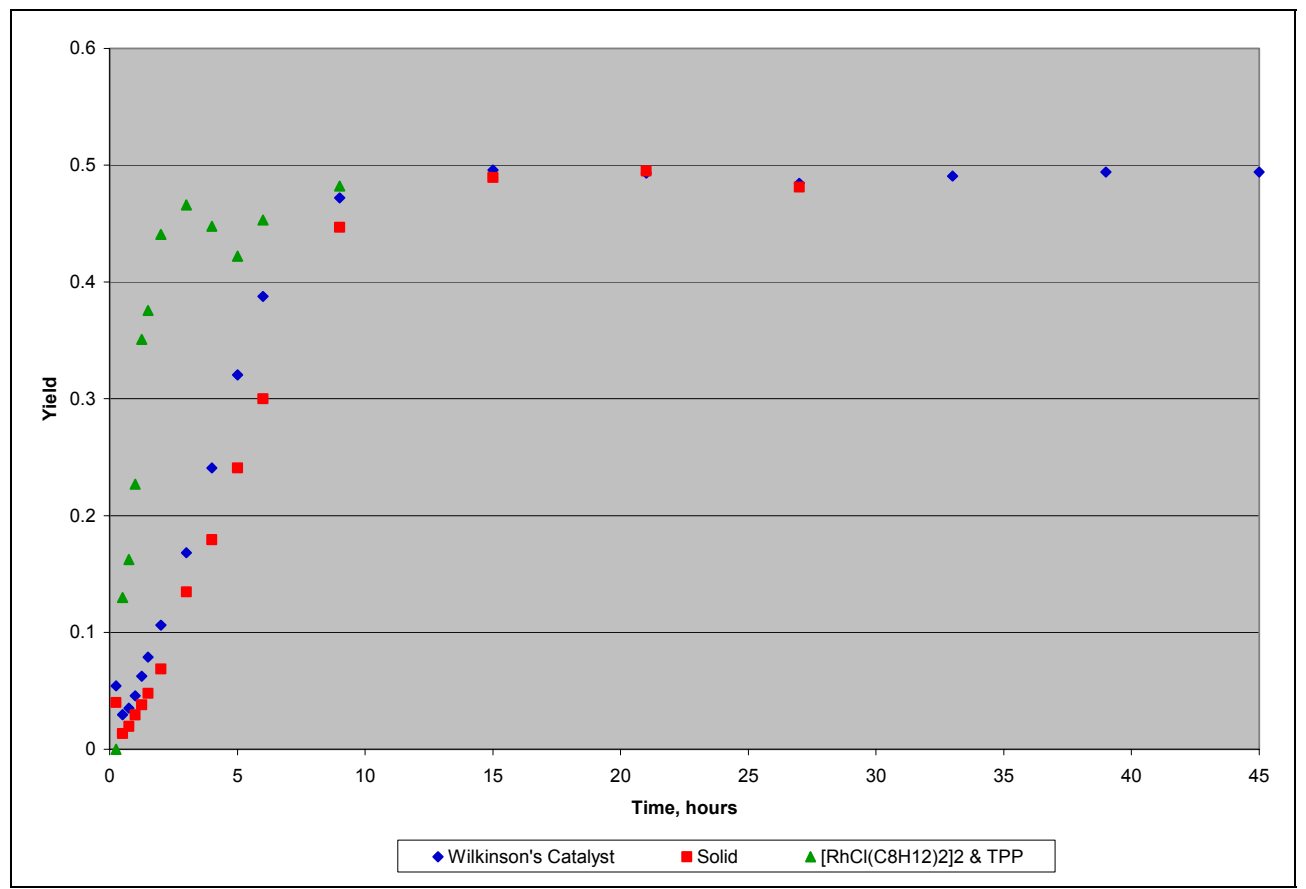

Figure 4-29. Yield of Products - TPP as a ligand. Conditions: pretreatment $=90{ }^{\circ} \mathrm{C} \&$ 650 psig, reaction conditions $=90{ }^{\circ} \mathrm{C} \& 2500$ psig; Variables: catalyst and $\mathrm{Rh}: \mathrm{P}$ ratio. 
Figures 4-30 and 4-31 compare experiments in which BINAP was used as a ligand; $2 \mathrm{G}$ and $12 \mathrm{~S}$ (both in situ preparation), $3 \mathrm{H}\left(\left[\mathrm{RhCl}\left(\mathrm{C}_{8} \mathrm{H}_{12}\right)\right]_{2}\right.$ only), and 13T (Rh-BINAP produced in the laboratory). All reactions have in situ conditions of $90{ }^{\circ} \mathrm{C}$ and $650 \mathrm{psig}$ and reaction conditions of $90{ }^{\circ} \mathrm{C}$ and 2500 psig. The catalysts in which phosphorus ligands were used appear to have similar reaction profiles and the reaction in which no ligand was used had the largest rate of reaction; as previously discussed, the presence of phosphorus slows the reaction rate, but may enhance enantioselectivity. These graphs show that the laboratory-prepared catalyst performed similarly to the ones that are prepared in situ, indicating that the catalysts were made inside the reactor, despite the NMR spectroscopy findings.

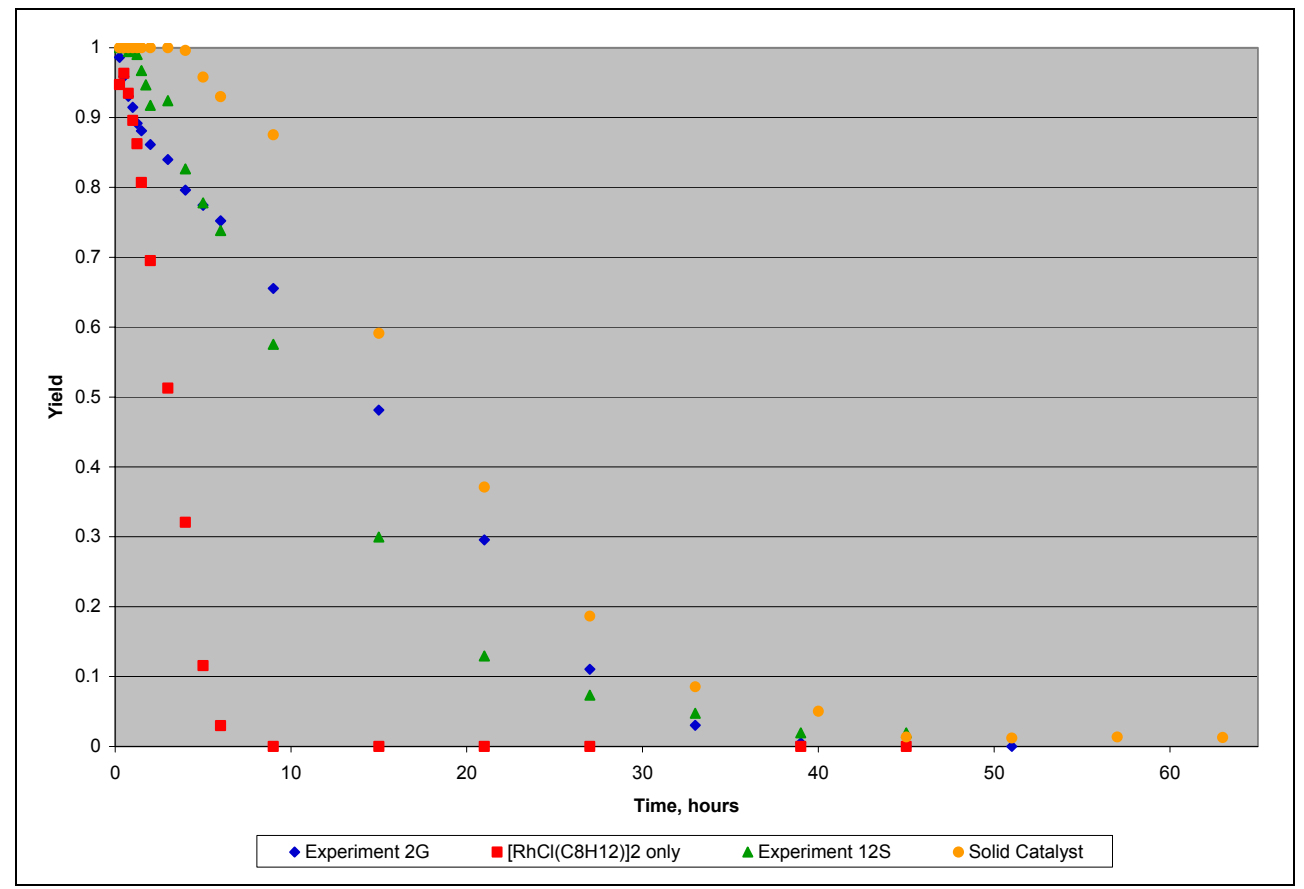

Figure 4-30. Loss of Styrene - BINAP as a ligand. Conditions: pretreatment $=90{ }^{\circ} \mathrm{C}$ $\& 650$ psig, reaction conditions $=90^{\circ} \mathrm{C} \& 2500$ psig; Variable: catalyst. 


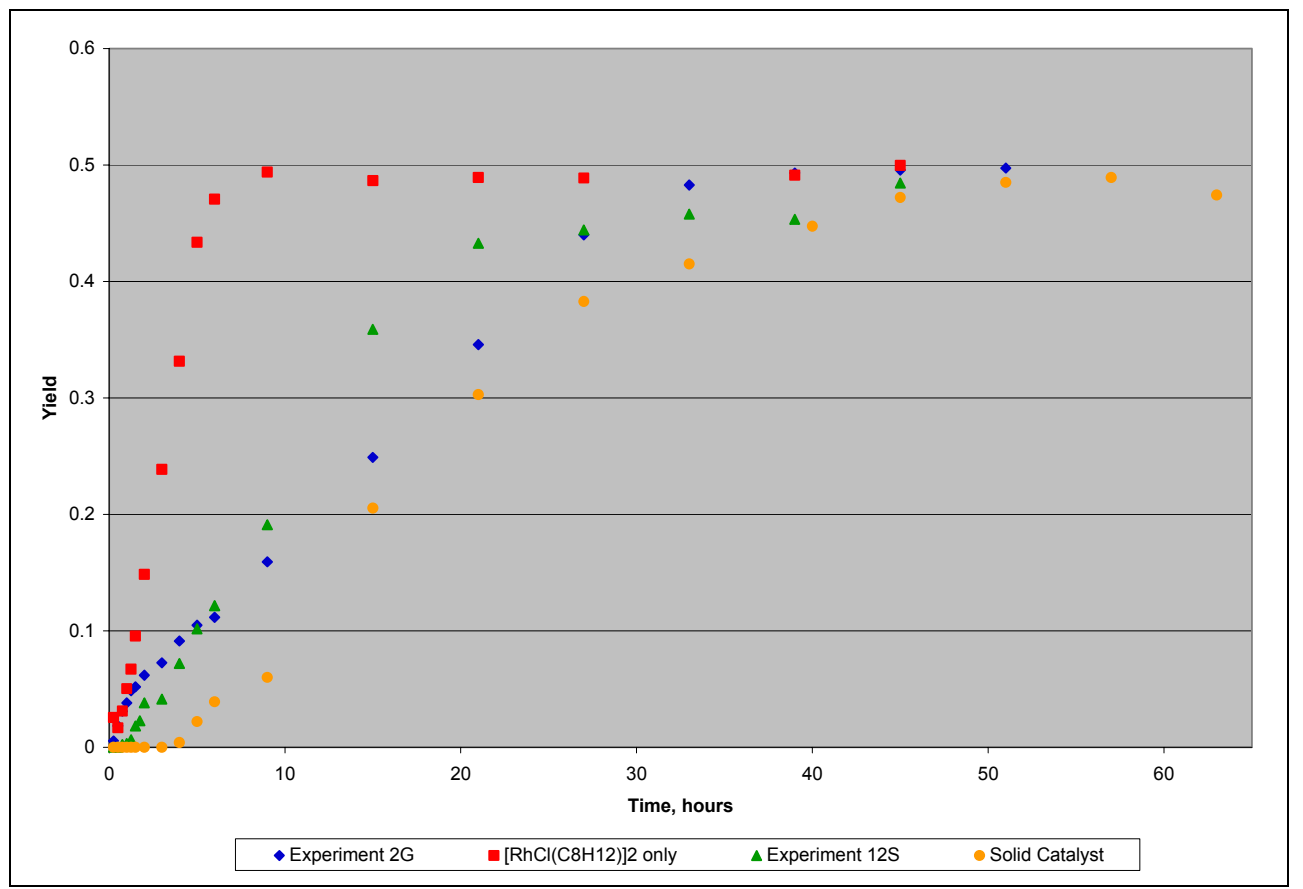

Figure 4-31. Yield of Products - BINAP as a ligand. Conditions: pretreatment $=90{ }^{\circ} \mathrm{C}$ $\& 650$ psig, reaction conditions $=90^{\circ} \mathrm{C} \& 2500$ psig; Variable: catalyst.

\section{$\underline{4.7 \text { Selectivity of Products }}$}

Since the products of the hydroformylation reaction are enantiomers, the ratio of the areas of the enantiomer peaks can be used to determine if the reaction is selective towards either the $\mathrm{R}$ or the $\mathrm{S}$ configuration of the product. The use of a chiral ligand with an $\mathrm{R}$ configuration should yield an enantiomeric excess of products with R configuration.

Figure 4-32 compares experiments 1F (TPP), 2G (BINAP), and 3H (No Phosphorus), in order to evaluate the effects of ligand on selectivity. The reactions were conducted with pretreatment conditions of $90{ }^{\circ} \mathrm{C}$ and 650 psig, reaction conditions of $90{ }^{\circ} \mathrm{C}$ and 2500 psig, and Rh:P ratios of 1:8, 1:4, and 1:0, respectively. The reaction in which (R)BINAP was used as the ligand provided some enantiomeric selectivity with an enantiomeric excess (defined as the yield of the second peak product minus the yield of the first peak product) of $10-15 \%$ at short times. 


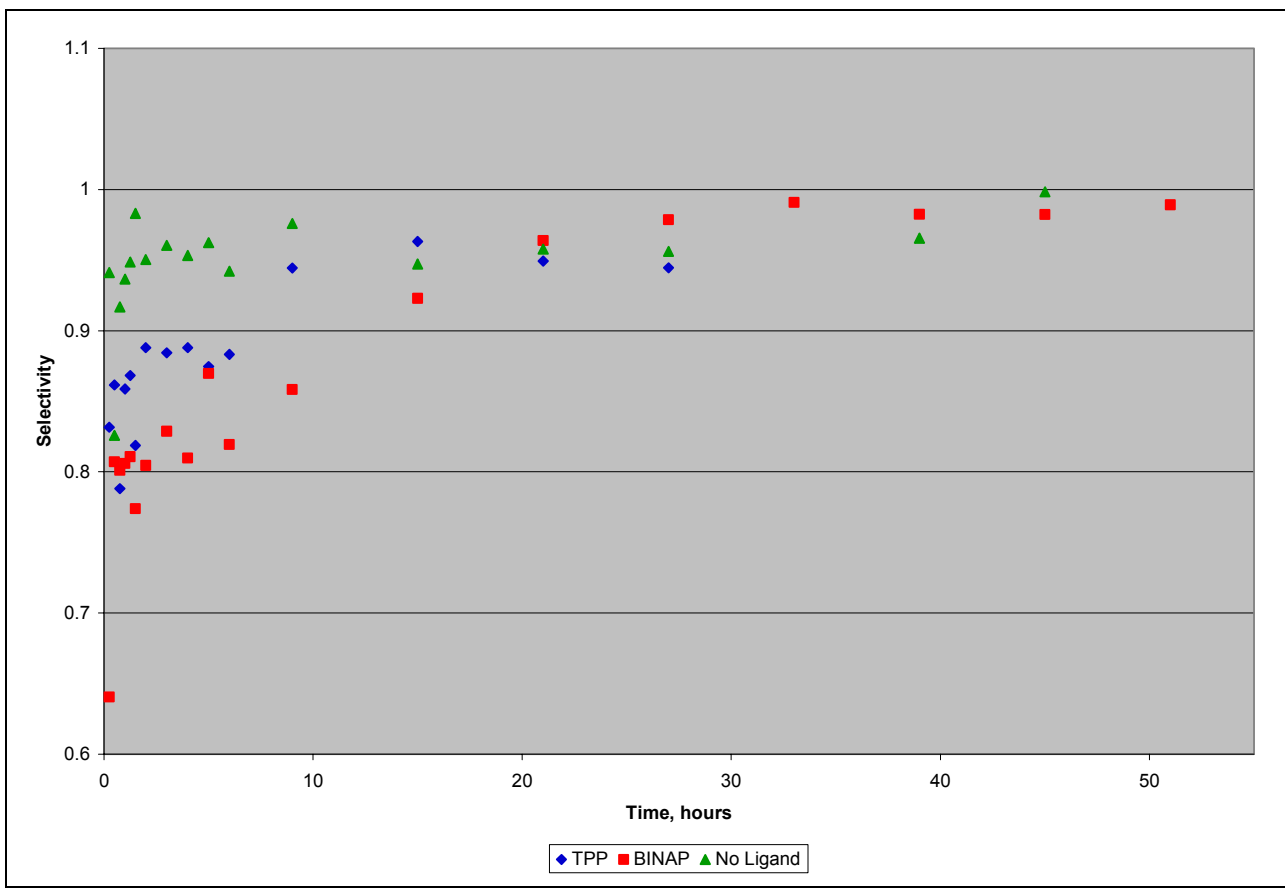

Figure 4-32. Selectivity. Conditions: $\left[\mathrm{RhCl}\left(\mathrm{C}_{8} \mathrm{H}_{12}\right)\right]_{2}$, pretreatment conditions $=90{ }^{\circ} \mathrm{C}$ $\& 650$ psig, reaction conditions $=90{ }^{\circ} \mathrm{C} \& 2500$ psig; Variables: ligands \& $\mathrm{Rh}: \mathrm{P}$ ratios.

Figure 4-33 shows the ratio of the peaks among reactions using laboratory-produced catalysts. These experiments had pretreatment conditions of $90{ }^{\circ} \mathrm{C}$ and $650 \mathrm{psig}$ and reaction conditions at $90{ }^{\circ} \mathrm{C}$ and 2500 psig. The reactions being compared are $3 \mathrm{H}$ ([RhCl( $\left.\left.\mathrm{C}_{8} \mathrm{H}_{12}\right)\right]_{2}$ only), 4J (Wilkinson's Catalyst), 5K (Immobilized Wilkinson's catalyst), and $13 \mathrm{~T}$ (Laboratory-produced Rh-BINAP). Except for the experiments at short reaction times, for which very low conversions were observed, the Rh-BINAP catalyst shows a tendency to favor the formation of the second product, suggesting possible enantioselectivity from this catalyst. 


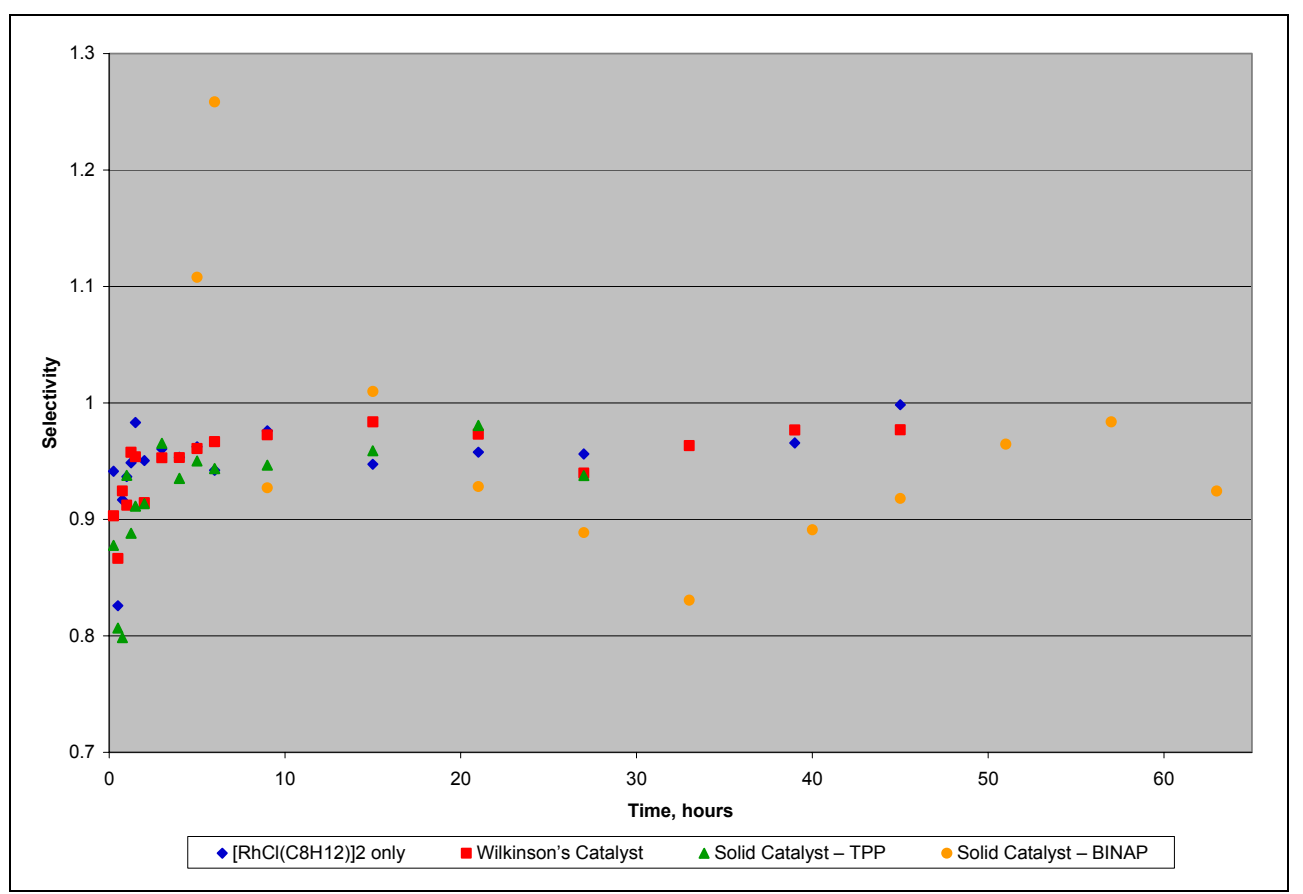

Figure 4-33. Selectivity Comparison - Solid Catalysts. Conditions: pretreatment $=90$ ${ }^{\circ} \mathrm{C} \& 650$ psig, reaction conditions $=90^{\circ} \mathrm{C} \& 2500$ psig; Variable: catalyst.

Figure 4-34 compiles the data into two groups: (1) those using BINAP as a ligand and (2) those using TPP as a ligand. Again, except for experiments at short reaction times (and thus very low conversion), the catalysts produced with BINAP ligand have a tendency to favor the second product. 


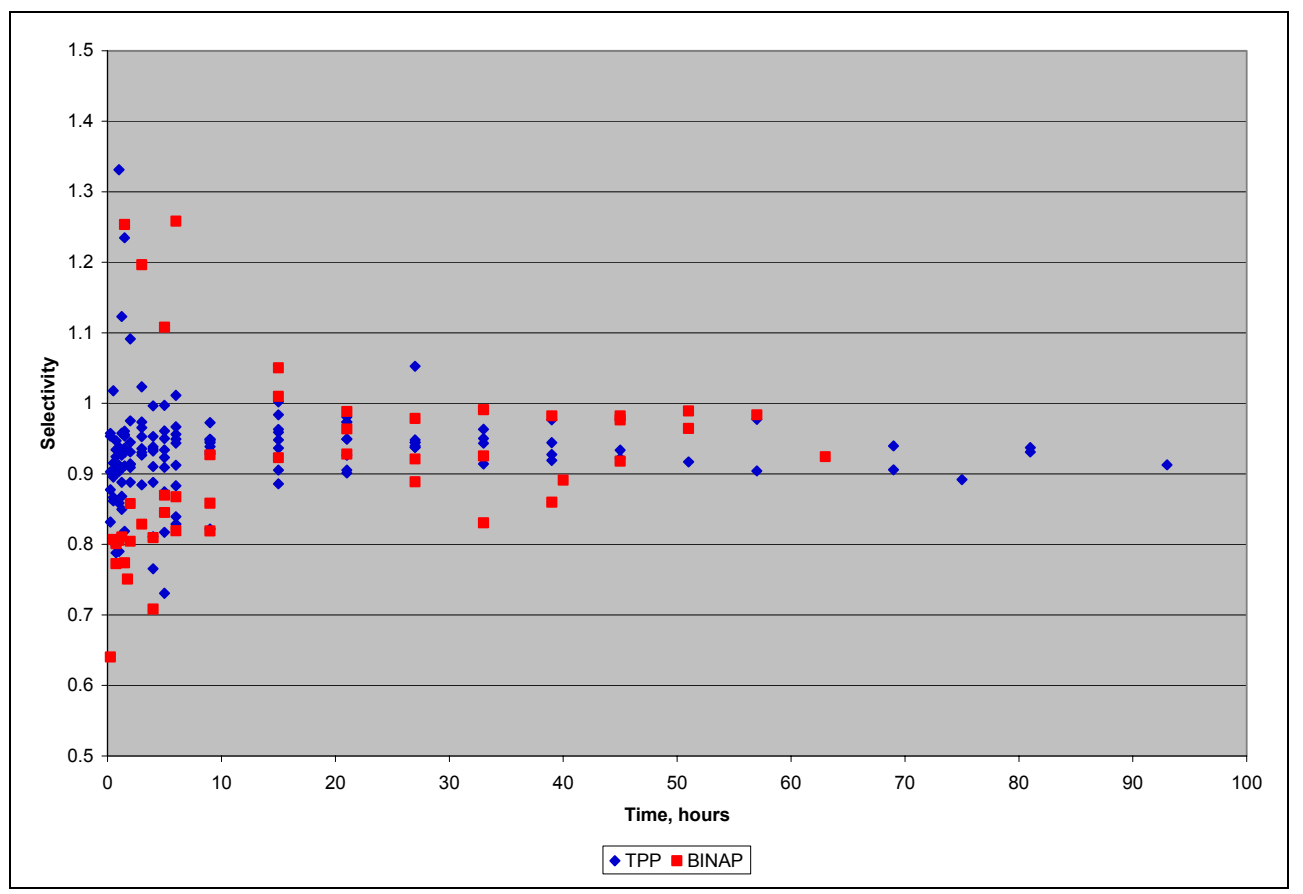

Figure 4-34. Selectivity of Ligands. The data has been grouped based on the ligand being used. 


\section{Chapter Five}

\section{Conclusions and Recommendations}

\section{$\underline{5.1 \text { Conclusions }}$}

Nuclear magnetic resonance and infrared spectroscopy were used to evaluate the catalysts and catalyst precursors on a structural level. Comparison of current results with known data from published works demonstrate that catalysts were made in situ using $\left[\mathrm{RhCl}\left(\mathrm{C}_{8} \mathrm{H}_{12}\right)\right]_{2}$ and triphenylphosphine. The formation of reaction products and the variation in catalyst performance brought on by varying catalyst preparation conditions further confirms that active catalyst was prepared through the in situ reaction.

However, no residual catalyst was detected in the basket from experiments using $\left[\mathrm{RhCl}\left(\mathrm{C}_{8} \mathrm{H}_{12}\right)\right]_{2}$ and (R)-BINAP as catalyst precursors. On the other hand, experiments with $\left[\mathrm{RhCl}\left(\mathrm{C}_{8} \mathrm{H}_{12}\right)\right]_{2}$ and $(\mathrm{R})$-BINAP showed that a catalyst was likely produced in the reactor, despite the inability of NMR and IR to confirm this conclusion. Since the NMR and IR spectroscopy was only able to analyze the catalyst remaining in the envelope, it can be concluded that the catalyst made in situ did not remain in the catalyst pouch after the reaction; instead, it was likely solubilized and disbursed throughout the supercritical fluid in the reactor. This conclusion is supported by the fact that the solid rhodiumBINAP complex produced by the Department of Chemistry was also not present in the catalyst envelope after the reaction. 
The most active catalyst was formed by pretreatment at $50{ }^{\circ} \mathrm{C}$ and 2000 psig pressure. Reaction conditions of $90^{\circ} \mathrm{C}$ and 2500 psig, with a $\mathrm{Rh}: \mathrm{P}=1: 8$, were found to be active for the hydroformylation reaction. Higher loadings of phosphorus led to slower reaction, as expected from literature data. Similarly, increasing reaction temperature gave better activity. The effect of reaction pressure could not be independently discerned from these experiments, since pressure and temperature were always varied simultaneously. The catalysts prepared in situ performed comparably to those prepared in the laboratory, and to catalysts that were immobilized on solid supports.

Based on previous work on asymmetric hydroformylation, the reactions in which BINAP ligands were used should have provided enantioselective products, while the reactions using triphenylphosphine ligands should not have produced enantioselectivity. Despite the appearance of mild enantioselectivity in most reactions, the reactions using BINAP were similar to those found in the literature. Hegedus, et al. (2004) reported enantiomeric excess of $13 \%$ for conditions most similar to those used in the current work; this is compatible to the $10-15 \%$ enantiomeric excess observed in the current work. Hegedus, et al. (2004) noted high enantioselectivity at fairly low reaction temperature, much lower than that used in the current work, and decreasing enantioselectivity as the temperature increased. Thus, it is concluded that the mild enantioselectivity observed herein is consistent with previous asymmetric hydroformylation results.

\section{$\underline{5.2 \text { Recommendations }}$}

To determine if the rhodium-BINAP catalyst was made in situ, the in situ conditions should be used to produce the catalyst and the experiment terminated prior to injecting 
the vessel with reactants. Since the reaction vessel would be free from reactants and products, the catalyst should be recoverable from the pouch and/or the walls of the reaction vessel. In doing so, the catalysts that have undergone pretreatment can be examined using IR and NMR to determine if catalysts were made in situ. Additionally, the IR and NMR spectroscopy of the catalysts using rhodium and TPP prior to reaction should be similar to those of rhodium-TPP catalysts after a reaction.

Because the temperature of the current experiments was higher than that which should yield high enantioselectivity, additional experiments should be performed at lower temperatures to determine if greater enantioselectivity can be achieved. Based on the current results from experiments with both TPP and BINAP ligands, it is expected that greater enantioselectivity would be demonstrated if catalyst were prepared in situ from $\left[\mathrm{RhCl}\left(\mathrm{C}_{8} \mathrm{H}_{12}\right)\right]_{2}$ and $\mathrm{BINAP}$ at $50{ }^{\circ} \mathrm{C}$ and $2000 \mathrm{psig}$, followed by reaction at $75{ }^{\circ} \mathrm{C}$ and 2500 psig. Further experimentation should focus on obtaining optimal parameters for providing the desired selectivity. 


\section{References}

Abraham, Martin. Initiative for Chemical Engineers. Environmental Progress 23: 261-3, 2004.

Akgerman, Aydin. Supercritical fluid extraction of contaminants from environmental matrices. Waste Management 13: 403-415, 1993.

Akgerman, A. Supercritical Fluids in Environmental Remediation and Pollution Prevention. American Chemical Society, Washington, DC, 1997.

Ali, B. El, J. Tijani, M. Fettouhi, A. Al-Arfaj, and M. El-Faer. Heteropolyacids enhanced the catalytic activity of $\mathrm{Rh}_{6}(\mathrm{CO})_{16}$ in the hydroformylation of alkenes. Applied Organometallic Chemistry 19: 329-338, 2005.

Aresta, Michele. Carbon Dioxide Recovery and Utilization. Kluwer Academic Publishers, Boston, 2003.

Balsells, Jaume, and Patrick J. Walsh. Design of Diastereomeric Self-Inhibiting Catalysts for Control of Turnover Frequency and Enantioselectivity. Journal of the American Chemical Society 122: 3250-51, 2000. 
Bensaid, Laurence F. Rhodium-Catalyzed Hydroformylation of 1-Hexene Using $\pi$-Acidic Phosphines and Synthesis of a New Phosphine Ligand for Use in Supercritical Carbon Dioxide, M.S. Thesis, The University of Toledo, Toledo, Ohio, 2002.

Bunten, Kevin A., David H. Farrar, Anthony J. Poe, and Alan Lough. Stoichiometric and Catalytic Oxidation of BINAP by Dioxygen in Rhodium(I) Complex. Organometallics 21: 3344-3350, 2002.

Castellanos-Paez, A., S. Castillon, C. Claver. Synthesis of rhodium(I) complexes with the new dithiol chiral ligand (+)-trans-2,3-bis(mercaptomethyl)-bicyclo[2.2.2]octane $\left.\underline{\mathrm{H}}_{2} \underline{\mathrm{BCOS}}\right)$. Their application as catalysts precursors in the styrene hydroformylation. Journal of Organometallic Chemistry 539:1-7, 1997.

DeSimone, Joseph M. and William Tumas. Green Chemistry Using Liquid and Supercritical Carbon Dioxide. Oxford University Press, New York, 2003.

Dickson, Ronald S. Homogeneous Catalysis with Compounds of Rhodium and Iridium. D. Reidel Publishing Company, Boston, 1985.

Environmental Protection Agency. Available online: http://www.epa.gov/region5/defs/html/ppa.htm. March 30, 2005. 
Gassman, Paul G., David W. Macomber, and Stephen M. Willging. Isolation and $\underline{\text { Characterization of Reactive Intermediates and Active Catalysts in Homogeneous }}$ Catalysis. Journal of the American Chemical Society 107: 2380-8, 1985.

Giordano, G.; Crabtree, R.H. Di-Mu-Chloro-BIS(Eta-4-1,5-Cyclooctadiene) dirhodium (I). Inorganic Synthesis 28: 88-90, 1990.

Hegedus, Csaba, Jozsef Madarasz, Ildiko Gergely, Aron Szollosy, Axel Monsees, Thomas Riermeier, and Jozsef Bakos. Electronic and Steric Effects of Ligands as Control Elements for Rhodium-Catalyzed Asymmetric Hydroformylation. Part 3: Highly Active Hydroformylation of Styrene. Tetrahedron: Asymmetry 15: 2507-13, 2004.

Hudson, Richard. Personal Correspondence: September 2004.

Kani, Ibrahim, Roberto Flores, John P. Fackler, Aydin Akgerman. $\underline{\text { Hydroformylation of }}$ $\underline{\text { styrene in supercritical carbon dioxide with fluoroacrylate polymer supported rhodium }}$ catalysts. Journal of Supercritical Fluids 31: 287-294, 2004.

Kani, Ibrahim, Mohammad A. Omary, Manal A. Rawashdeh-Omary, Zulema K. LopezCastillo, Roberto Flores, Aydin Akgerman, and John P Fackler. Homogeneous catalysis in supercritical carbon dioxide with rhodium catalysts tethering fluoroacrylate polymer ligands. Tetrahedron 58: 3923-3928, 2002. 
Koch, Daniel, and Walter Leitner. Rhodium-Catalyzed Hydroformylation in Supercritical Carbon Dioxide. Journal of the American Chemical Society 120: 1339813404, 1998.

Lichtenberg, Frank R. Benefits and Costs of Newer Drugs: An Update. National Bureau of Economic Research, June 2002.

Liu, Chang-jun, Richard G. Mallinson, and Michele Aresta. Utilization of Greenhouse Gases. American Chemical Society, Washington, DC, 2003.

Marteel, Anne Eugenie. Development of Heterogeneous Catalysts for Hydroformylation of 1-Hexene in Supercritical Carbon Dioxide, Ph.D. Dissertation, The University of Toledo, Toledo, Ohio, 2003.

Matsuda, Tomoko, Ryuzo Kanamaru, Kazunori Watanabe, Tadao Harada, and Kaoru Nakamura. Control on Enantioselectivity with Pressure for Lipase-Catalyzed Esterification in Supercritical Carbon Dioxide. Tetrahedron Letters 42: 8319-21, 2001.

Ojima, Iwao. Catalytic Asymmetric Synthesis. Wiley-VCH, Inc., New York, 2000.

Palo, Daniel R. and Can Erkey. Effect of Ligand Modification on Rhodium-Catalyzed Homogeneous Hydroformylation in Supercritical Carbon Dioxide. Organometallics 19: $81-86,2000$. 
Quin, Louis D. and John G. Verkade. Phosphorus-31 NMR Spectral Properties in Compound Characterization and Structural Analysis. VCH Publishers, Inc., New York, 1994.

Reinius, H. K. and A. O. I. Krause. Hydroformylation of Functional Alkenes with Heterodonor Phosphine Rhodium Catalysts: Substrate or Ligand Directed Regioselectivity? Catalysis Letters 70: 149-154, 2000.

Satterfield, Charles N. Heterogeneous Catalysis In Industrial Practice. McGraw-Hill, Inc., New York, 1991.

Tack, Timothy T. $\quad$ Performance of Rhodium and Platinum Supported Catalysts for Hydroformylation in Supercritical Carbon Dioxide, M.S. Thesis, The University of Toledo, Toledo, Ohio, 2003.

Tadd, Andrew R. Evaluation of Kinetics and Catalysis for Hydroformylation of 1Hexene in Supercritical Carbon Dioxide, M.S. Thesis, The University of Toledo, Toledo, Ohio, 2001.

Van der Slot, Saskia C., Josep Duran, Jordy Luten, Paul C. J. Kamer, and Piet W. N. M. van Leeuwen. Rhodium-Catalyzed Hydroformylation and Deuterioformylation with Pyrrolyl-Based Phosphorus Amidite Ligands: Influence of Electronic Ligand Properties. Organometallics 21: 3873-3883, 2002. 
Van Leeuwen, P. W. N. M., Claver, C., Rhodium Catalyzed Hydroformylation, Kluwer Academic Publishers, Boston, 2000.

World Bank Group, The. Available online: http://www.worldbank.org/depweb/english/modules/social/life. July 20, 2004. 


\section{Appendix A}

\section{IR \& NMR Spectra}



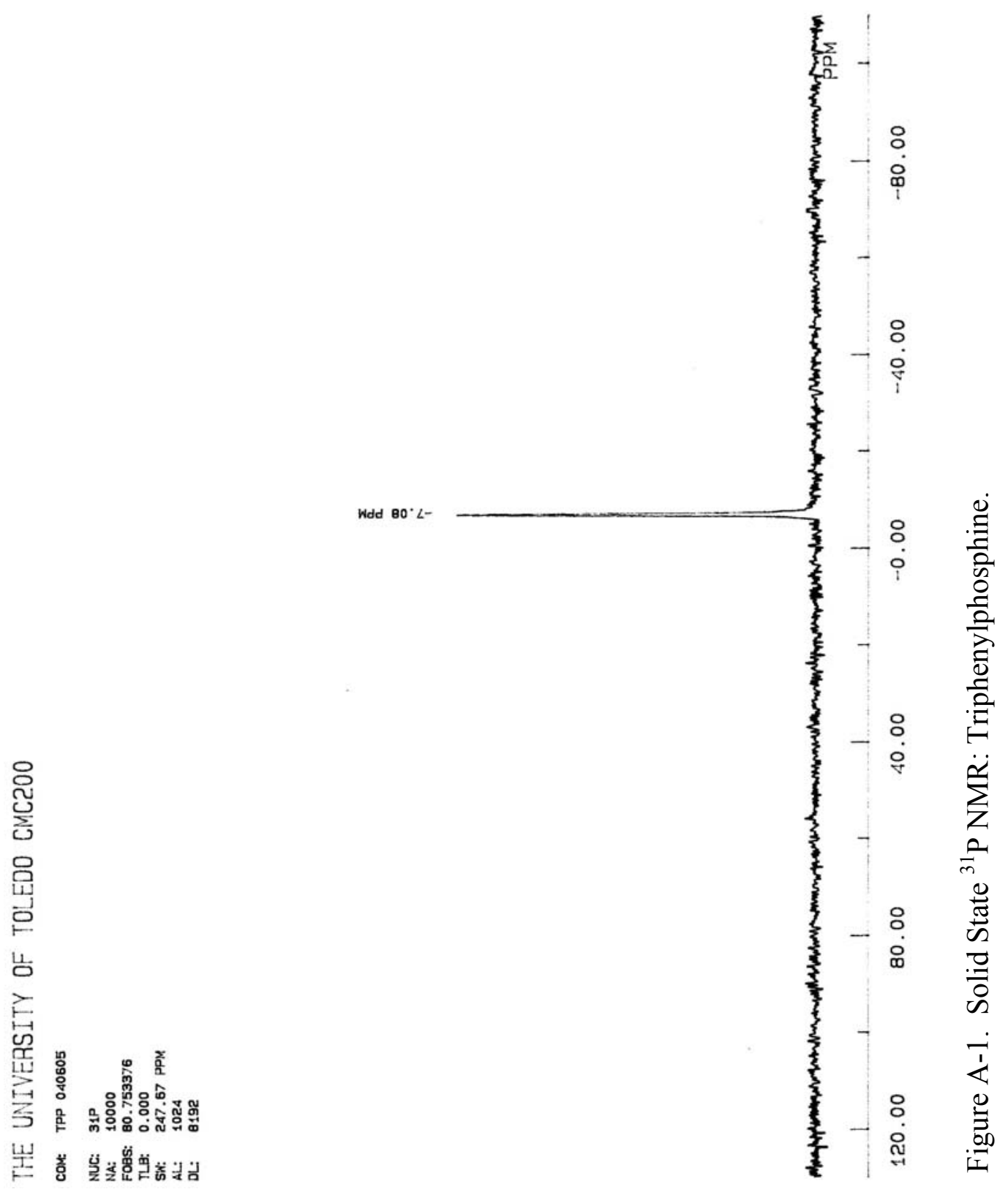


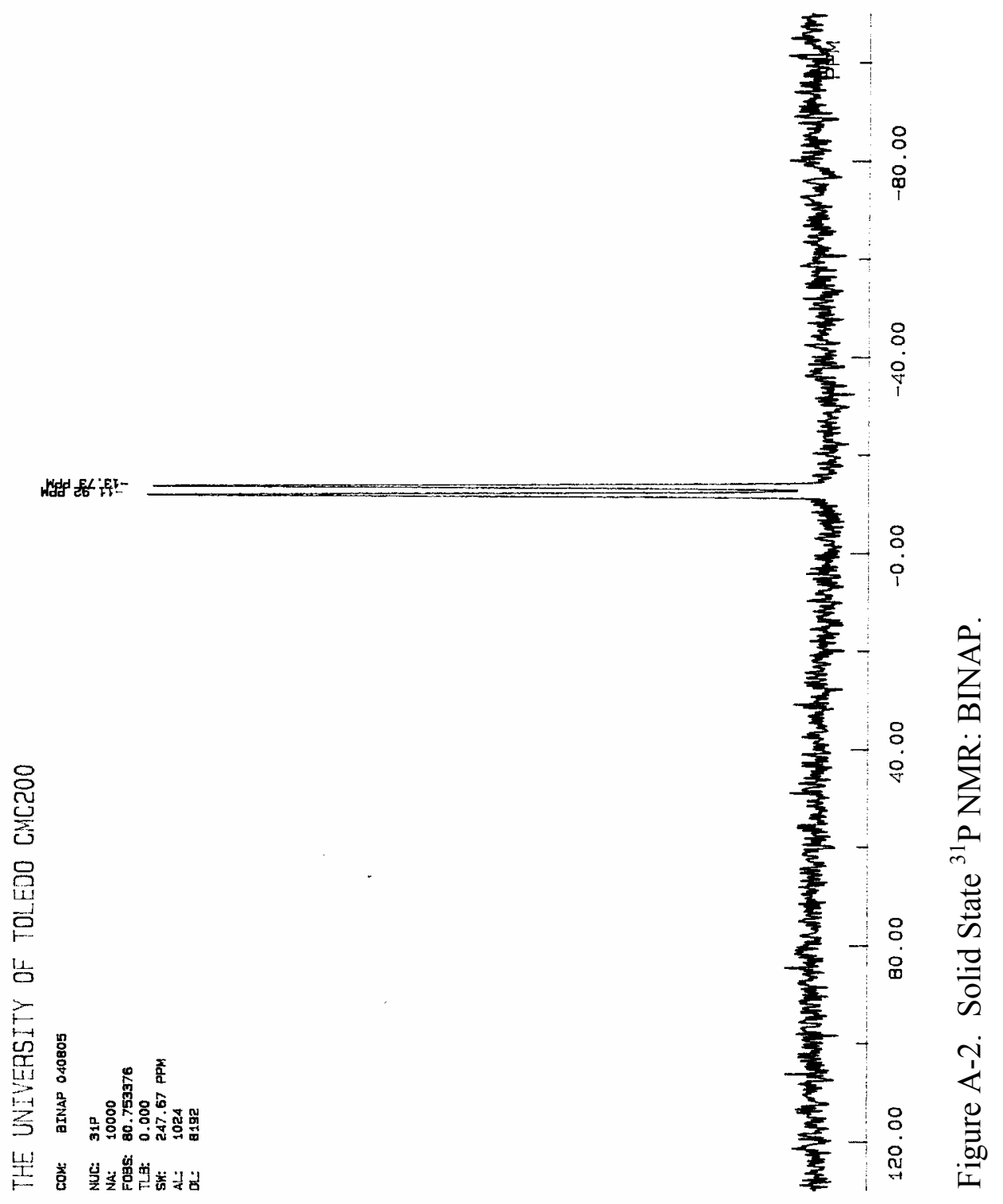




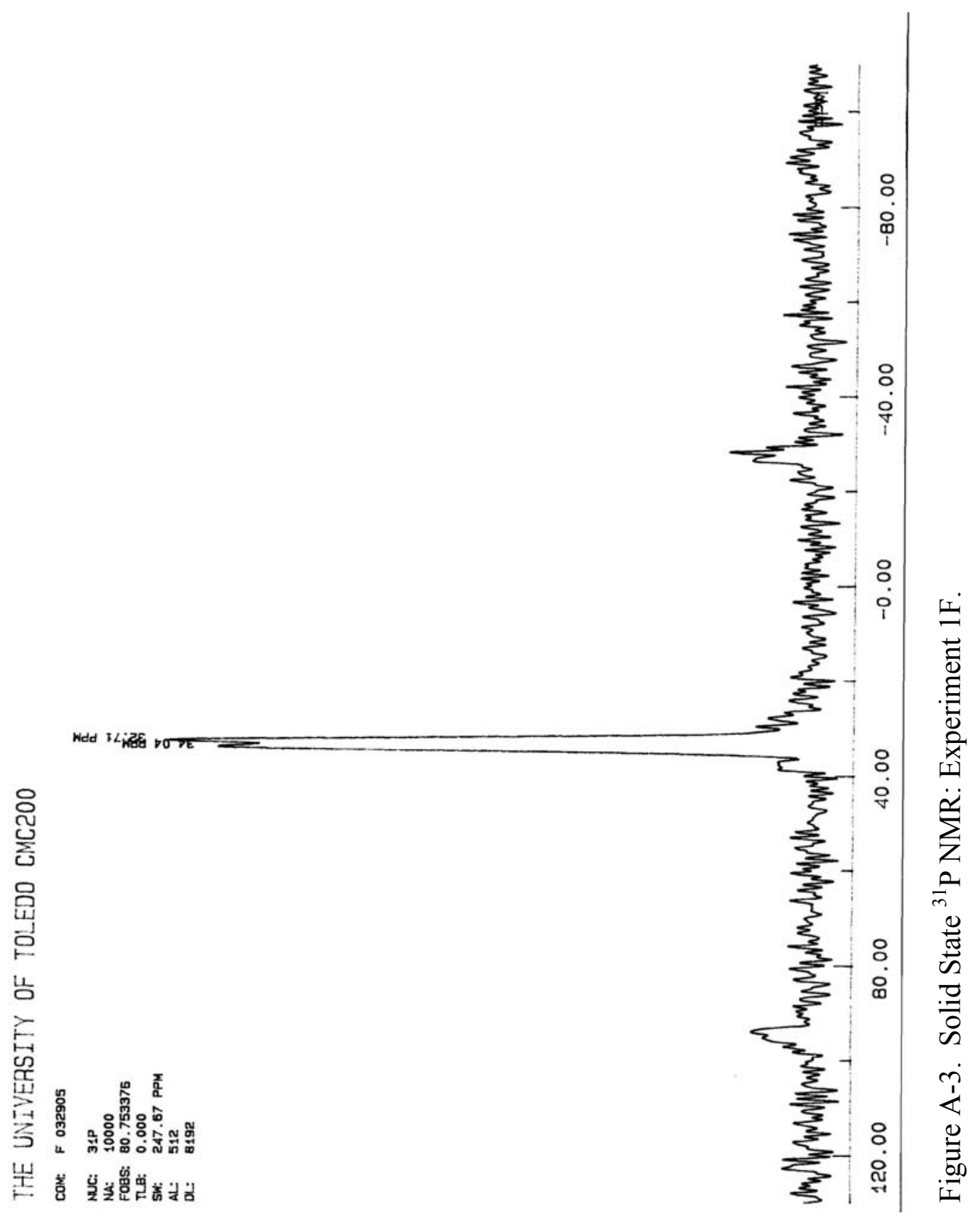




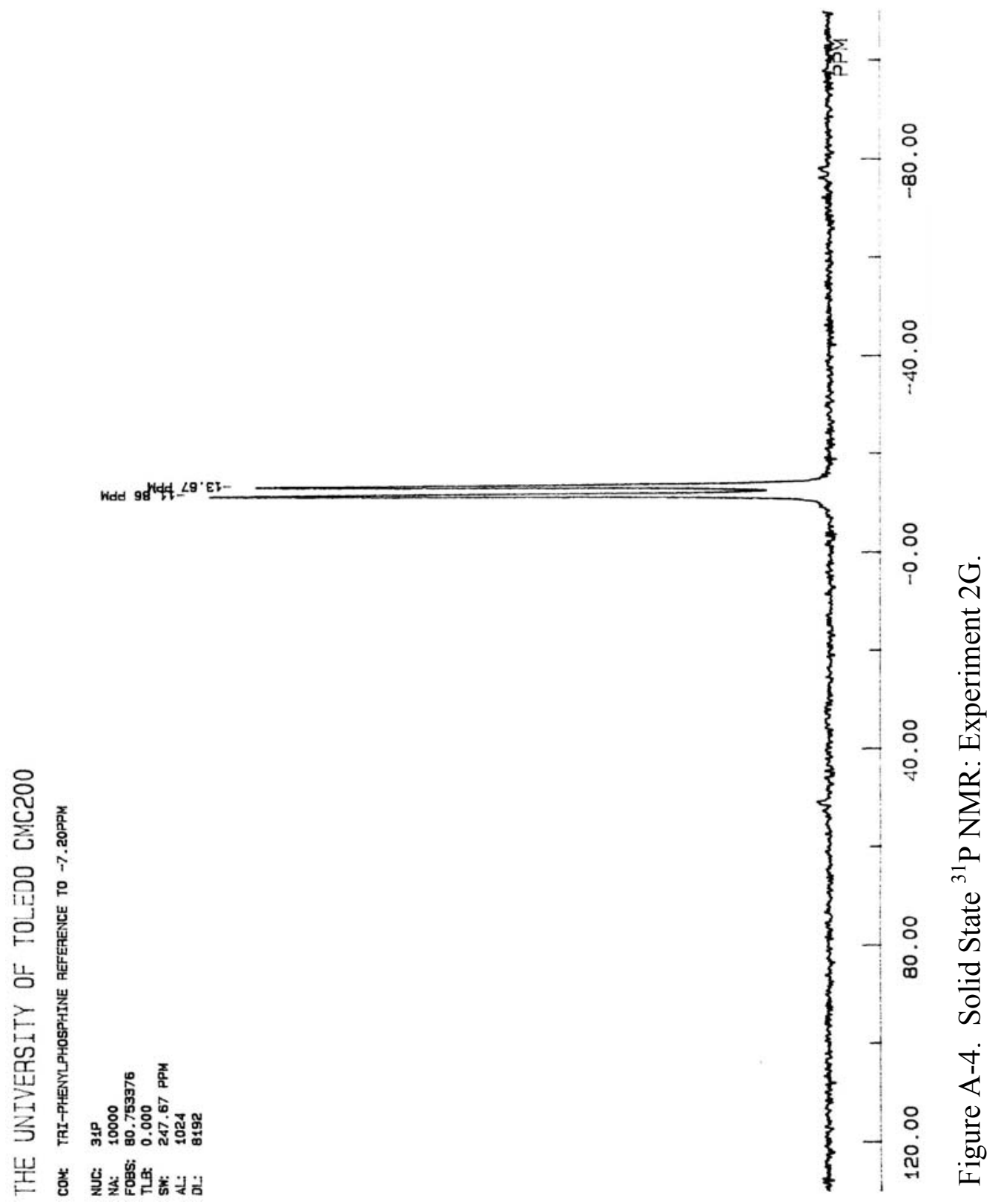




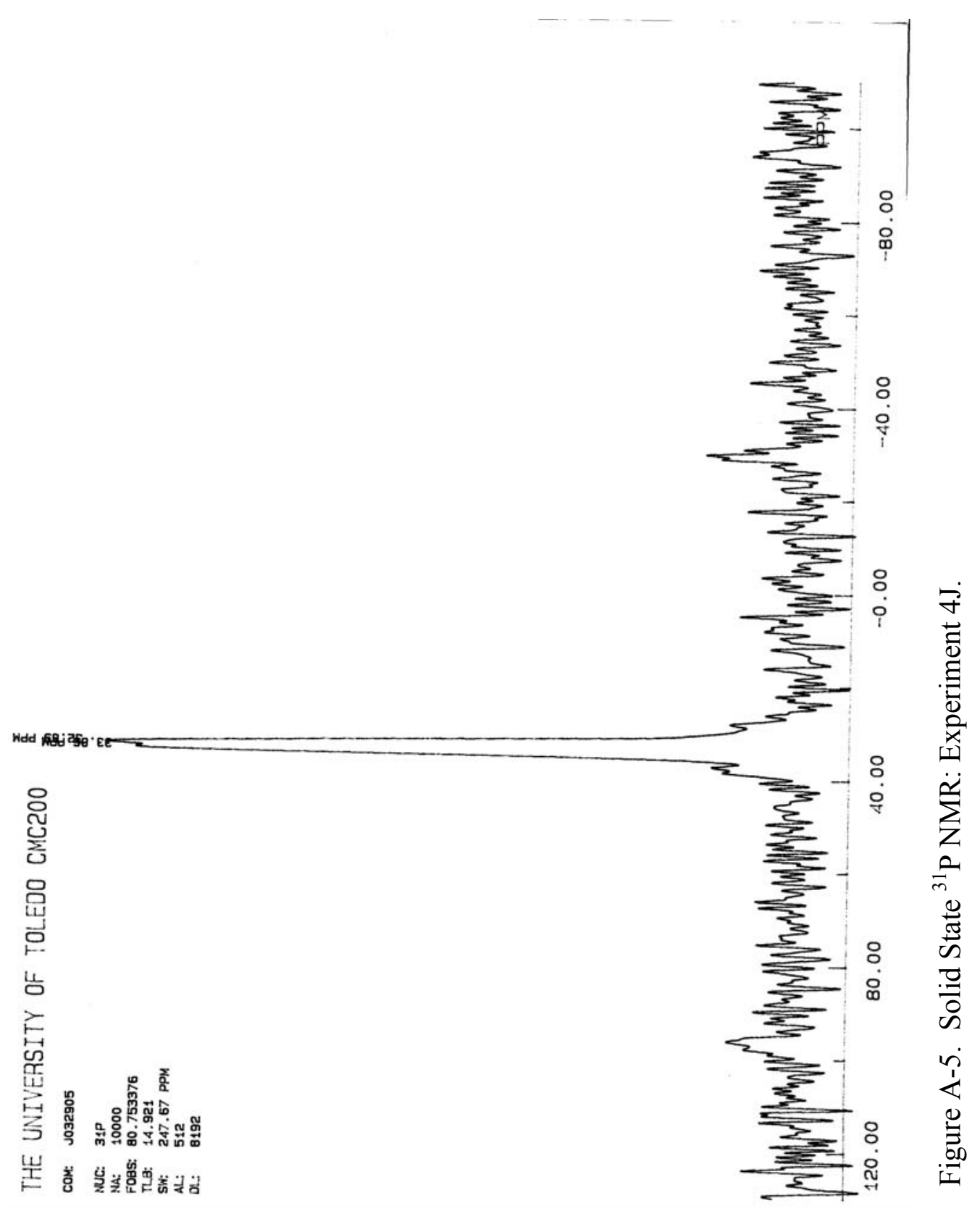



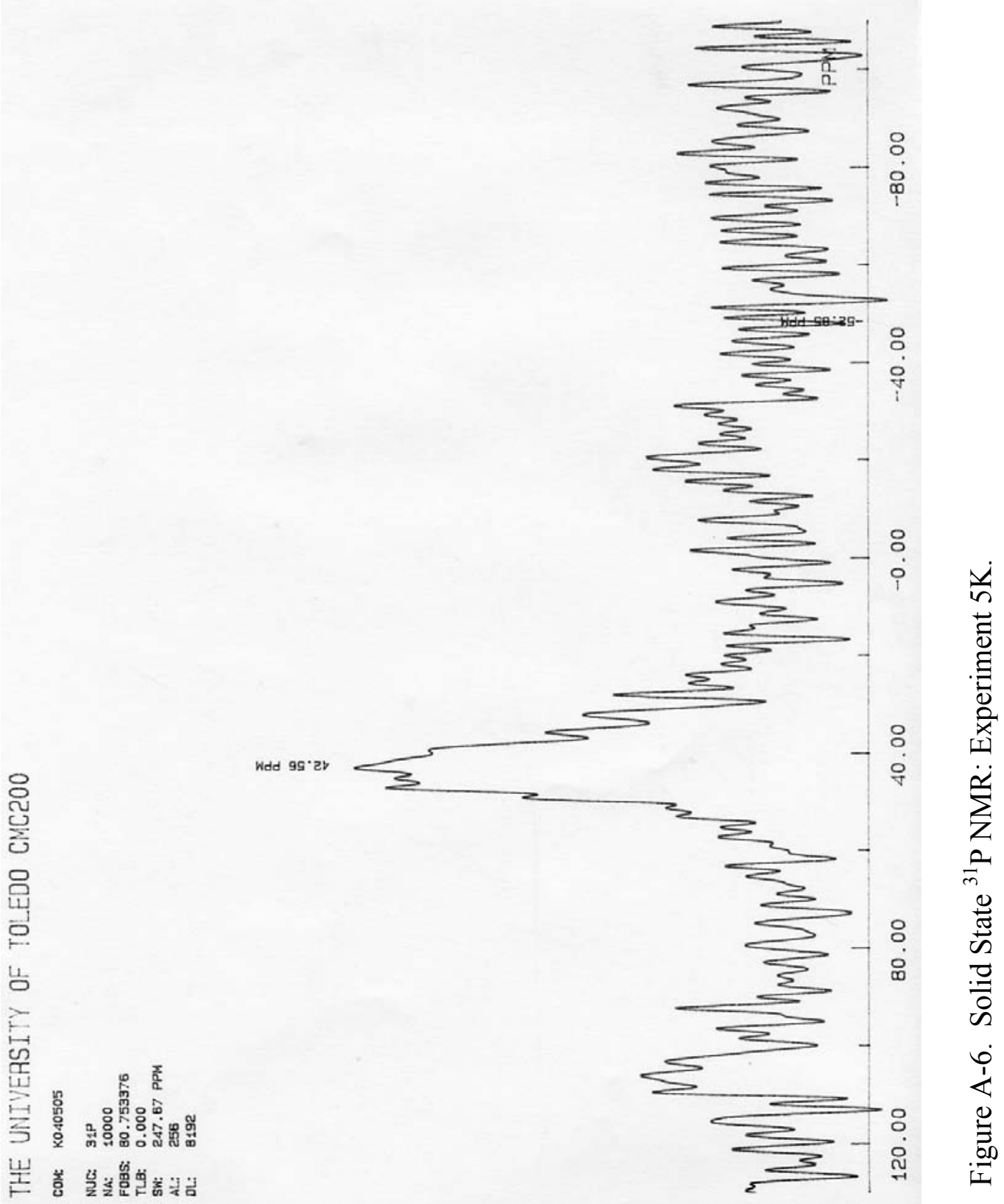

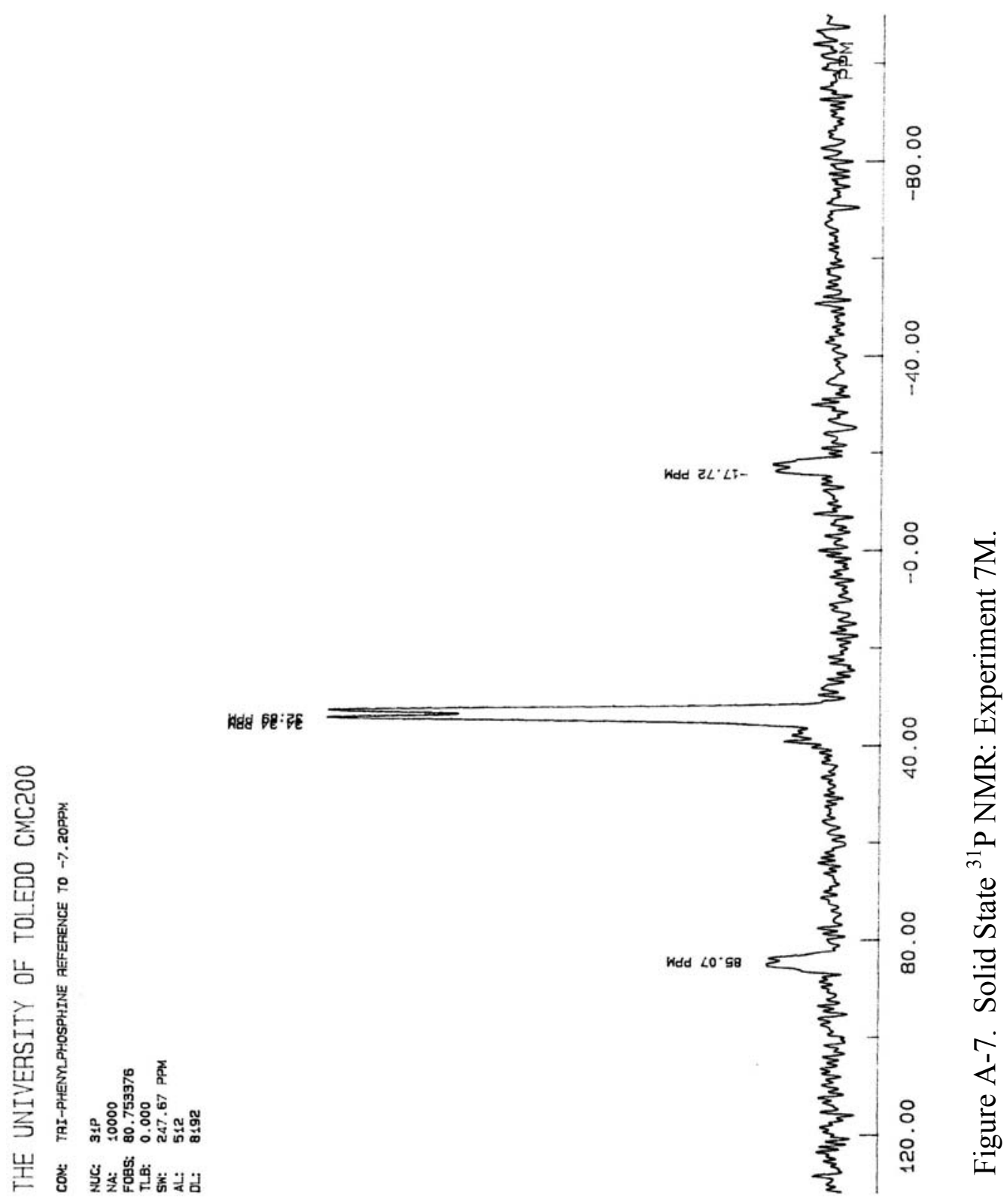

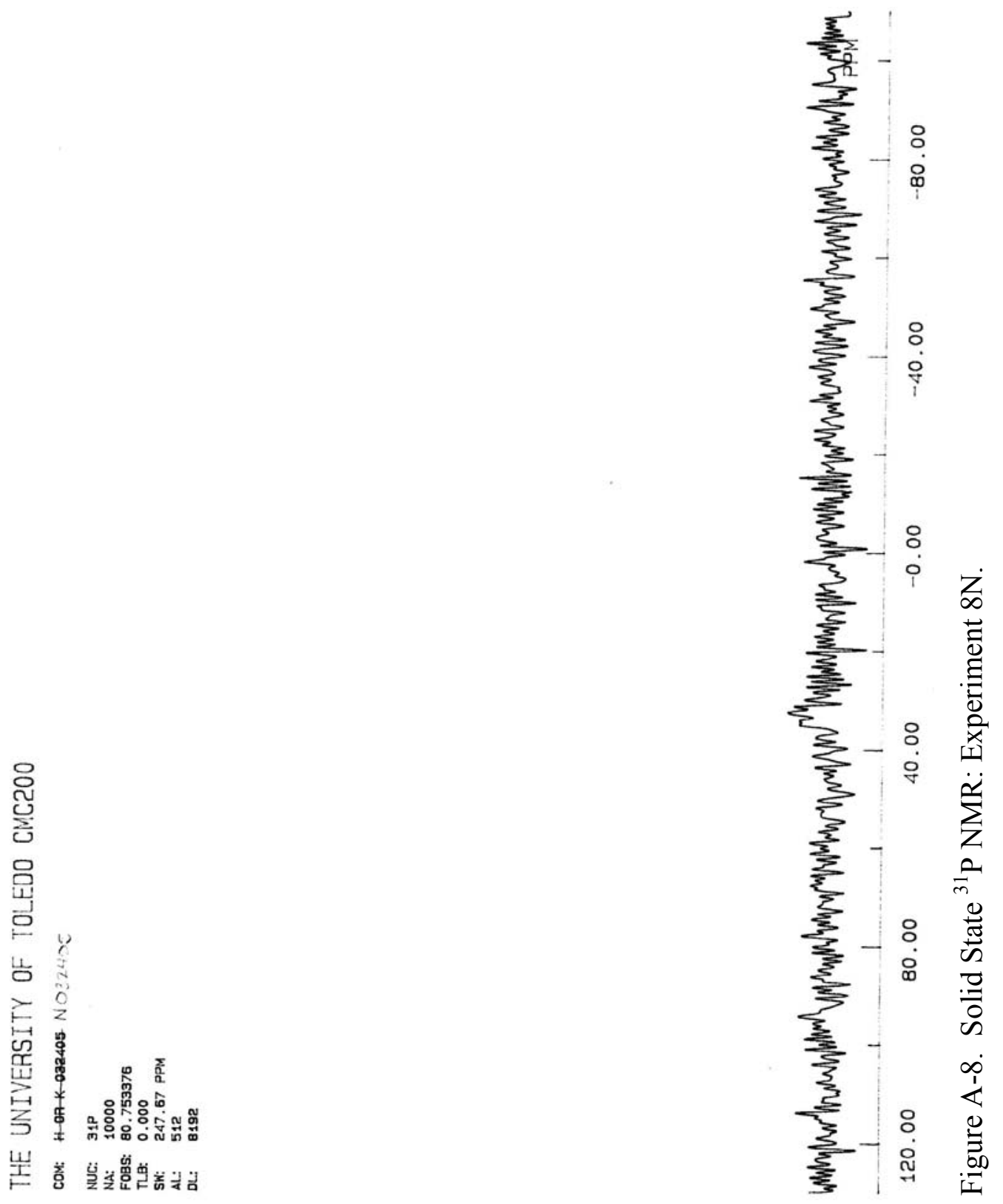


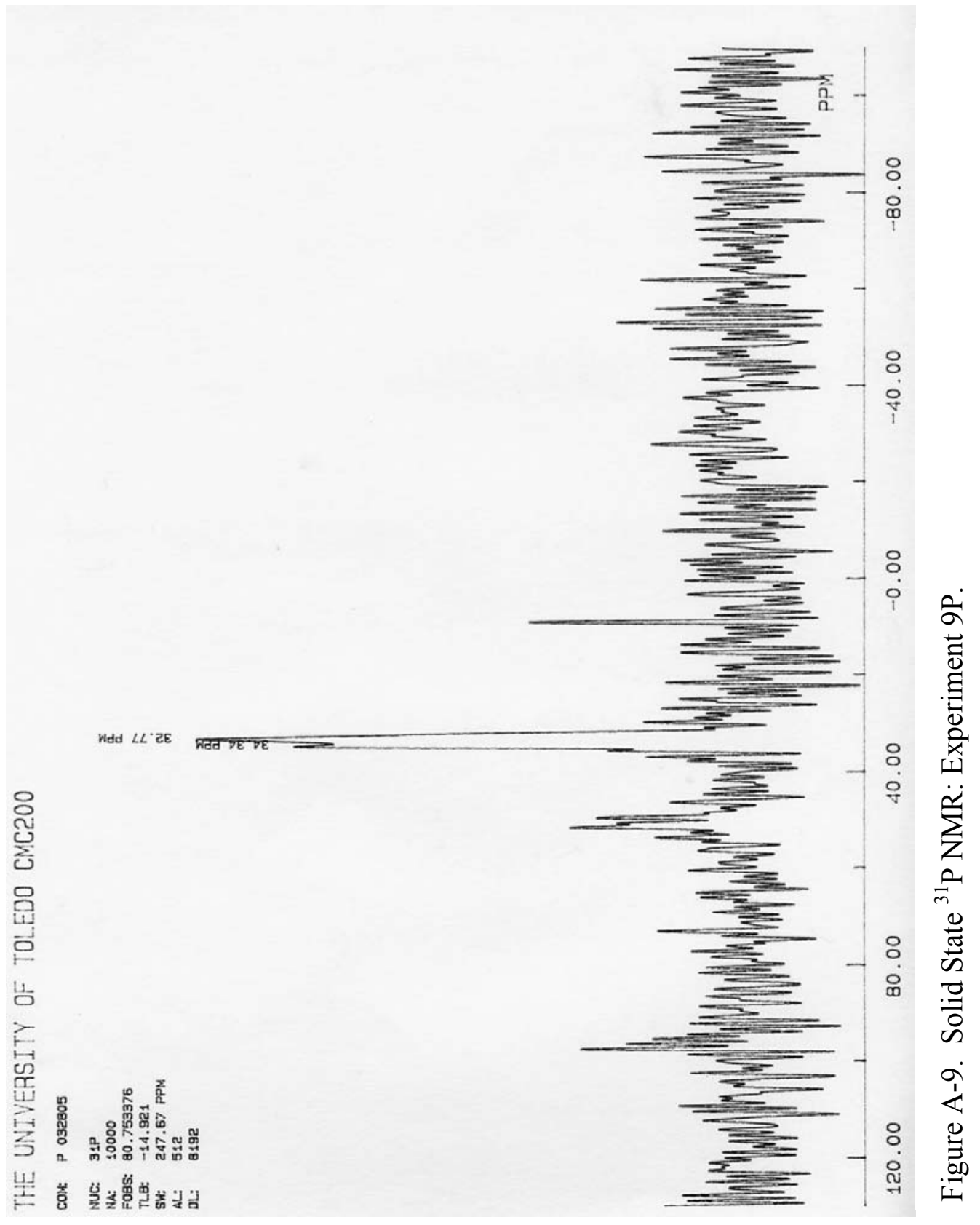




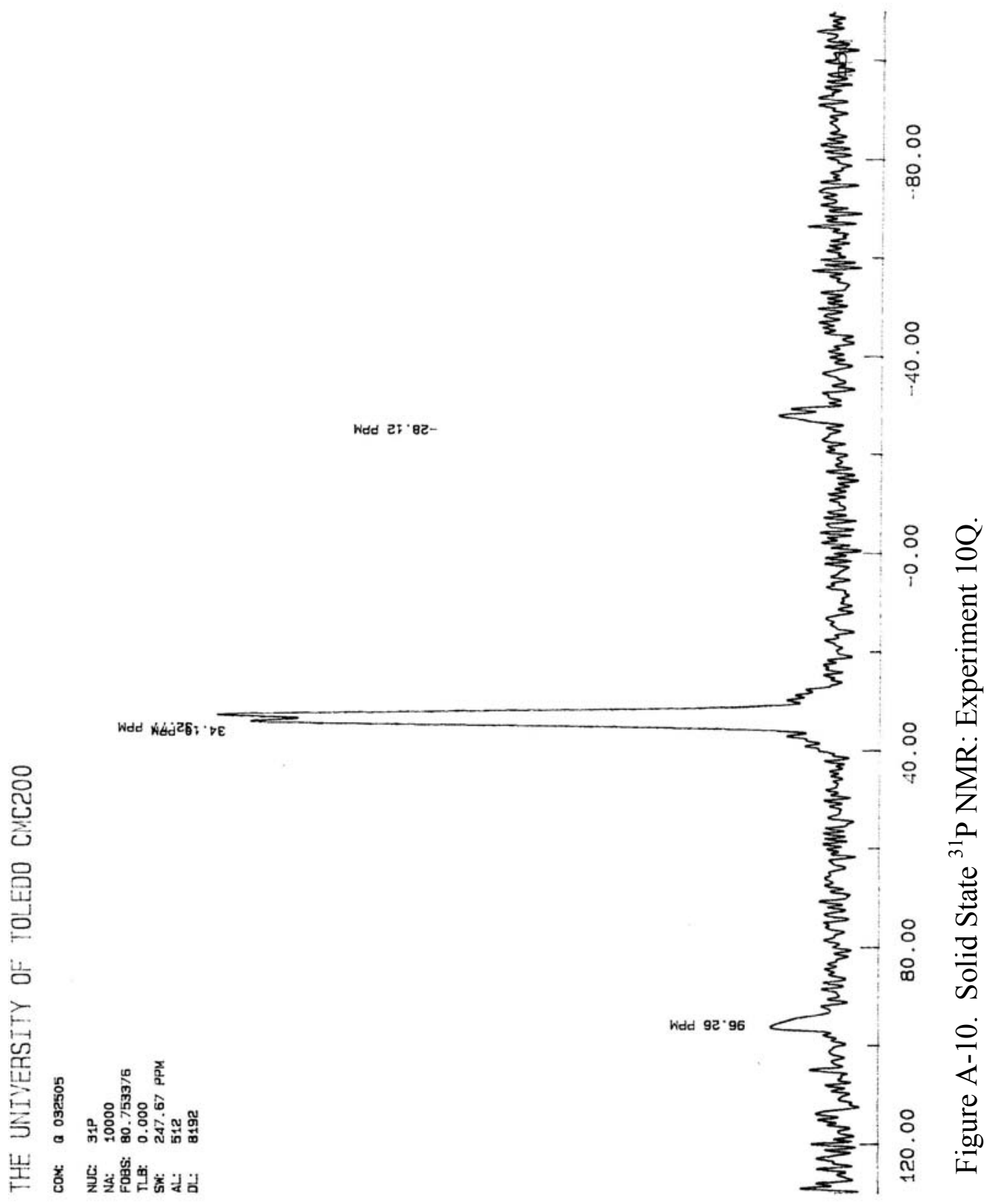



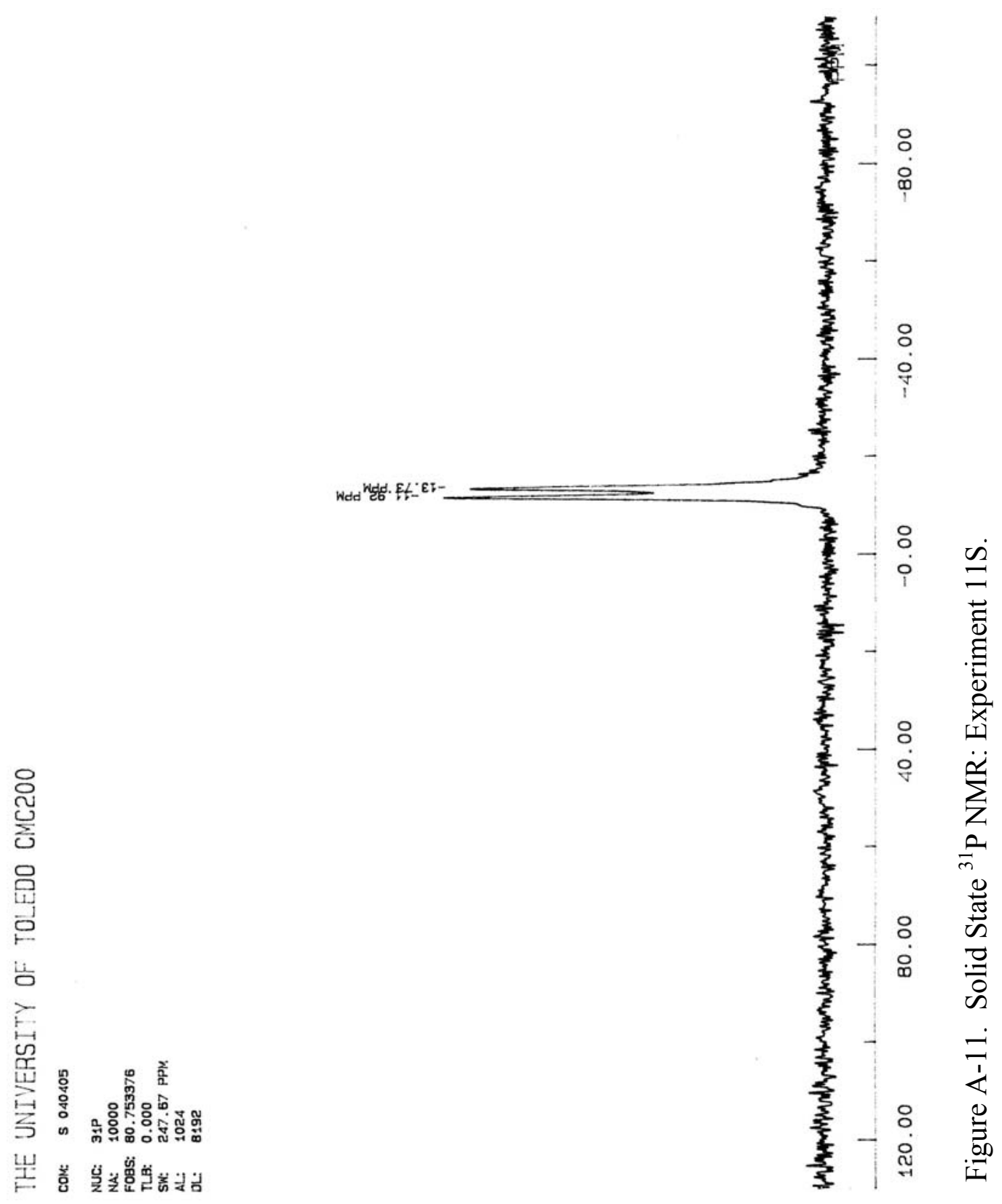


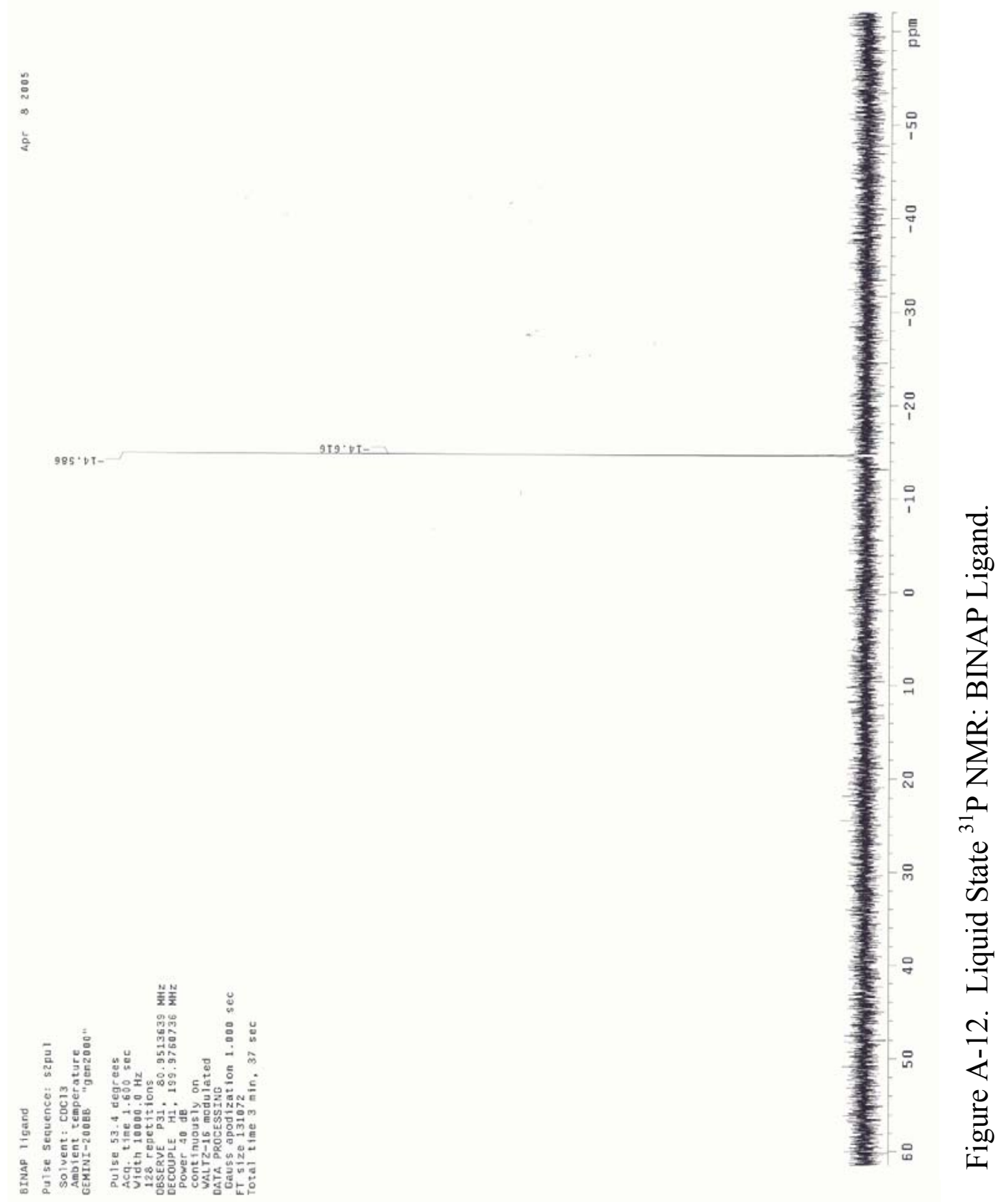



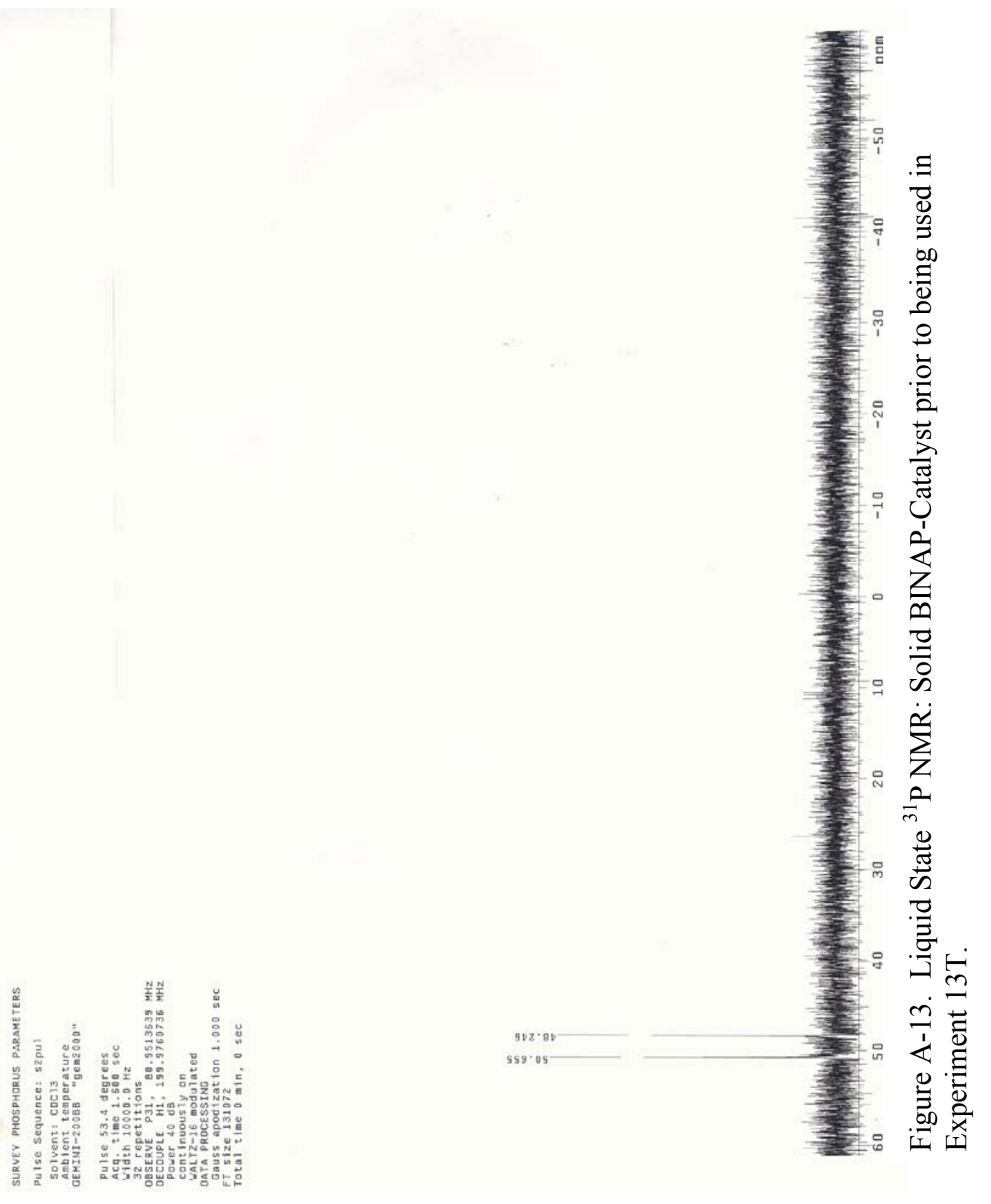


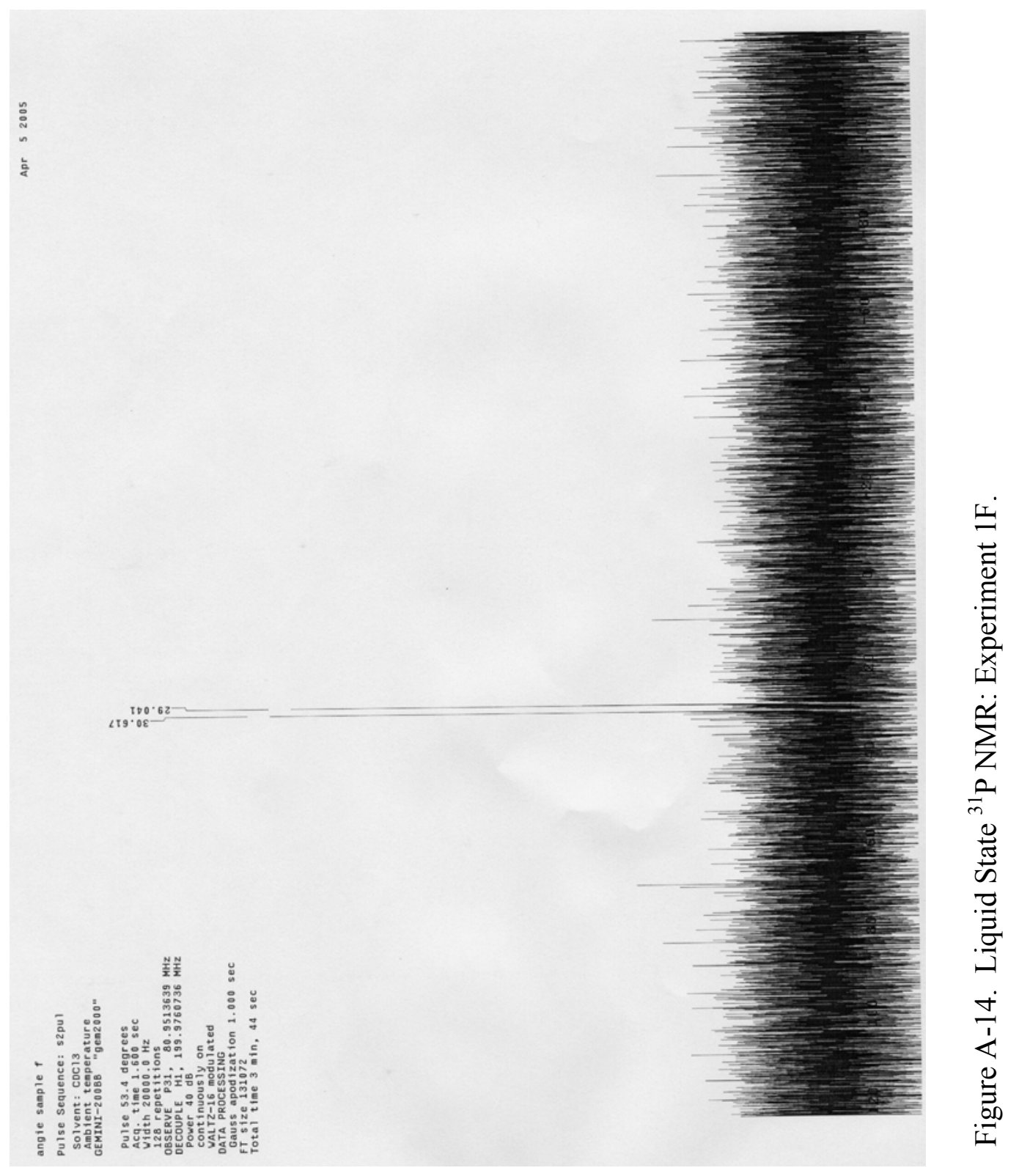




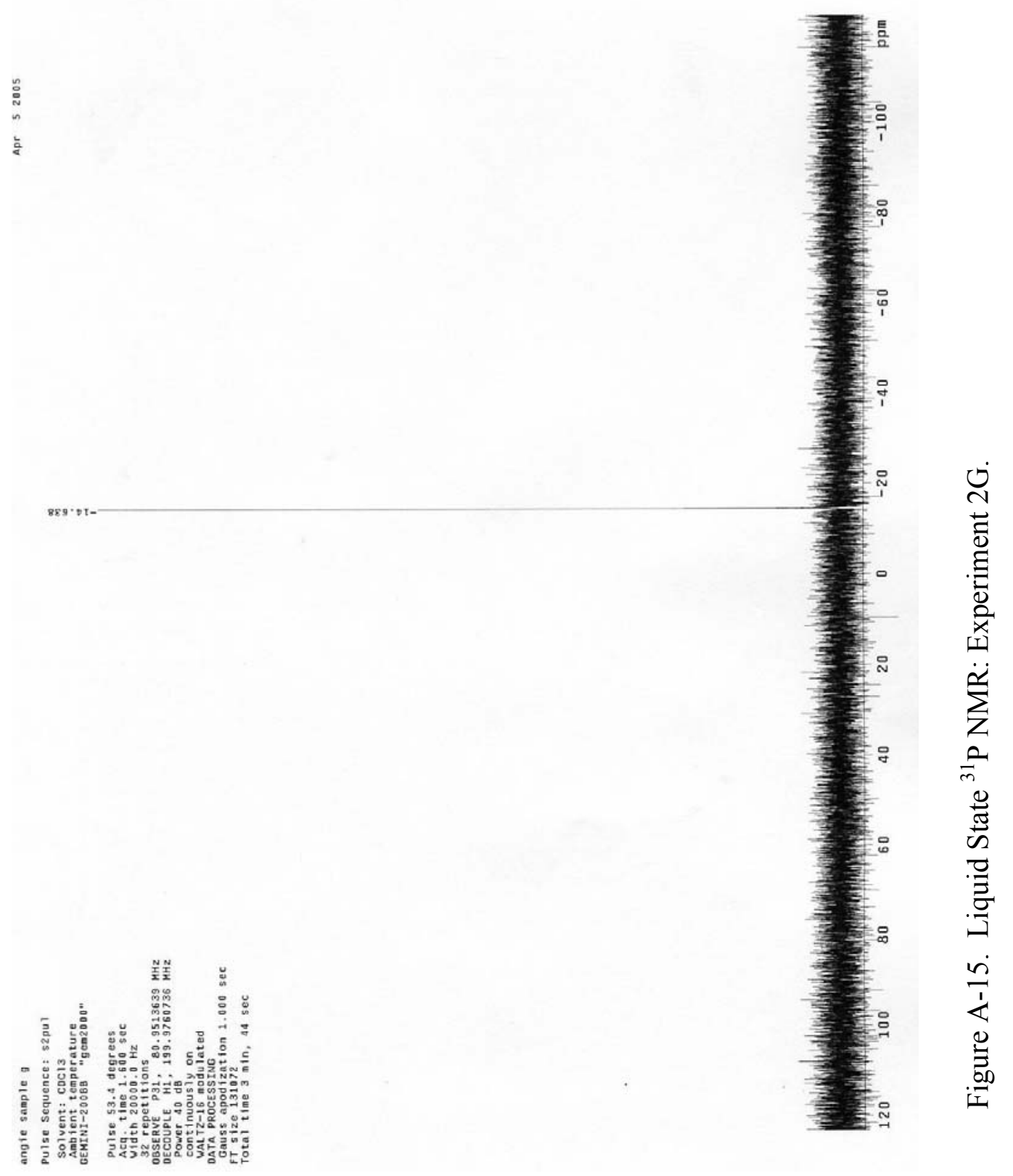




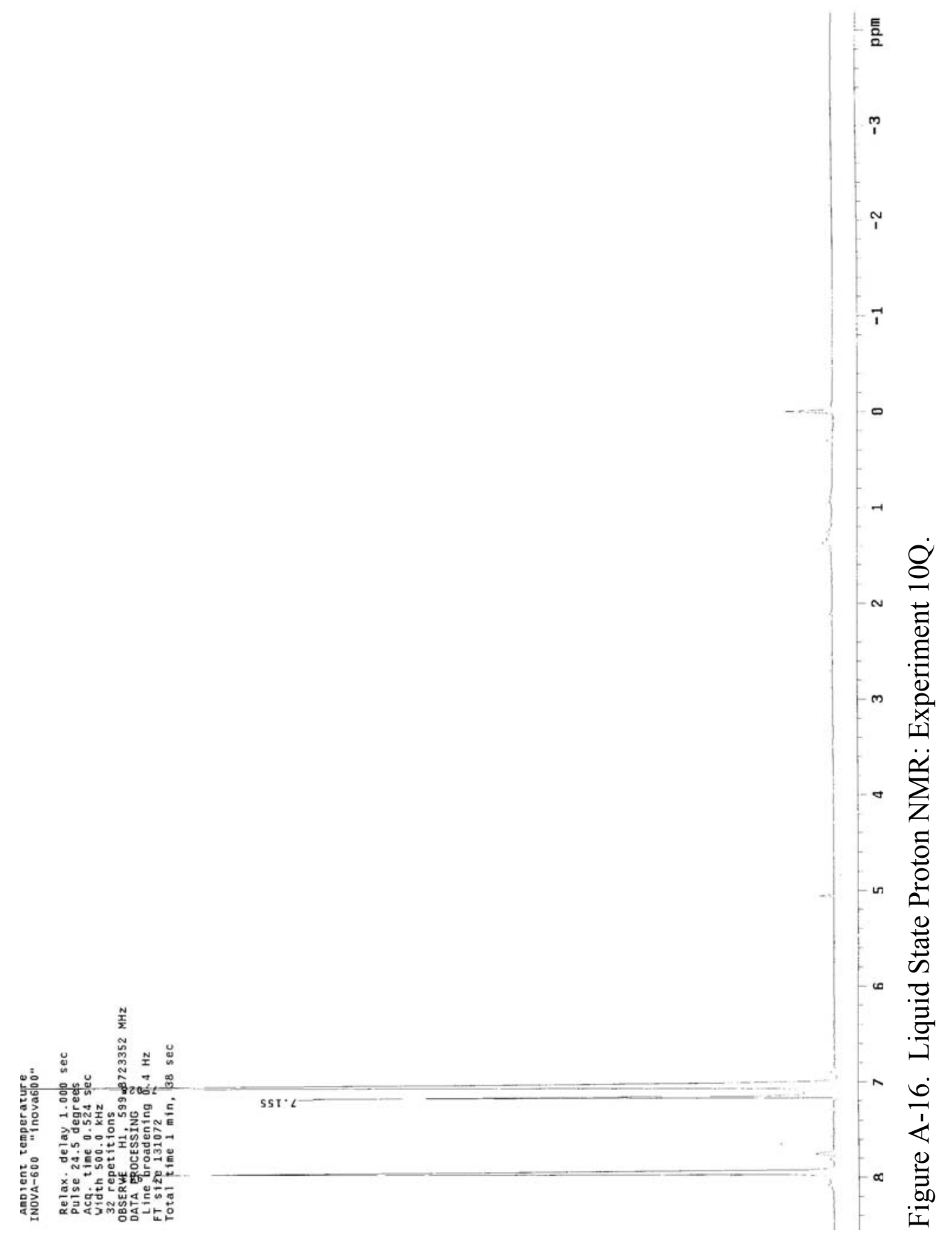




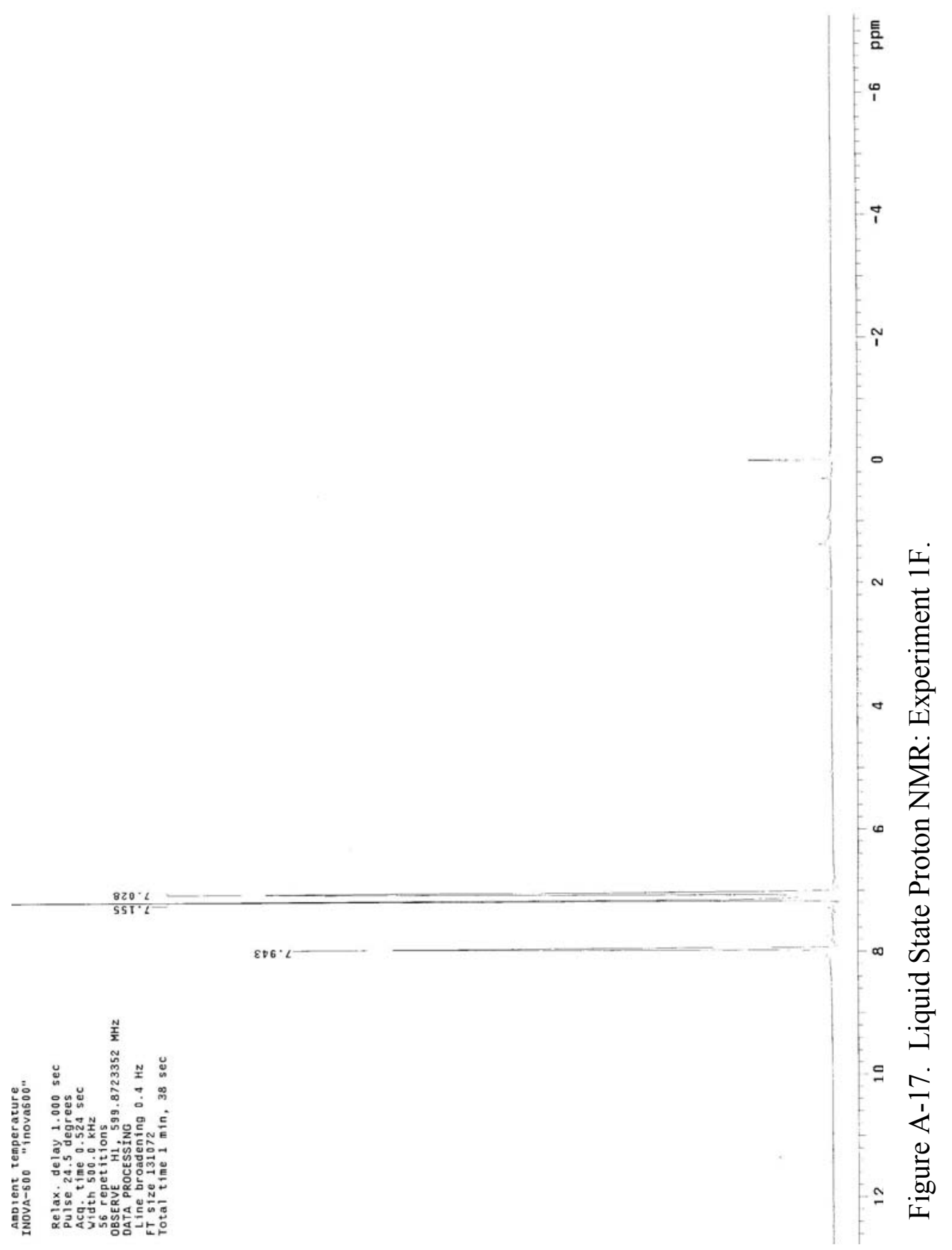




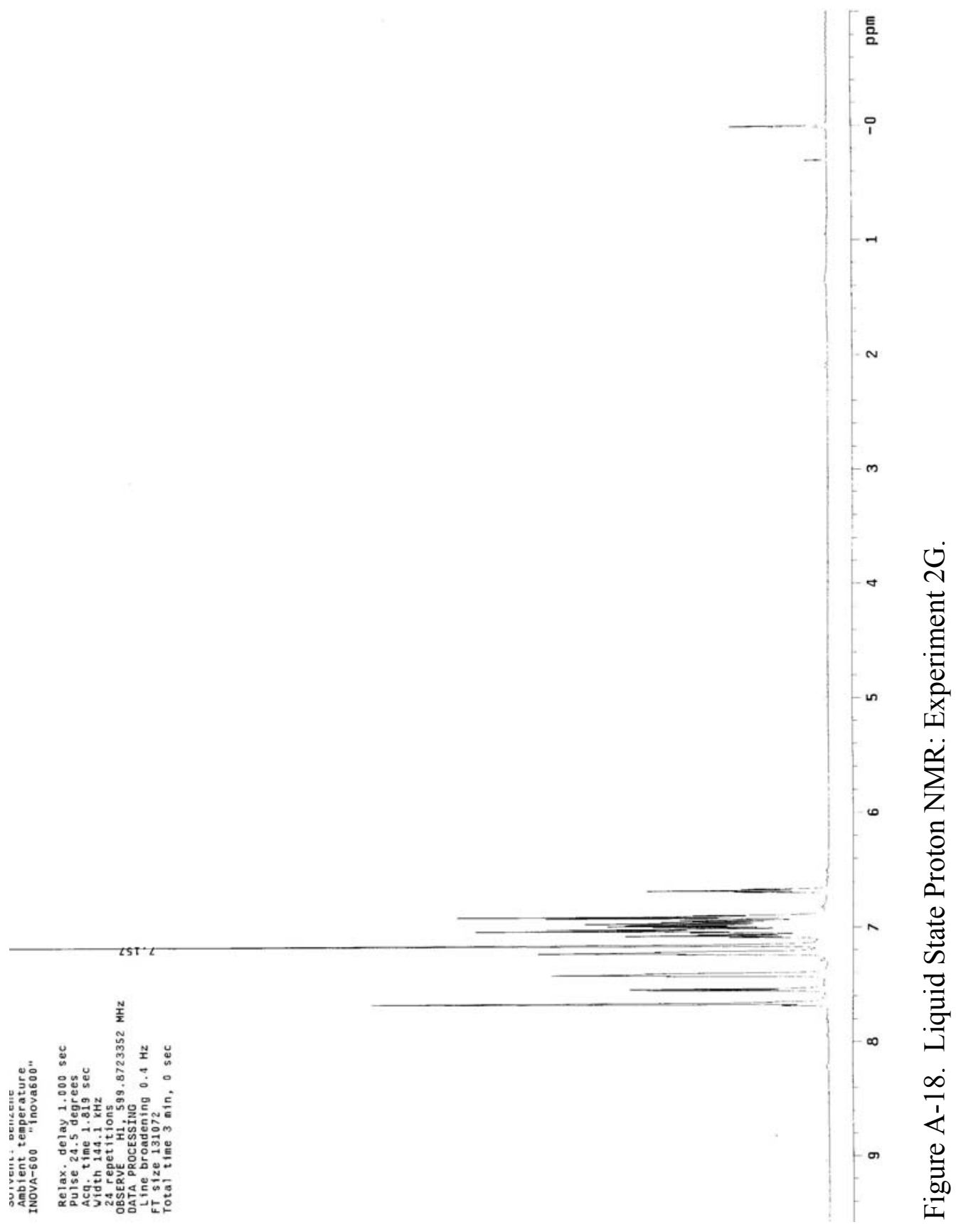




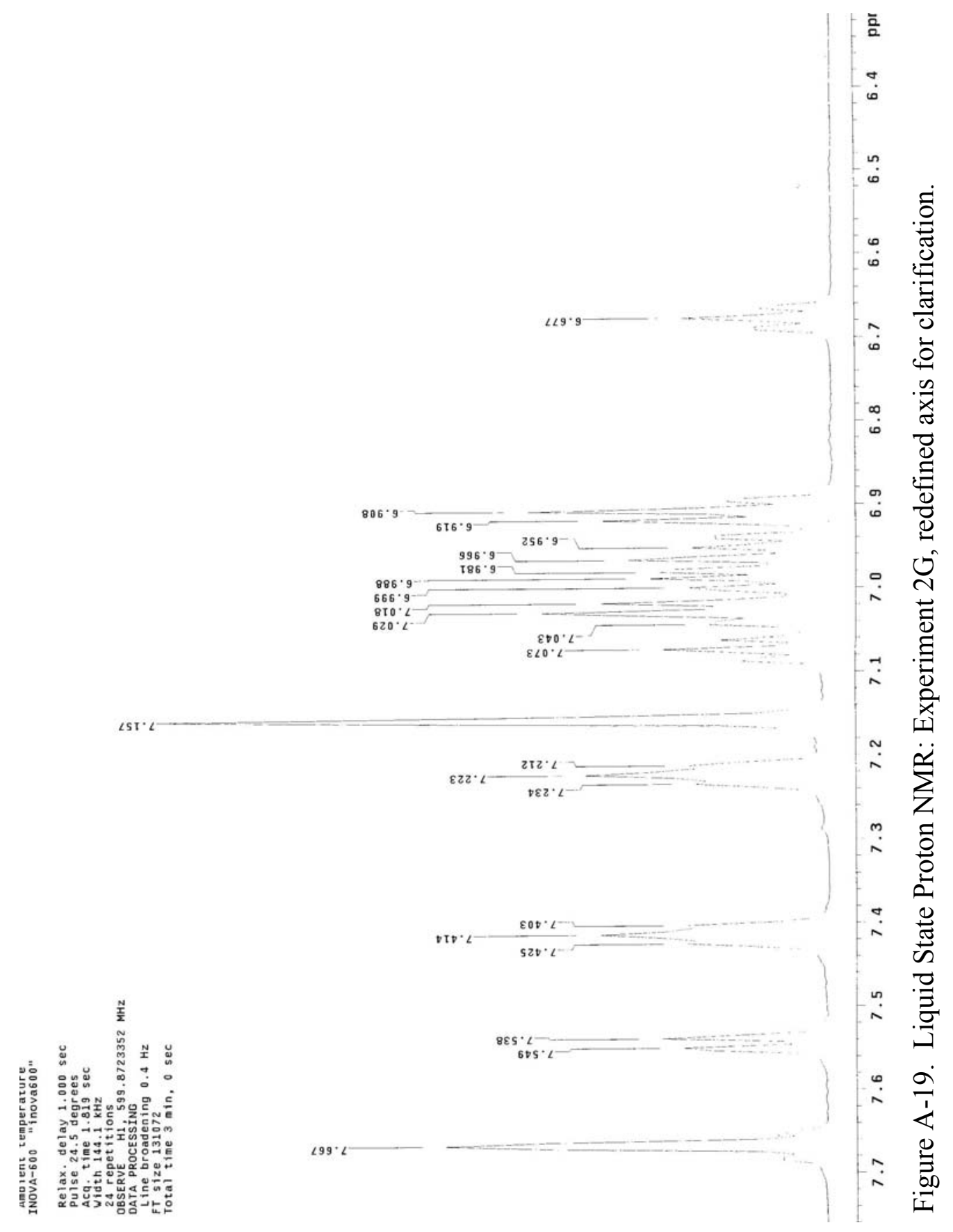




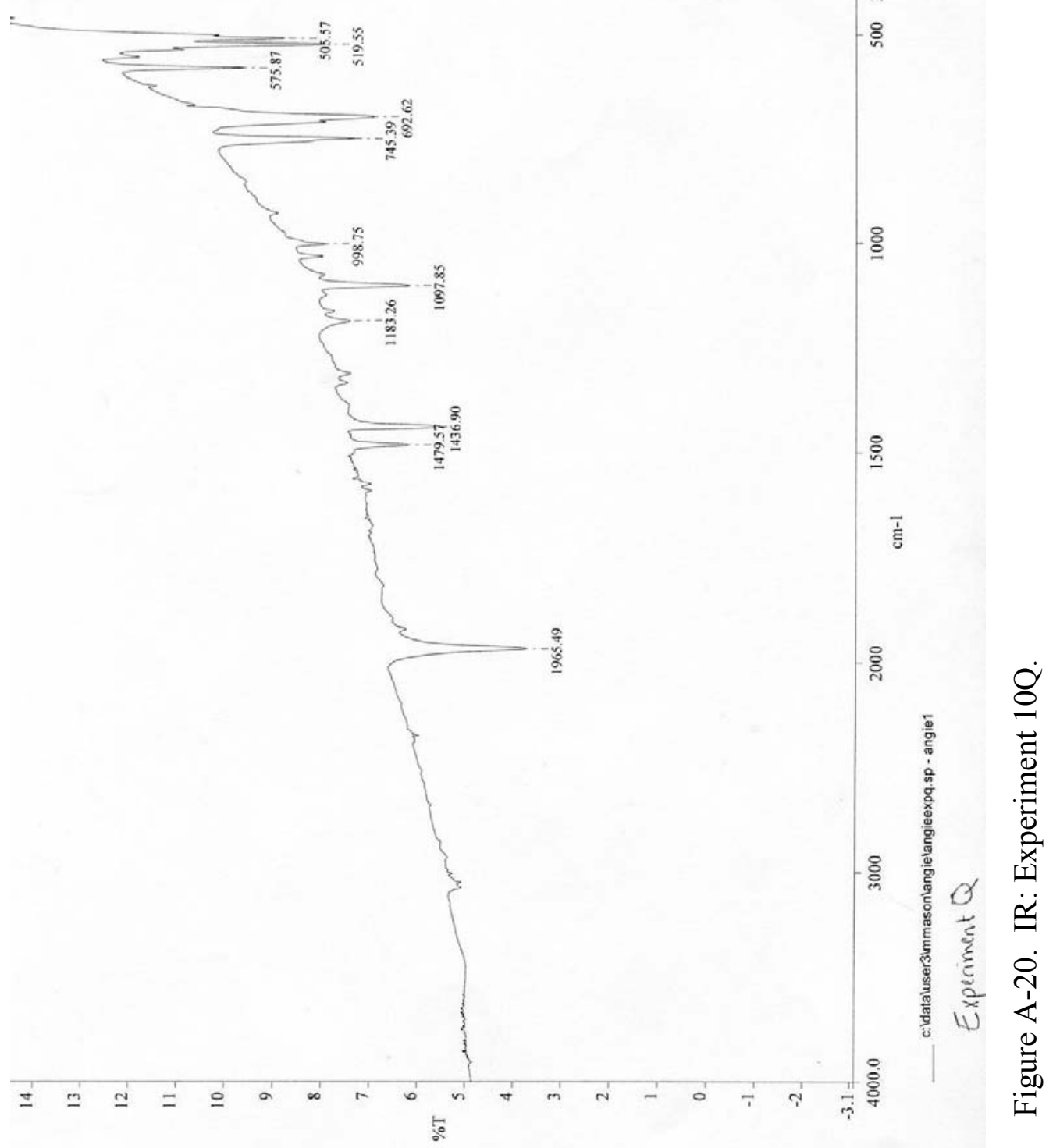




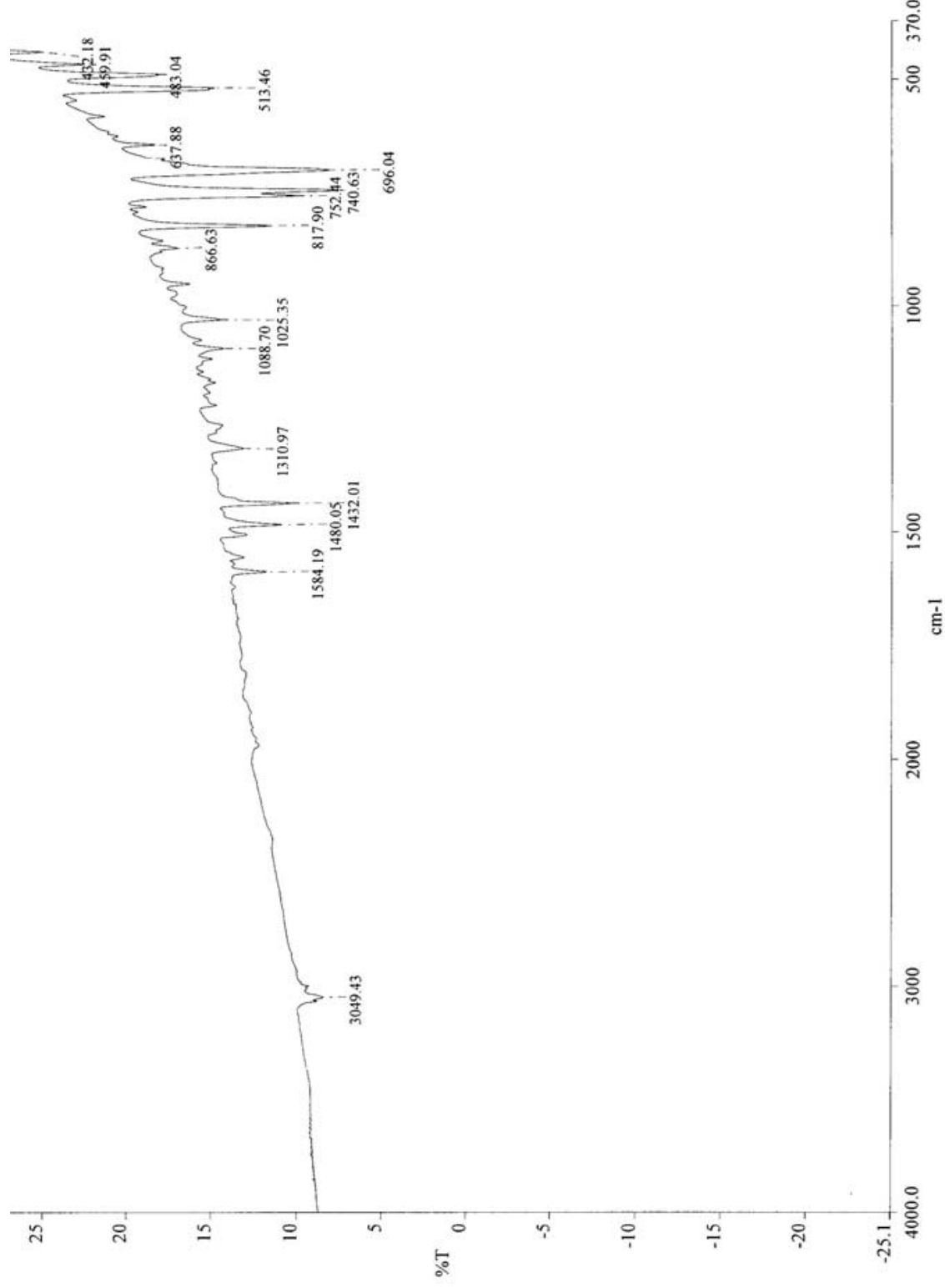

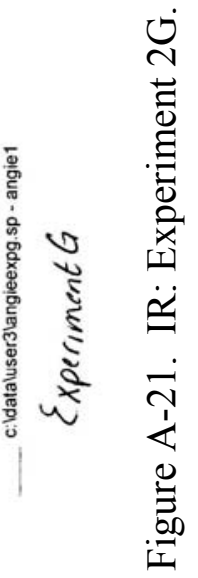




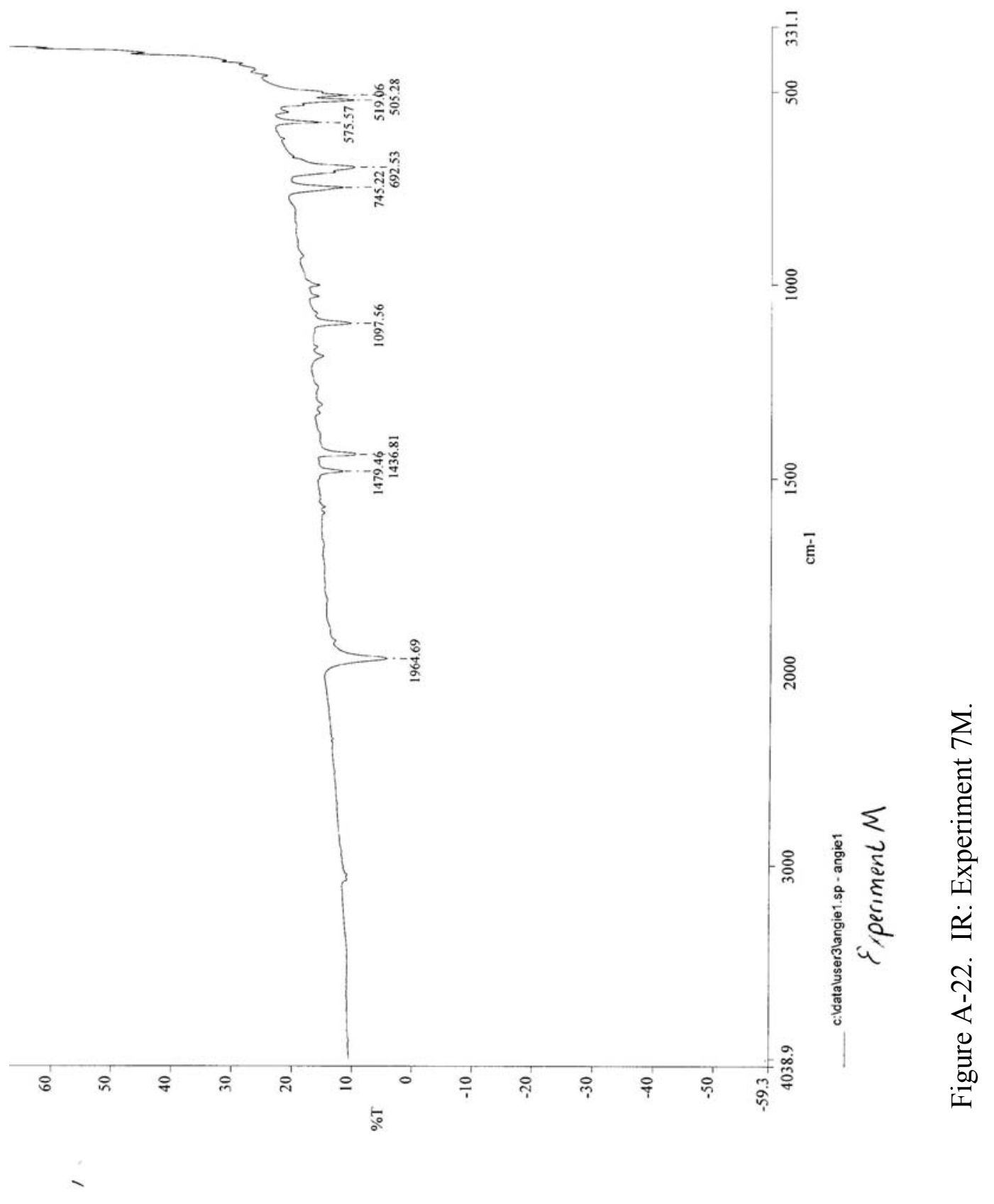


Appendix B

Data 
1F - [RhCl(C8H12)]2 \& TPP; Rh:P=1:8; Pre: $90^{\circ} \mathrm{C} \& 650$ psig; Rxn.: $90^{\circ} \mathrm{C} \& 2500$ psig

\begin{tabular}{|r|c|r|r|r|r|}
\hline \multicolumn{6}{|c|}{ Raw Data } \\
\hline time & Sample & Heptane & Styrene & 1 st Peak & 2cd Peak \\
\hline 0.25 & 1 & 12842796 & 40197623 & 1390048 & 1393908 \\
\hline 0.5 & 2 & 11767877 & 30311621 & 1252636 & 1214025 \\
\hline 0.75 & 3 & 14890612 & 42712811 & 1995703 & 2188330 \\
\hline 1 & 4 & 13559526 & 36234916 & 1845725 & 1878754 \\
\hline 1.25 & 5 & 10354202 & 28768106 & 1665677 & 1720337 \\
\hline 1.5 & 6 & 11609560 & 32656725 & 1924345 & 2105652 \\
\hline 2 & 7 & 13831594 & 31860925 & 2210485 & 2234551 \\
\hline 3 & 8 & 12717056 & 30514634 & 2865593 & 3019159 \\
\hline 4 & 9 & 11713407 & 24877731 & 2691819 & 2830049 \\
\hline 5 & 10 & 12882602 & 28526920 & 3753103 & 4077237 \\
\hline 6 & 11 & 12141565 & 24016218 & 3812598 & 4124148 \\
\hline 9 & 12 & 12014816 & 23907922 & 5504511 & 5690388 \\
\hline 15 & 13 & 12652555 & 18661099 & 8158559 & 8369497 \\
\hline 21 & 14 & 10858455 & 11072049 & 9336901 & 9782327 \\
\hline 27 & 15 & 14879975 & 9168435 & 15398717 & 16271526 \\
\hline
\end{tabular}

\begin{tabular}{|r|r|r|}
\hline \multicolumn{3}{|c|}{ Yield, Normalized } \\
\hline Styrene & \multicolumn{1}{|c|}{ st Peak } & 2cd Peak \\
\hline 0.944288 & 0.025295 & 0.030416 \\
\hline 0.935481 & 0.02986 & 0.034658 \\
\hline 0.918511 & 0.035915 & 0.045574 \\
\hline 0.915045 & 0.039248 & 0.045707 \\
\hline 0.901185 & 0.045922 & 0.052894 \\
\hline 0.896057 & 0.046789 & 0.057153 \\
\hline 0.884823 & 0.054173 & 0.061003 \\
\hline 0.841095 & 0.074575 & 0.08433 \\
\hline 0.82063 & 0.084364 & 0.095006 \\
\hline 0.783367 & 0.101075 & 0.115558 \\
\hline 0.748545 & 0.117927 & 0.133528 \\
\hline 0.672599 & 0.159013 & 0.168388 \\
\hline 0.514352 & 0.238261 & 0.247386 \\
\hline 0.345793 & 0.318607 & 0.3356 \\
\hline 0.201829 & 0.38771 & 0.410461 \\
\hline
\end{tabular}

Moles Styrene =

Moles Heptane $=$

Wt. of $[\mathrm{RhCl}(\mathrm{C} 8 \mathrm{H} 12)] 2(\mathrm{~g})$

Wt. of Ligand (g)
0.016863

0.0076914

0.0110

0.0937

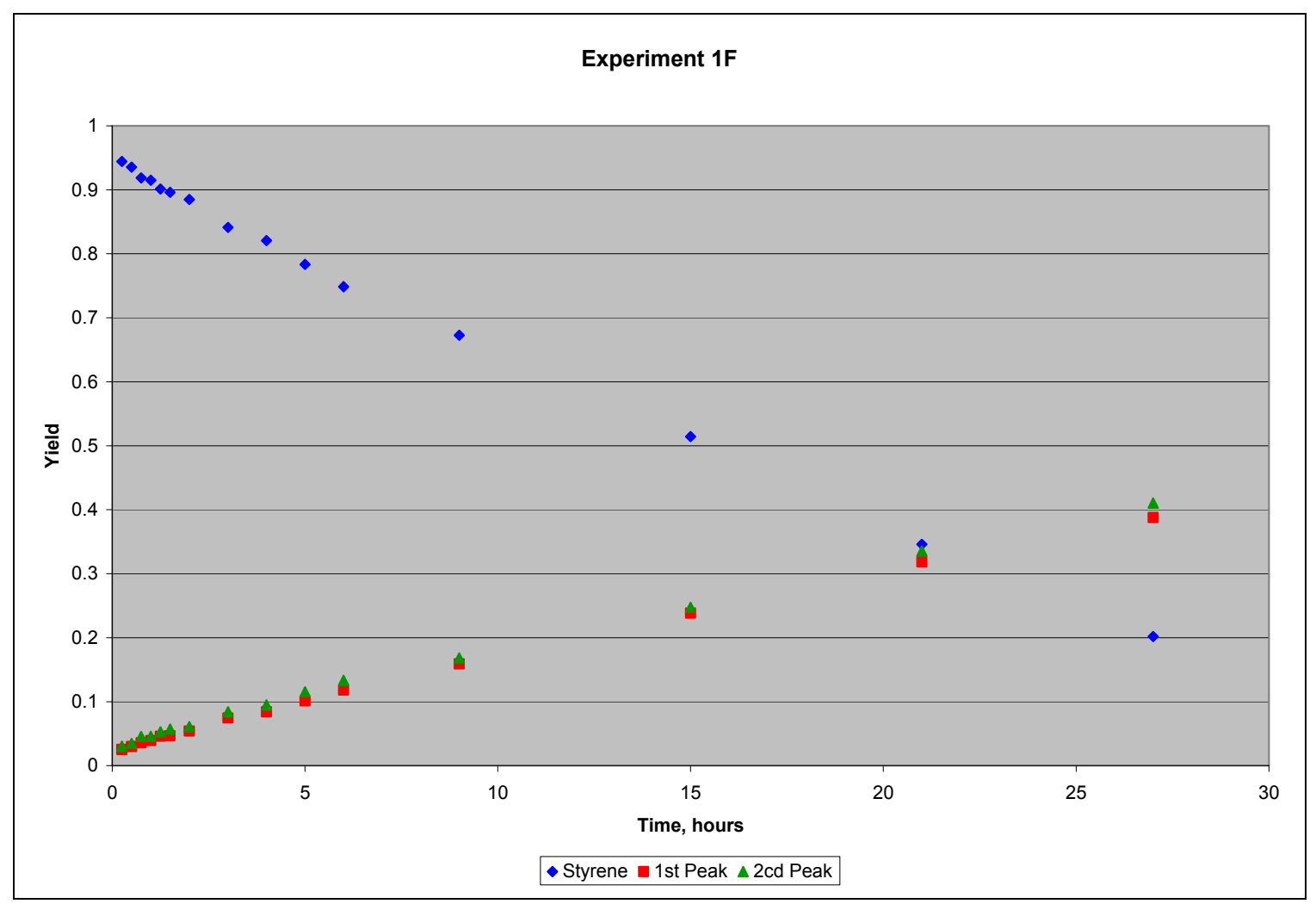


$2 \mathrm{G}-[\mathrm{RhCl}(\mathrm{C} 8 \mathrm{H} 12)] 2$ \& BINAP; $\mathrm{Rh}: \mathrm{P}=1: 4 ;$ Pre: $90^{\circ} \mathrm{C} \& 650$ psig; Rxn.: $90^{\circ} \mathrm{C} \& 2500$ psig

\begin{tabular}{|c|c|c|c|c|c|}
\hline \multicolumn{6}{|c|}{ Raw Data } \\
\hline time & Sample & Heptane & Styrene & 1st Peak & 2cd Peak \\
\hline 0.25 & 1 & 2265599 & 29515845 & 220543 & 270253 \\
\hline 0.5 & 2 & 4265374 & 50427782 & 1035897 & 1197748 \\
\hline 0.75 & 3 & 3554847 & 55795136 & 1836716 & 2239286 \\
\hline 1 & 4 & 3806546 & 45036363 & 1860759 & 2249955 \\
\hline 1.25 & 5 & 4624644 & 58577519 & 3105909 & 3776649 \\
\hline 1.5 & 6 & 4932428 & 59514113 & 3410478 & 4344630 \\
\hline 2 & 7 & 4769678 & 57007251 & 3950968 & 4868471 \\
\hline 3 & 8 & 3577141 & 36923370 & 3074094 & 3682136 \\
\hline$\overline{4}$ & 9 & 5060732 & 48743297 & 5343400 & 6576421 \\
\hline 5 & 10 & 4552256 & 40015204 & 5169203 & 5935782 \\
\hline 6 & 11 & 3186980 & 28630796 & 4041039 & 4931281 \\
\hline$\overline{9}$ & 12 & 5010594 & 37782831 & 8664154 & 10137205 \\
\hline 15 & 13 & 3727460 & 16575682 & 8020422 & 8751537 \\
\hline 21 & 14 & 3537381 & 9980066 & 10789068 & 11303232 \\
\hline 27 & 15 & 3048494 & 3232103 & 11471441 & 11848727 \\
\hline 33 & 16 & 2824092 & 839011 & 10224302 & 10428816 \\
\hline 39 & 17 & 2839377 & 281633 & 11168682 & 11494664 \\
\hline 45 & 18 & 3433185 & 97573 & 11830754 & 12169120 \\
\hline 51 & 19 & 2593666 & 0 & 10044404 & 10266640 \\
\hline
\end{tabular}

\begin{tabular}{|r|r|r|}
\hline \multicolumn{3}{|c|}{ Yield, Normalized } \\
\hline Styrene & 1st Peak & 2cd Peak \\
\hline 0.986238877 & 0.005372616 & 0.008388507 \\
\hline 0.95867873 & 0.01845405 & 0.02286722 \\
\hline 0.930477186 & 0.030921102 & 0.038601712 \\
\hline 0.914723443 & 0.038056941 & 0.047219616 \\
\hline 0.891713732 & 0.04848294 & 0.059803328 \\
\hline 0.881123865 & 0.051861517 & 0.067014618 \\
\hline 0.861377625 & 0.061801093 & 0.076821283 \\
\hline 0.83990704 & 0.072547081 & 0.087545879 \\
\hline 0.796129723 & 0.091218214 & 0.112652062 \\
\hline 0.774561862 & 0.104864331 & 0.120573807 \\
\hline 0.752227718 & 0.111585505 & 0.136186777 \\
\hline 0.655336385 & 0.159202852 & 0.185460763 \\
\hline 0.481322294 & 0.248935488 & 0.269742218 \\
\hline 0.295641001 & 0.345680953 & 0.358678046 \\
\hline 0.110483517 & 0.439962423 & 0.44955406 \\
\hline 0.030183454 & 0.482691191 & 0.487125354 \\
\hline 0.00500591 & 0.493078613 & 0.501915477 \\
\hline 0 & 0.495546668 & 0.504453332 \\
\hline 0 & 0.497269633 & 0.502730367 \\
\hline
\end{tabular}

Moles Styrene $=$

Moles Heptane $=$

Wt. of $[\mathrm{RhCl}(\mathrm{C} 8 \mathrm{H} 12)] 2(\mathrm{~g})$

Wt. of Ligand (g)
0.025235427

0.002357205

0.0114

0.1138

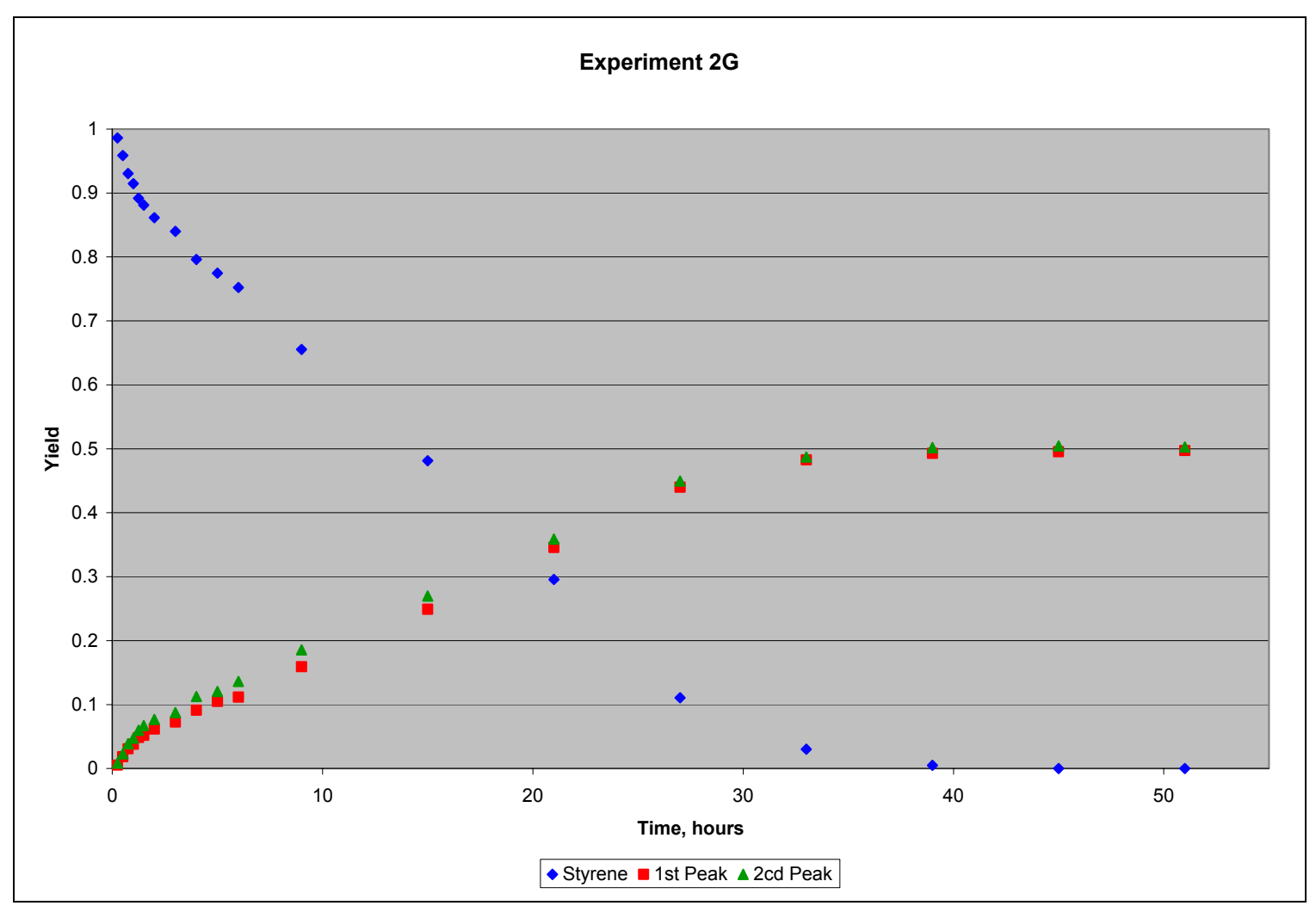


$3 \mathrm{H}$ - [RhCl(C8H12)]2 \& no ligand; Pre: $90^{\circ} \mathrm{C} \& 650$ psig; Rxn.: 90 $\mathrm{C}$ \& 2500 psig

\begin{tabular}{|c|c|c|c|c|c|}
\hline \multicolumn{6}{|c|}{ Raw Data } \\
\hline time & Sample & Heptane & Styrene & 1st Peak & 2cd Peak \\
\hline 0.25 & 1 & 7804057 & 61907168 & 1795783 & 1787800 \\
\hline 0.5 & 2 & 6885560 & 53770727 & 1076931 & 1159737 \\
\hline 0.75 & 3 & 6274314 & 45793222 & 1612632 & 1660294 \\
\hline$\overline{1}$ & 4 & 6385493 & 43466595 & 2460211 & 2543908 \\
\hline 1.25 & 5 & 5123277 & 32087292 & 2467614 & 2544769 \\
\hline 1.5 & 6 & 6229510 & 34330729 & 3952434 & 3972016 \\
\hline 2 & 7 & 7884077 & 37931922 & 7724675 & 8105179 \\
\hline 3 & 8 & 4179574 & 20134180 & 8779881 & 9205961 \\
\hline 4 & 9 & 4896629 & 6945415 & 6586655 & 6924839 \\
\hline 5 & 10 & 5577353 & 2782943 & 8807056 & 9191064 \\
\hline 6 & 11 & 4647413 & 779393 & 7783710 & 8300770 \\
\hline$\overline{9}$ & 12 & 4812539 & 0 & 8254622 & 8502300 \\
\hline 15 & 13 & 3928352 & 0 & 5877048 & 6226084 \\
\hline 21 & 14 & 5000706 & 0 & 8052647 & 8445571 \\
\hline 27 & 15 & 4750743 & $\overline{0}$ & 7477287 & 7853307 \\
\hline 39 & 16 & 4554790 & $\overline{0}$ & 6859354 & 7130674 \\
\hline 45 & 17 & 4327468 & 0 & 6918166 & 6962519 \\
\hline
\end{tabular}

\begin{tabular}{|r|r|r|}
\hline \multicolumn{3}{|c|}{ Yield, Normalized } \\
\hline Styrene & 1 st Peak & 2cd Peak \\
\hline 0.94721 & 0.025596 & 0.027193 \\
\hline 0.963216 & 0.016637 & 0.020146 \\
\hline 0.934784 & 0.031193 & 0.034023 \\
\hline 0.895987 & 0.050305 & 0.053708 \\
\hline 0.862369 & 0.067 & 0.070631 \\
\hline 0.807202 & 0.09558 & 0.097218 \\
\hline 0.695232 & 0.148509 & 0.156259 \\
\hline 0.51279 & 0.238689 & 0.248521 \\
\hline 0.320818 & 0.331467 & 0.347715 \\
\hline 0.115706 & 0.433655 & 0.450639 \\
\hline 0.029672 & 0.470712 & 0.499615 \\
\hline 0 & 0.493925 & 0.506075 \\
\hline 0 & 0.486453 & 0.513547 \\
\hline 0 & 0.4892 & 0.5108 \\
\hline 0 & 0.488777 & 0.511223 \\
\hline 0 & 0.49124 & 0.50876 \\
\hline 0 & 0.499584 & 0.500416 \\
\hline
\end{tabular}

Moles Styrene $=$

Moles Heptane $=$

Wt. of $[\mathrm{RhCl}(\mathrm{C} 8 \mathrm{H} 12)] 2(\mathrm{~g})$

Wt. of Ligand (g)

\subsection{5}

0.00387212

0.0134

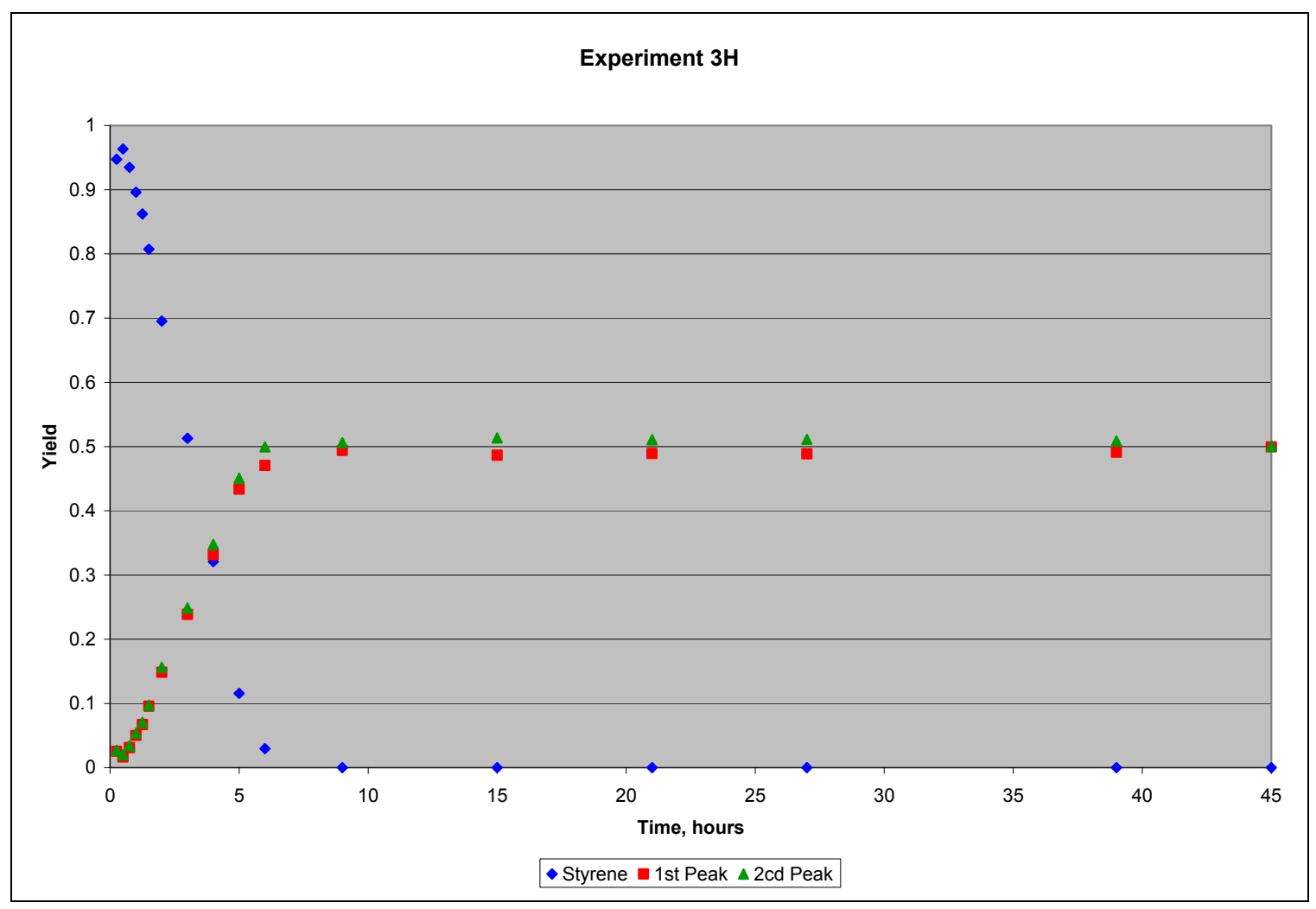


4J - Wilkinson's Catalyst; Rh:P=1:3; Pre: $90^{\circ} \mathrm{C} \& 650$ psig; Rxn.: $90^{\circ} \mathrm{C} \& 2500$ psig

\begin{tabular}{|c|c|c|c|c|c|}
\hline \multicolumn{6}{|c|}{ Raw Data } \\
\hline time & Sample & Heptane & Styrene & 1st Peak & 2cd Peak \\
\hline 0.25 & 1 & 4043804 & 34138735 & 2070406 & 2245080 \\
\hline 0.5 & 2 & 5184881 & 42011516 & 1398533 & 1524511 \\
\hline 0.75 & 3 & 6108651 & 46980734 & 1846813 & 1907902 \\
\hline 1 & 4 & 5955761 & 42479710 & 2182202 & 2308911 \\
\hline 1.25 & 5 & 6193015 & 42570039 & 3022979 & 3090689 \\
\hline 1.5 & 6 & 5980398 & 43607984 & 3990774 & 4137389 \\
\hline 2 & 7 & 5650286 & 35808153 & 4707146 & 5114594 \\
\hline 3 & 8 & 6484937 & 29699504 & 7232773 & 7587004 \\
\hline 4 & 9 & 6272968 & 22324272 & 9952817 & 10487797 \\
\hline 5 & 10 & 5644455 & 12869993 & 11043831 & 11568675 \\
\hline 6 & 11 & 7386133 & 10102324 & 16830108 & 17544477 \\
\hline 9 & 12 & 5075729 & 1528008 & 12993437 & 13475310 \\
\hline 15 & 13 & 5347466 & 0 & 10860988 & 11117560 \\
\hline 21 & 14 & 4466523 & 0 & 12399368 & 12859528 \\
\hline 27 & 15 & 1705395 & 0 & 5169072 & 5552976 \\
\hline 33 & 16 & 4623584 & 0 & 11892161 & 12452657 \\
\hline 39 & 17 & 4741742 & 0 & 11327410 & 11691159 \\
\hline 45 & 18 & 9933570 & 0 & 26011667 & 26860204 \\
\hline
\end{tabular}

\begin{tabular}{|r|c|c|}
\hline \multicolumn{3}{|c|}{ Yield, Normalized } \\
\hline Styrene & 1 st Peak & 2cd Peak \\
\hline 0.885465 & 0.054348 & 0.060187 \\
\hline 0.936032 & 0.029696 & 0.034272 \\
\hline 0.926676 & 0.035222 & 0.038102 \\
\hline 0.903918 & 0.045833 & 0.050249 \\
\hline 0.872085 & 0.062572 & 0.065344 \\
\hline 0.83835 & 0.078909 & 0.082741 \\
\hline 0.77748 & 0.106275 & 0.116245 \\
\hline 0.65532 & 0.168175 & 0.176505 \\
\hline 0.506441 & 0.240842 & 0.252717 \\
\hline 0.345739 & 0.320585 & 0.333676 \\
\hline 0.21122 & 0.387715 & 0.401065 \\
\hline 0.042587 & 0.472048 & 0.485365 \\
\hline 0 & 0.495888 & 0.504112 \\
\hline 0 & 0.493172 & 0.506828 \\
\hline 0 & 0.484469 & 0.515531 \\
\hline 0 & 0.490631 & 0.509369 \\
\hline 0 & 0.494132 & 0.505868 \\
\hline 0 & 0.494168 & 0.505832 \\
\hline
\end{tabular}

Moles Styrene =

Moles Heptane $=$

0.02410534

0.00405276

Wt. of Wilinson's Catalyst (g)

0.026

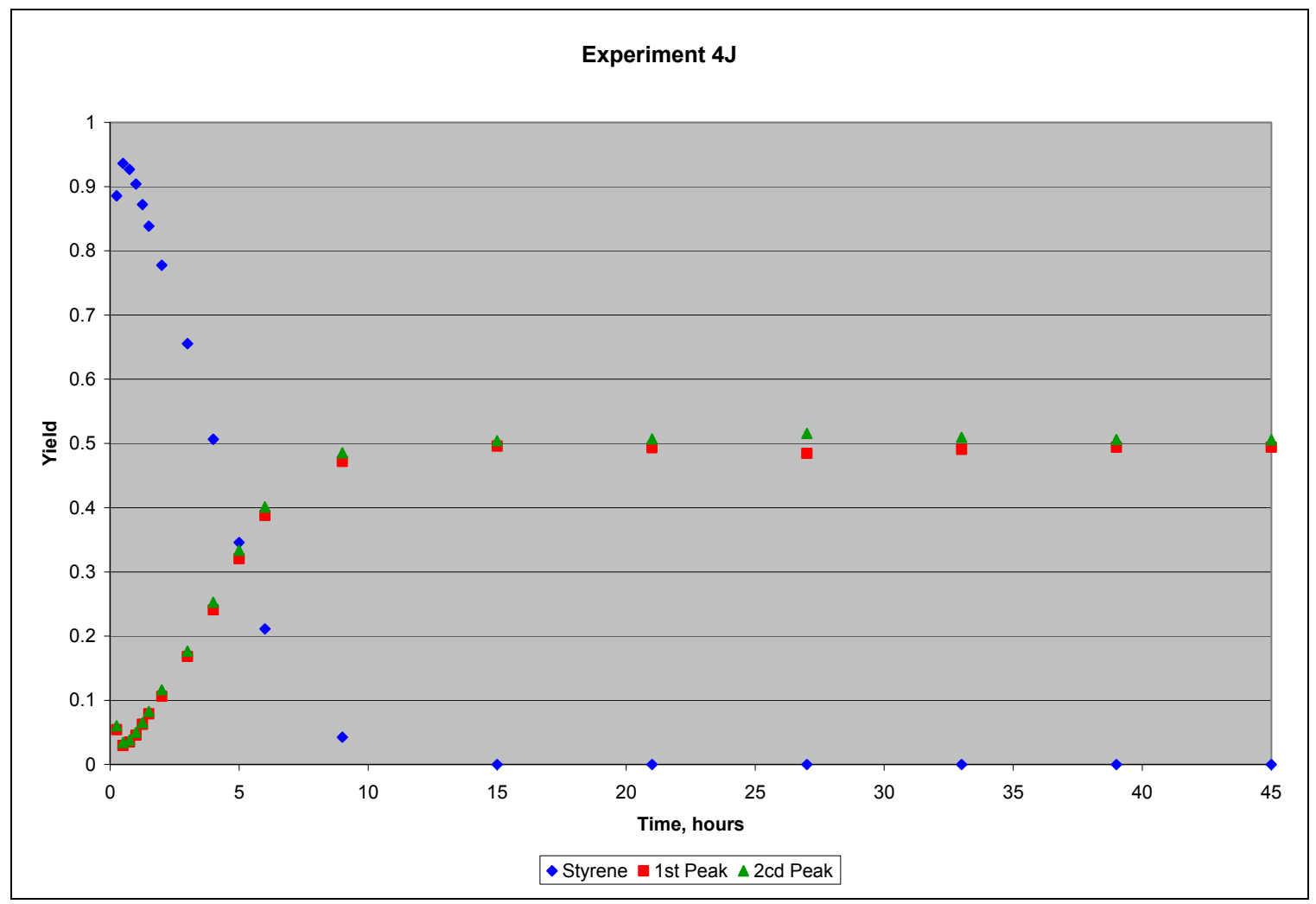


5K - Solid Catalyst - TPP; Rh:P=1:3; Pre: $90^{\circ} \mathrm{C} \& 650$ psig; Rxn.: $90^{\circ} \mathrm{C} \& 2500$ psig

\begin{tabular}{|r|c|r|r|r|r|}
\hline \multicolumn{7}{|c|}{ Raw Data } \\
\hline time & Sample & Heptane & Styrene & 1st Peak & 2cd Peak \\
\hline 0.25 & 1 & 7846047 & 49659372 & 2256725 & 2441677 \\
\hline 0.5 & 2 & 5279215 & 34473107 & 607169 & 633389 \\
\hline 0.75 & 3 & 10103794 & 58668473 & 1433824 & 1568825 \\
\hline 1 & 4 & 7177484 & 44481967 & 1517685 & 1505121 \\
\hline 1.25 & 5 & 6972499 & 42802805 & 1864657 & 1984536 \\
\hline 1.5 & 6 & 6515840 & 32220457 & 1790664 & 1863296 \\
\hline 2 & 7 & 6705050 & 28887965 & 2345551 & 2472227 \\
\hline 3 & 8 & 7069851 & 31154391 & 5559399 & 5718528 \\
\hline 4 & 9 & 7591004 & 20903545 & 5692471 & 6034266 \\
\hline 5 & 10 & 8150817 & 15945101 & 7141449 & 7479496 \\
\hline 6 & 11 & 7559781 & 10249946 & 7439310 & 7862132 \\
\hline 9 & 12 & 5907929 & 1666736 & 7019780 & 7419334 \\
\hline 15 & 13 & 9661403 & 96778 & 11992181 & 12521341 \\
\hline 21 & 14 & 2764942 & 0 & 24014328 & 24818390 \\
\hline 27 & 15 & 4081076 & 301871 & 5765045 & 6165029 \\
\hline
\end{tabular}

\begin{tabular}{|r|r|r|}
\hline \multicolumn{3}{|c|}{ Yield, Normalized } \\
\hline Styrene & 1 st Peak & 2cd Peak \\
\hline 0.914409258 & 0.04000546 & 0.045585282 \\
\hline 0.969937004 & 0.013422458 & 0.016640537 \\
\hline 0.955679142 & 0.019676461 & 0.024644398 \\
\hline 0.939057037 & 0.029491431 & 0.031451532 \\
\hline 0.918805578 & 0.038189313 & 0.043005109 \\
\hline 0.899393938 & 0.047967977 & 0.052638085 \\
\hline 0.856149274 & 0.068670861 & 0.075179864 \\
\hline 0.725484969 & 0.134839118 & 0.139675913 \\
\hline 0.628783444 & 0.1793901 & 0.191826456 \\
\hline 0.50567974 & 0.240833199 & 0.253487061 \\
\hline 0.38203072 & 0.300013498 & 0.317955782 \\
\hline 0.08126878 & 0.446741256 & 0.471989964 \\
\hline 0 & 0.489499361 & 0.510500639 \\
\hline 0 & 0.495116542 & 0.504883458 \\
\hline 0.005596378 & 0.481199003 & 0.513204619 \\
\hline
\end{tabular}

Moles Styrene =

Moles Heptane $=$

Wt. of Catalyst (g)
0.024105

0.004053

0.0992

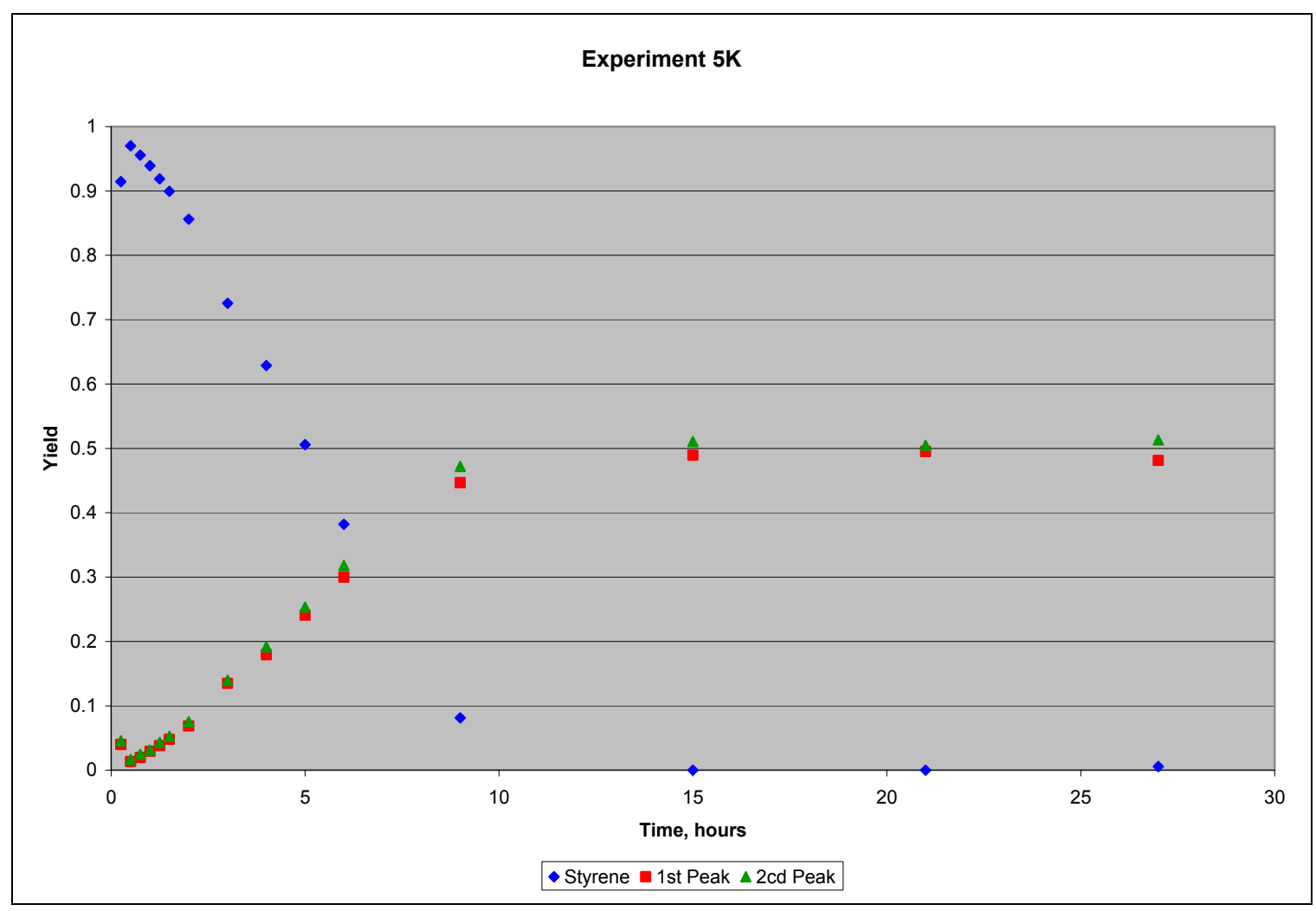


6L - [RhCl(C8H12) 2 \& TPP; Rh:P=1:34; Pre: $50^{\circ} \mathrm{C} \& 2000$ psig; Rxn.: $75^{\circ} \mathrm{C} \& 3000$ psig

\begin{tabular}{|c|c|c|c|c|c|c|c|c|}
\hline \multicolumn{6}{|c|}{ Raw Data } & \multicolumn{3}{|c|}{ Yield, Normalized } \\
\hline time & Sample & Heptane & Styrene & 1st Peak & 2cd Peak & Styrene & 1st Peak & 2cd Peak \\
\hline 0.25 & 1 & 3788814 & 33827905 & 0 & 0 & 1 & 0 & 0 \\
\hline 0.5 & 2 & 2316110 & 23893576 & 0 & 0 & 1 & 0 & 0 \\
\hline 0.75 & 3 & 3124945 & 30400071 & 0 & 0 & 1 & 0 & 0 \\
\hline 1 & 4 & 3310523 & 30861397 & 0 & 0 & 1 & 0 & 0 \\
\hline 1.25 & 5 & 3350063 & 31203662 & 0 & 0 & 1 & 0 & 0 \\
\hline 1.5 & 6 & 3983788 & 40288694 & 0 & 0 & 1 & 0 & 0 \\
\hline 2 & 7 & 287312 & 2043979 & 0 & 0 & 1 & 0 & 0 \\
\hline 3 & 8 & 3370196 & 28970678 & 0 & 0 & 1 & 0 & 0 \\
\hline 4 & 9 & 3044738 & 26603581 & 186553 & 165472 & 0.99156091 & 0.003658867 & 0.004780223 \\
\hline 5 & 10 & 3122801 & 28003932 & 301076 & 298209 & 0.982913485 & 0.007684219 & 0.009402297 \\
\hline 6 & 11 & 3625912 & 31800149 & 506157 & 447268 & 0.974226385 & 0.012958823 & 0.012814792 \\
\hline 9 & 12 & 3765647 & 29024449 & 554828 & 594994 & 0.965260701 & 0.015669051 & 0.019070249 \\
\hline 15 & 13 & 2796856 & 22306906 & 688618 & 714975 & 0.942381203 & 0.02737943 & 0.030239366 \\
\hline 21 & 14 & 3318124 & 25654102 & 1160924 & 1150958 & 0.917358669 & 0.040768824 & 0.041872506 \\
\hline 27 & 15 & 2367985 & 17972378 & 958678 & 887947 & 0.906181636 & 0.048111841 & 0.045706523 \\
\hline 33 & 16 & 2786850 & 19055386 & 1170798 & 1206919 & 0.887736441 & 0.054500539 & 0.057763021 \\
\hline 39 & 17 & 2564094 & 18130272 & 1373996 & 1466871 & 0.861456936 & 0.066351182 & 0.072191882 \\
\hline 45 & 18 & 2399137 & 16033525 & 1300505 & 1384518 & 0.853215416 & 0.070418839 & 0.076365745 \\
\hline 57 & 19 & 2477384 & 16762246 & 1770502 & 1795047 & 0.819247066 & 0.089345569 & 0.091407365 \\
\hline 69 & 20 & 1635047 & 11241141 & 1192917 & 1257829 & 0.815417516 & 0.08941761 & 0.095164875 \\
\hline 81 & 21 & 1878030 & 11936121 & 1256589 & 1325245 & 0.816928988 & 0.088569919 & 0.094501093 \\
\hline
\end{tabular}

Moles Styrene =

Moles Heptane $=$

Wt. of $[\mathrm{RhCl}(\mathrm{C} 8 \mathrm{H} 12)] 2(\mathrm{~g})$

Wt. of Ligand $(\mathrm{g})$

\subsection{1}

0.003612652

0.0105

0.3695

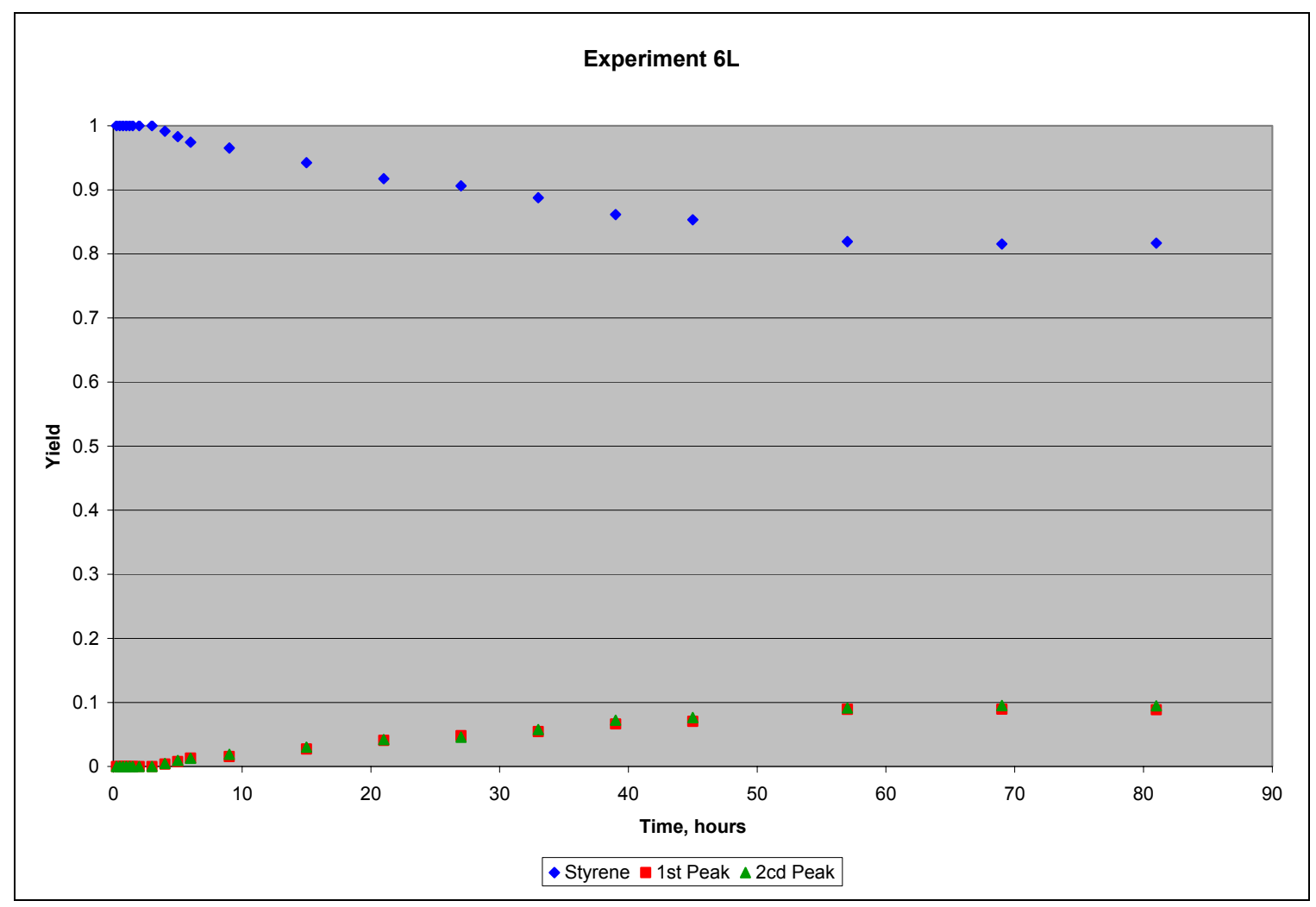


7M - [RhCl(C8H12)]2 \& TPP; Rh:P=1:8; Pre: 50 C\& 2000 psig; Rxn.: 90 ${ }^{\circ} \mathrm{C} \& 2500$ psig

\begin{tabular}{|r|c|r|r|r|r|}
\hline \multicolumn{6}{|c|}{ Raw Data } \\
\hline time & Sample & Heptane & Styrene & 1 st Peak & 2cd Peak \\
\hline 0.25 & 1 & 2854588 & 22223229 & 947850 & 952196 \\
\hline 0.5 & 2 & 4817704 & 30947492 & 1990712 & 2157056 \\
\hline 0.75 & 3 & 4585559 & 24732241 & 2739071 & 2976529 \\
\hline 1 & 4 & 4548180 & 19534506 & 3501611 & 3841779 \\
\hline 1.25 & 5 & 5041434 & 17506601 & 5121103 & 5511760 \\
\hline 1.5 & 6 & 4897187 & 13212402 & 5424671 & 5787340 \\
\hline 2 & 7 & 5486574 & 6729433 & 7646248 & 8114647 \\
\hline 3 & 8 & 5442609 & 1320788 & 10466236 & 11250950 \\
\hline 4 & 9 & 5045346 & 399330 & 9787458 & 10494657 \\
\hline 5 & 10 & 5115583 & 286251 & 9758478 & 10510379 \\
\hline 6 & 11 & 5038512 & 240920 & 10096754 & 10706422 \\
\hline 9 & 12 & 5292298 & 564579 & 10734841 & 11384078 \\
\hline 15 & 13 & 5555147 & 843132 & 11208549 & 11898941 \\
\hline 21 & 14 & 4524933 & 388657 & 9363868 & 9930432 \\
\hline 27 & 15 & 4336106 & 257898 & 8249036 & 8848673 \\
\hline 33 & 16 & 5266358 & 129953 & 9793093 & 10368094 \\
\hline 39 & 17 & 4599848 & 79712 & 9052239 & 9647239 \\
\hline
\end{tabular}

\begin{tabular}{|r|r|r|}
\hline \multicolumn{3}{|c|}{ Yield, Normalized } \\
\hline Styrene & 1 st Peak & 2cd Peak \\
\hline 0.921509 & 0.038393 & 0.0400977 \\
\hline 0.880322 & 0.056536 & 0.0631416 \\
\hline 0.807152 & 0.091663 & 0.1011852 \\
\hline 0.717819 & 0.133943 & 0.1482382 \\
\hline 0.60916 & 0.187999 & 0.2028411 \\
\hline 0.525664 & 0.229395 & 0.2449404 \\
\hline 0.28034 & 0.349601 & 0.3700589 \\
\hline 0.042484 & 0.462907 & 0.4946083 \\
\hline 0.005274 & 0.481551 & 0.5131755 \\
\hline 0 & 0.482942 & 0.517058 \\
\hline 0 & 0.486979 & 0.5130211 \\
\hline 0.011239 & 0.48151 & 0.5072515 \\
\hline 0.021277 & 0.476351 & 0.5023718 \\
\hline 0.006458 & 0.483875 & 0.5096668 \\
\hline 0.000654 & 0.483639 & 0.5157067 \\
\hline 0 & 0.487201 & 0.5127987 \\
\hline 0 & 0.485673 & 0.5143274 \\
\hline
\end{tabular}

Moles Styrene $=$

Moles Heptane $=$

Wt. of $[\mathrm{RhCl}(\mathrm{C} 8 \mathrm{H} 12)] 2(\mathrm{~g})$

Wt. of Ligand (g)

\subsection{5}

0.0038192

0.0104

0.0926

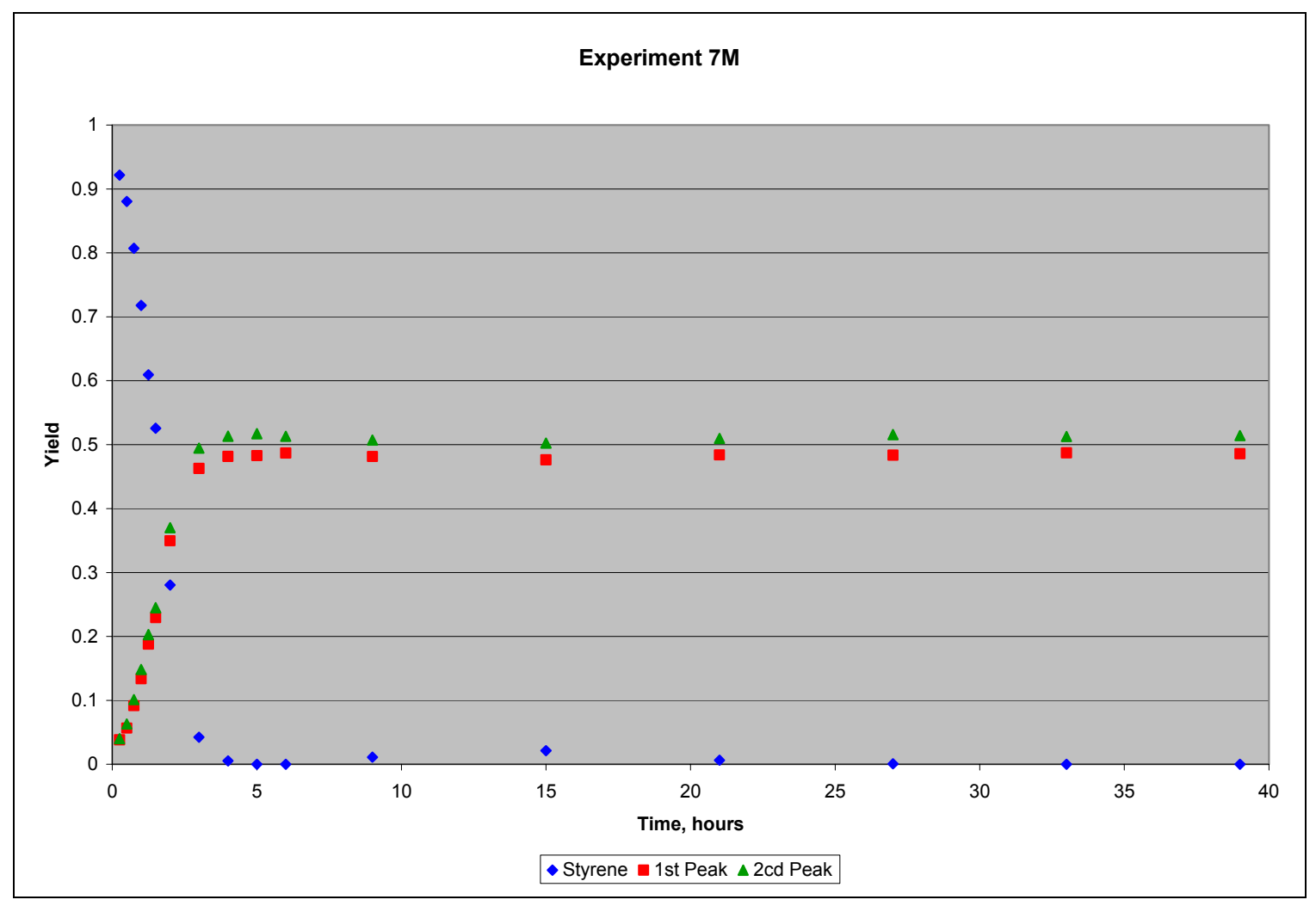


$8 \mathrm{~N}$ - [RhCl(C8H12)]2 \& TPP; $\mathrm{Rh}: \mathrm{P}=1: 34 ;$ Pre: $50^{\circ} \mathrm{C} \& 2000$ psig; Rxn.: $90^{\circ} \mathrm{C} \& 2500$ psig

\begin{tabular}{|r|c|r|r|r|r|}
\hline \multicolumn{7}{|c|}{ Raw Data } \\
\hline time & Sample & Heptane & Styrene & 1st Peak & 2cd Peak \\
\hline 0.25 & 1 & 4417753 & 50702663 & 0 & 0 \\
\hline 0.5 & 2 & 2992259 & 17290849 & 1685408 & 1809592 \\
\hline 0.75 & 3 & 4659516 & 21743771 & 4121760 & 4389493 \\
\hline 1 & 4 & 5324892 & 19500620 & 5798030 & 6211497 \\
\hline 1.25 & 5 & 5054786 & 14454369 & 6321532 & 6825489 \\
\hline 1.5 & 6 & 5772382 & 12584875 & 8436862 & 9095323 \\
\hline 2 & 7 & 4767089 & 6269331 & 7733355 & 8341830 \\
\hline 3 & 8 & 6173788 & 2947613 & 11169604 & 12119247 \\
\hline 4 & 9 & 4848106 & 773252 & 9391540 & 10135271 \\
\hline 5 & 10 & 3827076 & 178576 & 7292763 & 7945425 \\
\hline 6 & 11 & 3858650 & 89309 & 7804657 & 8217657 \\
\hline 9 & 12 & 4130432 & 0 & 7842527 & 8404674 \\
\hline 15 & 13 & 3709994 & 0 & 8329286 & 8960904 \\
\hline 21 & 14 & 3213567 & 0 & 5724113 & 6210943 \\
\hline 27 & 15 & 3922043 & 0 & 8492402 & 9057355 \\
\hline
\end{tabular}

Yield, Normalized \begin{tabular}{|l|l|l|}
\hline Styrene & 1st Peak & 2nd Peak \\
\hline
\end{tabular}

\begin{tabular}{|r|r|r|}
\multicolumn{1}{l|}{ Styrene } & st Peak & 2nd Peak \\
\hline 1 & 0 & 0 \\
\hline 0.82761 & 0.08238 & 0.090004 \\
\hline 0.70905 & 0.14054 & 0.150418 \\
\hline 0.6057 & 0.19024 & 0.204052 \\
\hline 0.50804 & 0.23666 & 0.255296 \\
\hline 0.40057 & 0.28891 & 0.310517 \\
\hline 0.26261 & 0.35552 & 0.381862 \\
\hline 0.09607 & 0.43475 & 0.469179 \\
\hline 0.02371 & 0.47104 & 0.50525 \\
\hline 0 & 0.48005 & 0.519949 \\
\hline 0 & 0.48878 & 0.511223 \\
\hline 0 & 0.48419 & 0.515811 \\
\hline 0 & 0.48358 & 0.516416 \\
\hline 0 & 0.48091 & 0.519088 \\
\hline 0 & 0.48569 & 0.514307 \\
\hline
\end{tabular}

Moles Styrene $=$

0.023859

Moles Heptane $=$

0.002966

Wt. of $[\mathrm{RhCl}(\mathrm{C} 8 \mathrm{H} 12)] 2(\mathrm{~g}) \quad 0.0101$

Wt. of Ligand $(\mathrm{g})$

0.3689

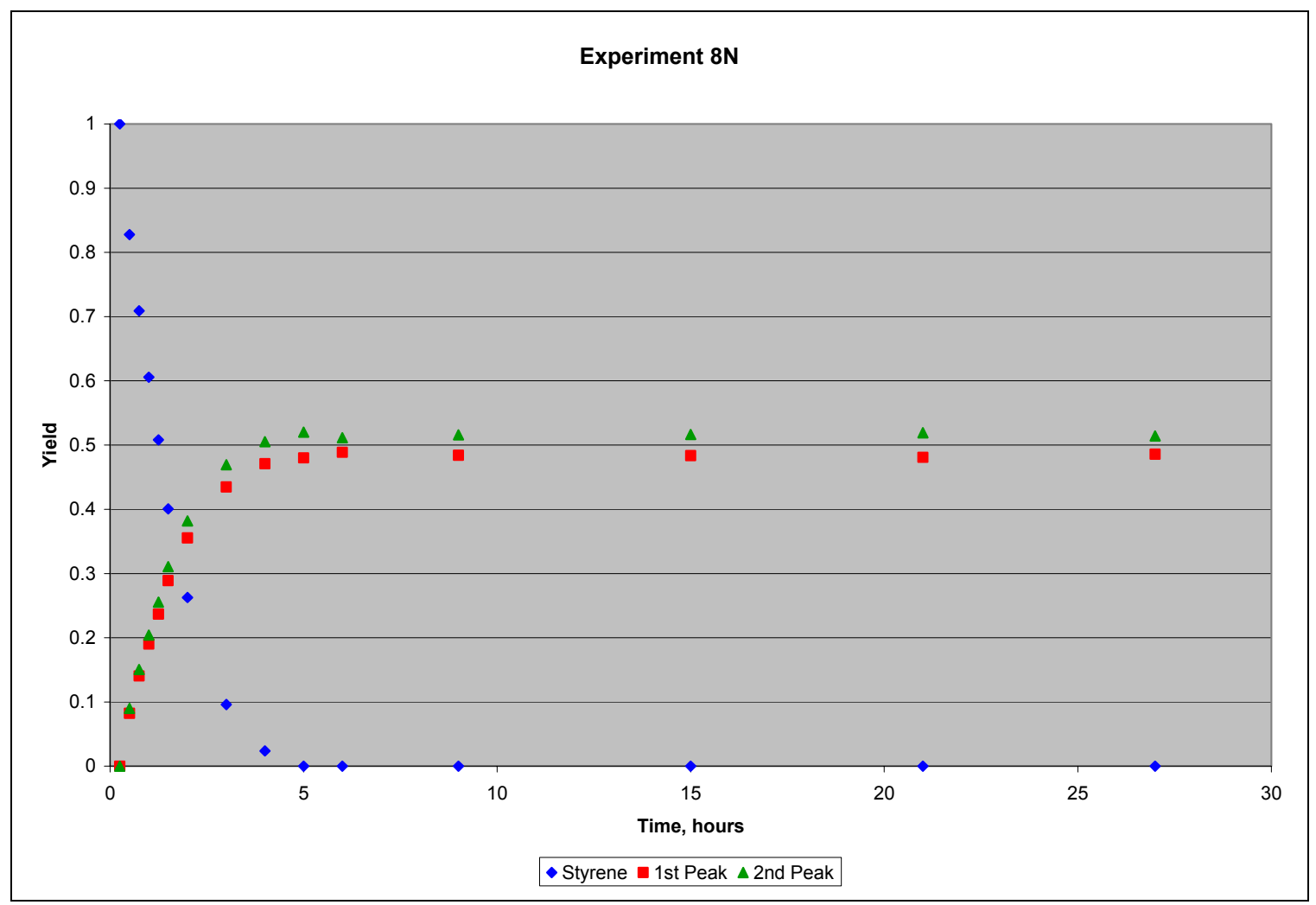


9P - $[\mathrm{RhCl}(\mathrm{C} 8 \mathrm{H} 12)] 2$ \& TPP; Rh:P=1:8; Pre: $50^{\circ} \mathrm{C} \& 2000$ psig; Rxn.: $75^{\circ} \mathrm{C} \& 3000$ psig

\begin{tabular}{|r|r|r|r|r|r|}
\hline \multicolumn{7}{|c|}{ Raw Data } \\
\hline time & Sample & Heptane & Styrene & 1st Peak & 2cd Peak \\
\hline 0.25 & 1 & 406314 & 13945048 & 0 & 0 \\
\hline 0.5 & 2 & 979804 & 18798057 & 0 & 705208 \\
\hline 0.75 & 3 & 984539 & 19977715 & 335343 & 488077 \\
\hline 1 & 4 & 628621 & 14260677 & 637079 & 1358587 \\
\hline 1.25 & 5 & 1323138 & 23314281 & 1241519 & 1186737 \\
\hline 1.5 & 6 & 1084919 & 17744225 & 1204582 & 1485885 \\
\hline 2 & 7 & 885139 & 14676668 & 1453383 & 14379 \\
\hline 3 & 8 & 780434 & 16079819 & 2632016 & 2499375 \\
\hline 4 & 9 & 853352 & 14345687 & 3504391 & 3539238 \\
\hline 5 & 10 & 1153546 & 11128341 & 3609589 & 3658183 \\
\hline 6 & 11 & 989979 & 12085565 & 5350087 & 5834972 \\
\hline 9 & 12 & 945997 & 7741637 & 5983132 & 5914544 \\
\hline 15 & 13 & 738100 & 4163809 & 6110158 & 6314934 \\
\hline 21 & 14 & 502442 & 2932555 & 7648117 & 7760229 \\
\hline 27 & 15 & 650146 & 1851914 & 8367690 & 8078348 \\
\hline 33 & 16 & 934100 & 1334872 & 7751900 & 7768384 \\
\hline 39 & 17 & 923432 & 639319 & 7919301 & 7823276 \\
\hline 45 & 18 & 1042782 & 571700 & 9322482 & 9149738 \\
\hline 51 & 19 & 848597 & 455577 & 7484214 & 7475811 \\
\hline 57 & 20 & 1031207 & 432152 & 10976293 & 11111606 \\
\hline 69 & 21 & 935057 & 361819 & 8246930 & 8338224 \\
\hline 75 & 22 & 890719 & 283889 & 10809109 & 11086871 \\
\hline 81 & 23 & 833817 & 199754 & 7849820 & 7723914 \\
\hline 93 & 24 & 639703 & 419822 & 7213070 & 7232839 \\
\hline
\end{tabular}

\begin{tabular}{|r|r|r|}
\hline \multicolumn{3}{|c|}{ Yield, Normalized } \\
\hline Styrene & 1 st Peak & 2cd Peak \\
\hline 1 & 0 & 0 \\
\hline 1 & 0 & 0 \\
\hline 0.97023 & 0.007081 & 0.02269 \\
\hline 0.948435 & 0.029445 & 0.022119 \\
\hline 0.926518 & 0.033755 & 0.039728 \\
\hline 0.910885 & 0.043661 & 0.045454 \\
\hline 0.865856 & 0.063878 & 0.070265 \\
\hline 0.792948 & 0.102141 & 0.104911 \\
\hline 0.710789 & 0.137825 & 0.151386 \\
\hline 0.652308 & 0.165584 & 0.182108 \\
\hline 0.562705 & 0.199539 & 0.237756 \\
\hline 0.436642 & 0.271204 & 0.292154 \\
\hline 0.283922 & 0.33636 & 0.379718 \\
\hline 0.182388 & 0.387567 & 0.430045 \\
\hline 0.117519 & 0.429517 & 0.452964 \\
\hline 0.093743 & 0.432821 & 0.473437 \\
\hline 0.047519 & 0.458351 & 0.49413 \\
\hline 0.036987 & 0.464979 & 0.498035 \\
\hline 0.036443 & 0.460931 & 0.502627 \\
\hline 0.023972 & 0.463428 & 0.5126 \\
\hline 0.026891 & 0.462489 & 0.51062 \\
\hline 0.016304 & 0.463718 & 0.519979 \\
\hline 0.016671 & 0.474103 & 0.509226 \\
\hline 0.034362 & 0.460789 & 0.50485 \\
\hline
\end{tabular}

Moles Styrene =

Moles Heptane $=$

Wt. of $[\mathrm{RhCl}(\mathrm{C} 8 \mathrm{H} 12)] 2(\mathrm{~g})$

Wt. of Ligand $(\mathrm{g})$
0.02710386

0.00282525

0.0108

0.0912

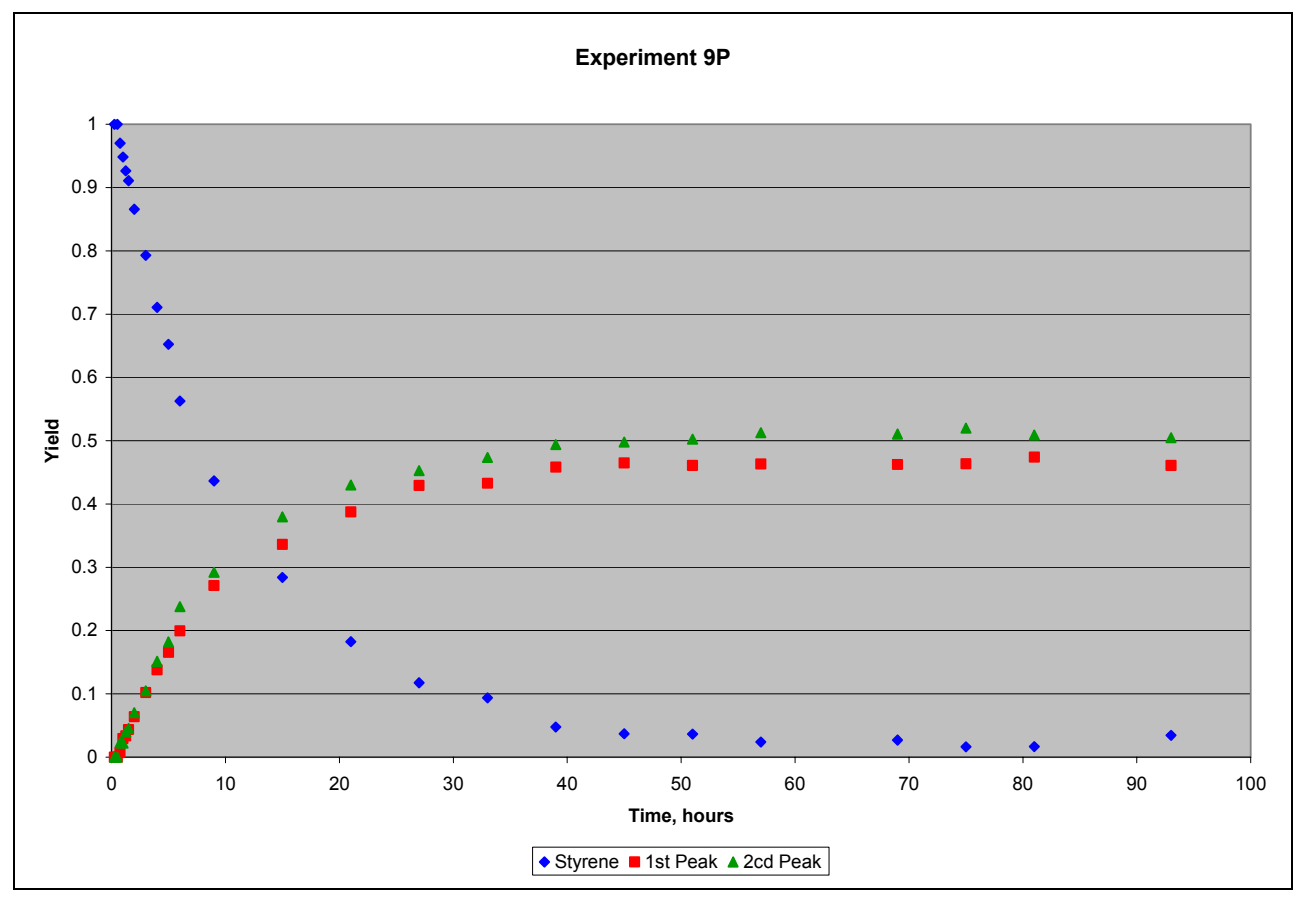


$10 \mathrm{Q}$ - [RhCl(C8H12)]2 \& TPP; Rh:P=1:8; Pre: 90 C \& 2000 psig; Rxn.: 90 C \& 2500 psig

\begin{tabular}{|r|c|r|l|r|r|}
\hline \multicolumn{7}{|c|}{ Raw Data } \\
\hline time & Sample & Heptane & Styrene & 1st Peak & 2cd Peak \\
\hline 0.25 & 1 & 6674921 & 41125891 & 0 & 0 \\
\hline 0.5 & 2 & 5104691 & 33724554 & 0 & 0 \\
\hline 0.75 & 3 & 7969270 & 49262407 & 0 & 0 \\
\hline 1 & 4 & 7013585 & 42261857 & 1118437 & 1110170 \\
\hline 1.25 & 5 & 5035865 & 28443574 & 935244 & 940579 \\
\hline 1.5 & 6 & 6560946 & 52955726 & 2339473 & 2207670 \\
\hline 2 & 7 & 5720615 & 31884417 & 1614738 & 1677817 \\
\hline 3 & 8 & 6990963 & 32449123 & 3148156 & 3145057 \\
\hline 4 & 9 & 5208272 & 20191529 & 3522761 & 3457869 \\
\hline 5 & 10 & 4832866 & 15043679 & 3971228 & 3849857 \\
\hline 6 & 11 & 4608391 & 9955885 & 5162533 & 5306707 \\
\hline 9 & 12 & 5890138 & 3151852 & 10160035 & 9992940 \\
\hline 15 & 13 & 4606392 & 0 & 8822938 & 8244811 \\
\hline 21 & 14 & 5469007 & 0 & 10838907 & 11089091 \\
\hline
\end{tabular}

\begin{tabular}{|r|r|r|}
\hline \multicolumn{3}{|c|}{ Yield, Normalized } \\
\hline Styrene & 1st Peak & 2cd Peak \\
\hline 1 & 0 & 0 \\
\hline 1 & 0 & 0 \\
\hline 1 & 0 & 0 \\
\hline 1 & 0 & 0 \\
\hline 0.996473396 & 0.003526604 & 0 \\
\hline 0.965172076 & 0.019243274 & 0.01558465 \\
\hline 0.966928527 & 0.017258068 & 0.015813405 \\
\hline 0.820615765 & 0.089532549 & 0.089851686 \\
\hline 0.74166811 & 0.128983592 & 0.129348298 \\
\hline 0.568320738 & 0.205937893 & 0.225741369 \\
\hline 0.175246769 & 0.401506468 & 0.423246763 \\
\hline 0 & 0.500507631 & 0.499492369 \\
\hline 0 & 0.475148676 & 0.524851324 \\
\hline
\end{tabular}

Moles Styrene $=$

Moles Heptane $=$

Wt. of $[\mathrm{RhCl}(\mathrm{C} 8 \mathrm{H} 12)] 2(\mathrm{~g})$

Wt. of Ligand $(\mathrm{g})$

\subsection{9 \\ 0.005606}

0.0100

0.0925

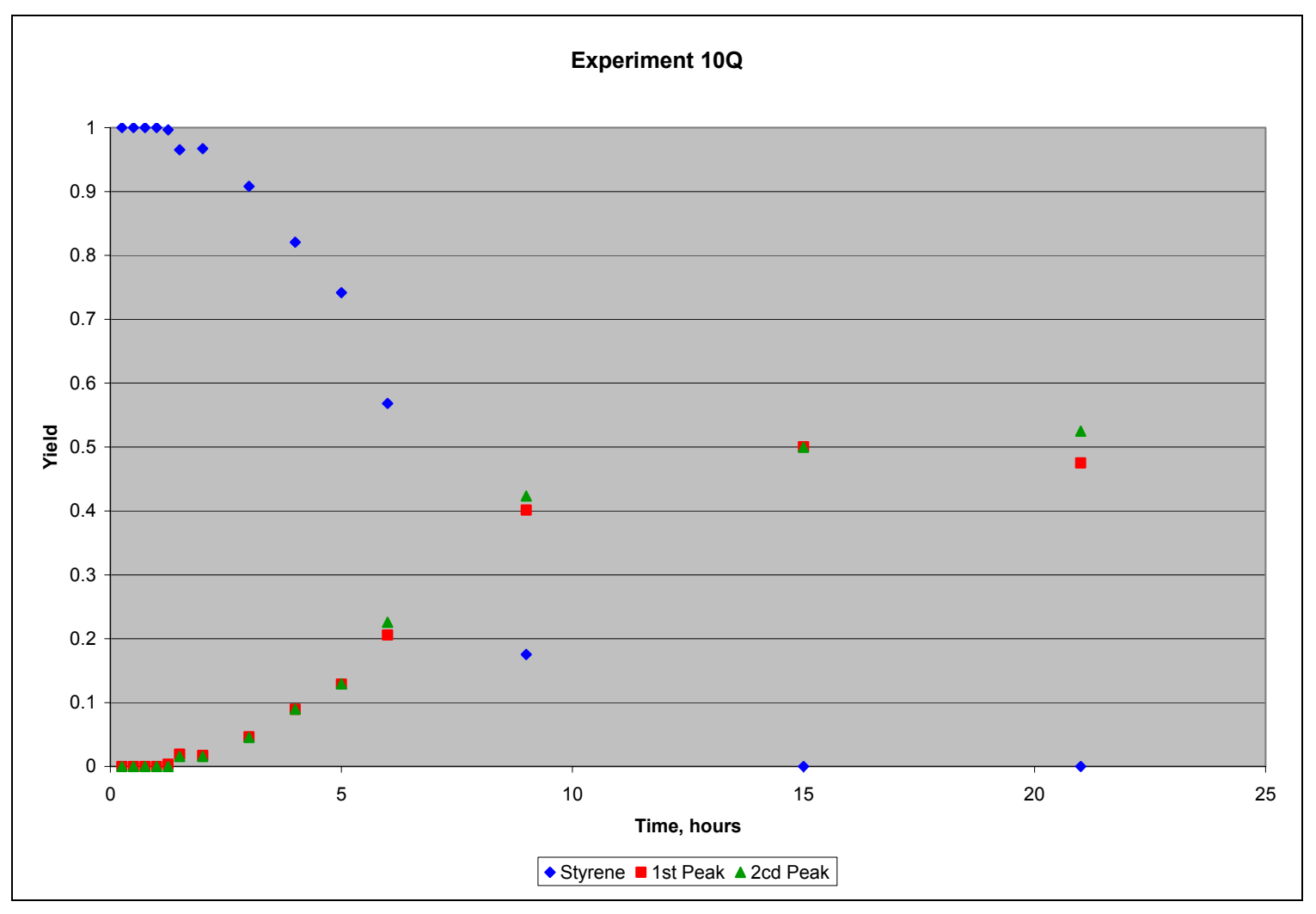


11R - [RhCl(C8H12)]2 \& TPP; Rh:P=1:2; Pre: $90^{\circ} \mathrm{C} \& 650$ psig; Rxn.: $90^{\circ} \mathrm{C} \& 2500$ psig

\begin{tabular}{|r|c|r|r|r|r|}
\hline \multicolumn{7}{|c|}{ Raw Data } \\
\hline time & Sample & Heptane & Styrene & 1st Peak & 2cd Peak \\
\hline 0.25 & 1 & 1005775 & 7905558 & 0 & 0 \\
\hline 0.5 & 2 & 2725074 & 17921973 & 4247723 & 3938643 \\
\hline 0.75 & 3 & 222510 & 11540850 & 3782006 & 3726783 \\
\hline 1 & 4 & 2629067 & 9883885 & 6049307 & 7004257 \\
\hline 1.25 & 5 & 2363234 & 5775272 & 7737359 & 6432185 \\
\hline 1.5 & 6 & 2745668 & 3746932 & 7955130 & 7700523 \\
\hline 2 & 7 & 2147908 & 1227389 & 6766556 & 6421528 \\
\hline 3 & 8 & 2437024 & 370976 & 7960742 & 7892819 \\
\hline 4 & 9 & 2101504 & 0 & 5764211 & 6509410 \\
\hline 5 & 10 & 2316145 & 0 & 4958222 & 6171815 \\
\hline 6 & 11 & 2010816 & 0 & 4823569 & 5341176 \\
\hline 9 & 12 & 2046932 & 0 & 5306922 & 5269800 \\
\hline
\end{tabular}

\begin{tabular}{|r|r|r|}
\hline \multicolumn{3}{|c|}{ Yield, Normalized } \\
\hline Styrene & 1st Peak & 2cd Peak \\
\hline 1 & 0 & 0 \\
\hline 0.742348 & 0.129962 & 0.127691 \\
\hline 0.66582 & 0.162537 & 0.171643 \\
\hline 0.485686 & 0.226986 & 0.287328 \\
\hline 0.33682 & 0.35082 & 0.31236 \\
\hline 0.231323 & 0.375671 & 0.393005 \\
\hline 0.107124 & 0.440831 & 0.452045 \\
\hline 0.032996 & 0.466047 & 0.500958 \\
\hline 0 & 0.447821 & 0.552179 \\
\hline 0 & 0.42219 & 0.57781 \\
\hline 0 & 0.45319 & 0.54681 \\
\hline 0 & 0.482263 & 0.517737 \\
\hline
\end{tabular}

Moles Styrene =

Moles Heptane $=$

Wt. of $[\mathrm{RhCl}(\mathrm{C} 8 \mathrm{H} 12)] 2(\mathrm{~g})$

Wt. of Ligand $(\mathrm{g})$
0.025935

0.004158

0.0107

0.0223

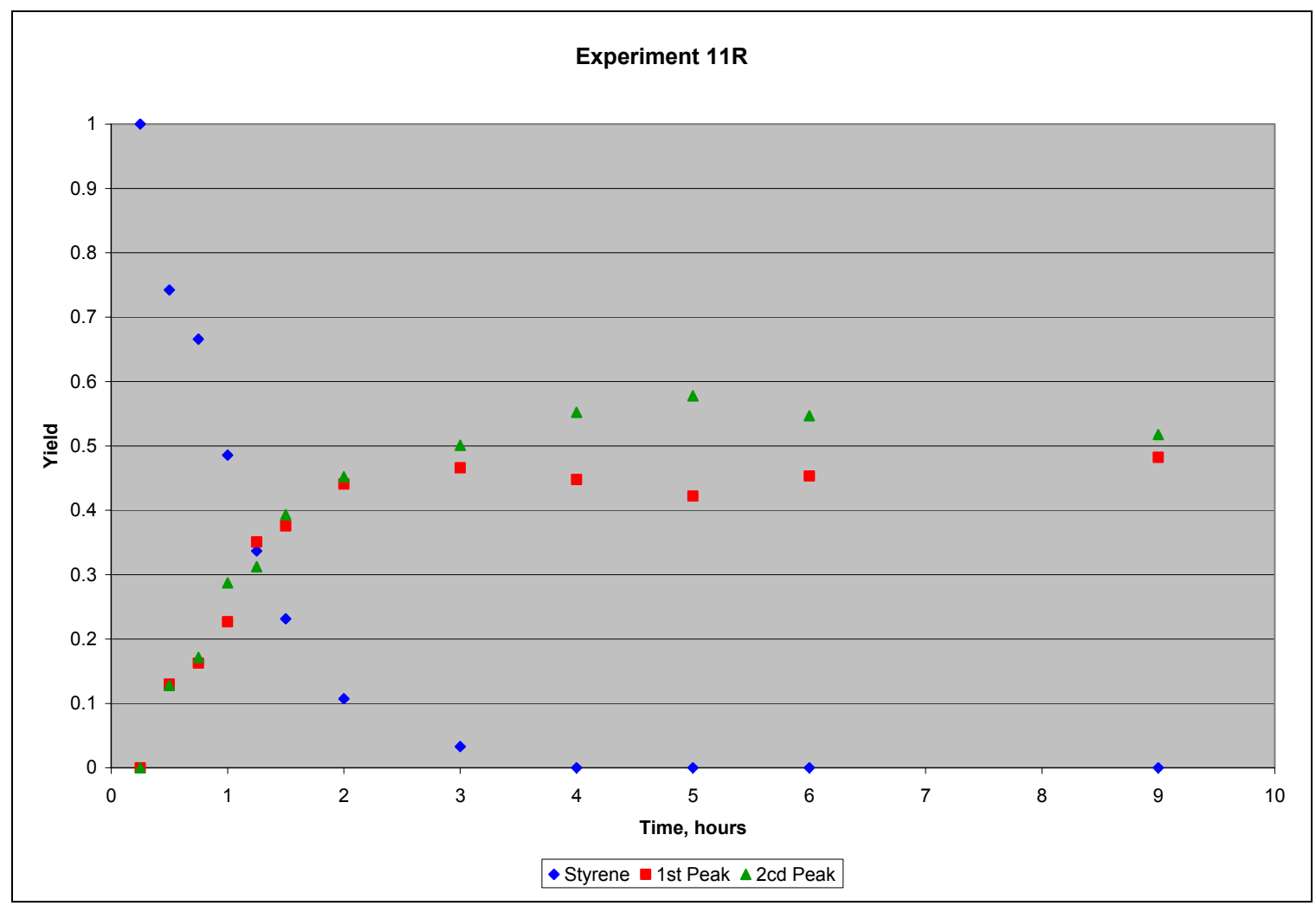


12S - [RhCl(C8H12)]2 \& BINAP; Rh:P=1:4; Pre: $90^{\circ} \mathrm{C} \& 650$ psig; Rxn.: $90^{\circ} \mathrm{C} \& 2500$ psig

\begin{tabular}{|r|r|r|r|r|r|}
\hline \multicolumn{6}{|c|}{ Raw Data } \\
\hline time & Sample & Heptane & Styrene & 1st Peak & 2cd Peak \\
\hline 0.25 & 1 & 4854678 & 14697285 & 0 & 0 \\
\hline 0.5 & 2 & 6974416 & 21161853 & 0 & 0 \\
\hline 0.75 & 3 & 10199961 & 31216609 & 1736882 & 2067423 \\
\hline 1 & 4 & 7883567 & 22351765 & 1362986 & 1482068 \\
\hline 1.25 & 5 & 7182070 & 19216233 & 1313429 & 1452484 \\
\hline 1.5 & 6 & 8723846 & 22919356 & 1936547 & 2061646 \\
\hline 1.75 & 7 & 8324376 & 20480017 & 1946709 & 2333181 \\
\hline 2 & 8 & 6061737 & 15329032 & 1757404 & 1993818 \\
\hline 3 & 9 & 7345428 & 15155850 & 2016430 & 2045591 \\
\hline 4 & 10 & 6784175 & 14218798 & 2611313 & 3258034 \\
\hline 5 & 11 & 6991427 & 12039903 & 3064947 & 3434911 \\
\hline 6 & 12 & 7019232 & 9847589 & 3133469 & 3454020 \\
\hline 9 & 13 & 6648512 & 7067721 & 3987340 & 4525158 \\
\hline 15 & 14 & 8179096 & 3445816 & 6659593 & 6212242 \\
\hline 21 & 15 & 6187830 & 1212548 & 6641613 & 6399747 \\
\hline 27 & 16 & 6864437 & 673904 & 7519891 & 7673017 \\
\hline 33 & 17 & 5868761 & 308684 & 6579754 & 6683382 \\
\hline 39 & 18 & 5866153 & & 5869626 & 6353335 \\
\hline 45 & 19 & 7219192 & 0 & 7648457 & 7447517 \\
\hline
\end{tabular}

\begin{tabular}{|r|r|r|}
\hline \multicolumn{3}{|c|}{ Yield, Normalized } \\
\hline Styrene & 1st Peak & 2cd Peak \\
\hline 1 & 0 & 0 \\
\hline 1 & 0 & 0 \\
\hline 0.994595 & 0.002356 & 0.003049 \\
\hline 0.996703 & 0.003297 & 0 \\
\hline 0.990188 & 0.006494 & 0.003318 \\
\hline 0.967205 & 0.018243 & 0.014552 \\
\hline 0.946847 & 0.022793 & 0.03036 \\
\hline 0.917425 & 0.038132 & 0.044443 \\
\hline 0.924143 & 0.041325 & 0.034532 \\
\hline 0.826522 & 0.071924 & 0.101554 \\
\hline 0.777808 & 0.101778 & 0.120414 \\
\hline 0.738319 & 0.121556 & 0.140125 \\
\hline 0.575618 & 0.191092 & 0.23329 \\
\hline 0.299533 & 0.358824 & 0.341642 \\
\hline 0.129409 & 0.432777 & 0.437814 \\
\hline 0.073498 & 0.444228 & 0.482274 \\
\hline 0.047454 & 0.457822 & 0.494724 \\
\hline 0.019411 & 0.453336 & 0.527253 \\
\hline 0.019384 & 0.484477 & 0.496139 \\
\hline
\end{tabular}

Moles Styrene $=$

Moles Heptane $=$

Wt. of $[\mathrm{RhCl}(\mathrm{C} 8 \mathrm{H} 12)] 2(\mathrm{~g})$

Wt. of Ligand (g)
0.01771847

0.00535311

0.0098

0.1058

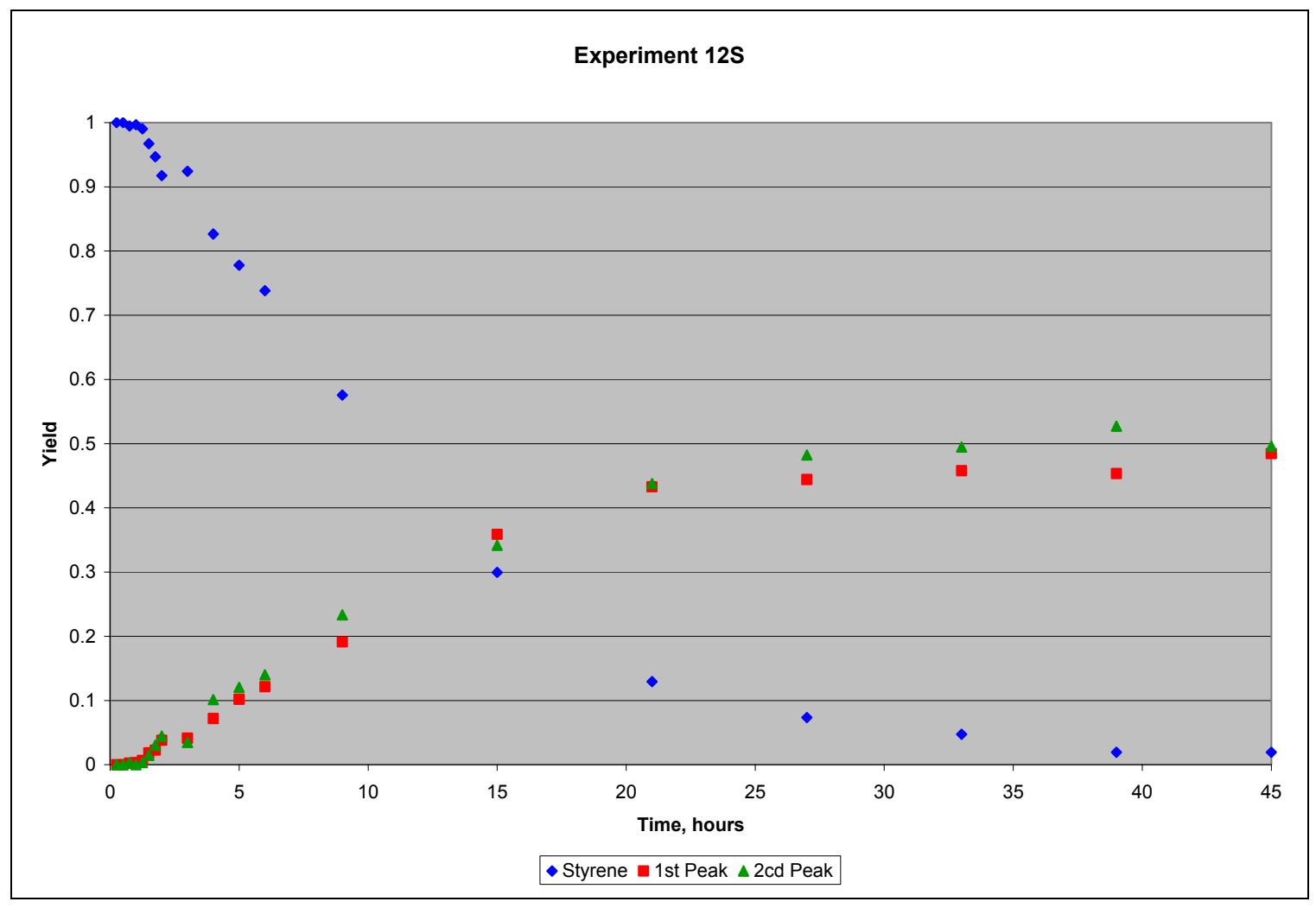


13T - C96H80Cl2P4Rh2 (BINAP); Rh:P=1:2; Pre: $90^{\circ} \mathrm{C} \& 650$ psig; Rxn.: $90^{\circ} \mathrm{C} \& 2500$ psig

\begin{tabular}{|c|c|c|c|c|c|}
\hline \multicolumn{6}{|c|}{ Raw Data } \\
\hline time & Sample & Heptane & Styrene & 1st Peak & 2cd Peak \\
\hline 0.25 & 1 & 6066938 & 35278514 & 0 & 0 \\
\hline 0.5 & 2 & 5767107 & 29671128 & 0 & 0 \\
\hline 0.75 & 3 & 6227815 & 31112429 & 0 & 0 \\
\hline 1 & 4 & 6365370 & 33165187 & $\overline{0}$ & 0 \\
\hline 1.25 & 5 & 7367490 & 37334014 & 0 & 0 \\
\hline 1.5 & 6 & 7176382 & 36735571 & 431529 & 391660 \\
\hline 2 & 7 & 7177532 & 34982501 & 636005 & 742898 \\
\hline 3 & 8 & 8207622 & 41692451 & 1280829 & 1206513 \\
\hline 4 & 9 & 7877832 & 37590264 & 1458587 & 1465304 \\
\hline 5 & 10 & 5937687 & 26056482 & 1689578 & 1743697 \\
\hline 6 & 11 & 7522395 & 30829255 & 2788282 & 2587658 \\
\hline 9 & 12 & 7938498 & 27803598 & 3602922 & 3811404 \\
\hline 15 & 13 & 6992849 & 13770908 & 6995680 & 6647154 \\
\hline 21 & 14 & 5721862 & 5468937 & 6482792 & 6566758 \\
\hline 27 & 15 & 6110539 & 2104404 & 6656376 & 6998221 \\
\hline 33 & 16 & 5000306 & 618793 & 5319334 & 5919954 \\
\hline 40 & 17 & 5180493 & 403332 & 6820177 & 7125307 \\
\hline 45 & 18 & 4723602 & 0 & 6672519 & 6784473 \\
\hline 51 & 19 & 3786645 & 0 & 6094264 & 5916786 \\
\hline 57 & 20 & 4281344 & 0 & 6258164 & 5988273 \\
\hline 63 & 21 & 4209365 & 0 & 6258794 & 6318566 \\
\hline
\end{tabular}

\begin{tabular}{|r|r|r|}
\hline \multicolumn{3}{|c|}{ Yield, Normalized } \\
\hline Styrene & 1st Peak & 2cd Peak \\
\hline 1 & 0 & 0 \\
\hline 1 & 0 & 0 \\
\hline 1 & 0 & 0 \\
\hline 1 & 0 & 0 \\
\hline 1 & 0 & 0 \\
\hline 1 & 0 & 0 \\
\hline 1 & 0 & 0 \\
\hline 1 & 0 & 0 \\
\hline 0.995929 & 0.004071 & 0 \\
\hline 0.957962 & 0.022095 & 0.019943 \\
\hline 0.929983 & 0.039014 & 0.031003 \\
\hline 0.875324 & 0.059981 & 0.064695 \\
\hline 0.591229 & 0.205382 & 0.203389 \\
\hline 0.371043 & 0.302758 & 0.326199 \\
\hline 0.186467 & 0.382786 & 0.430747 \\
\hline 0.085288 & 0.415014 & 0.499699 \\
\hline 0.050358 & 0.447467 & 0.502175 \\
\hline 0.013558 & 0.472119 & 0.514323 \\
\hline 0.012036 & 0.485047 & 0.502917 \\
\hline 0.013518 & 0.489195 & 0.497287 \\
\hline 0.012854 & 0.474159 & 0.512987 \\
\hline
\end{tabular}

Moles Styrene =

Moles Heptane $=$

0.02107071

0.00443298

Wt. of catalyst could not be measured; catalyst is air sensitive and complicates quantification.

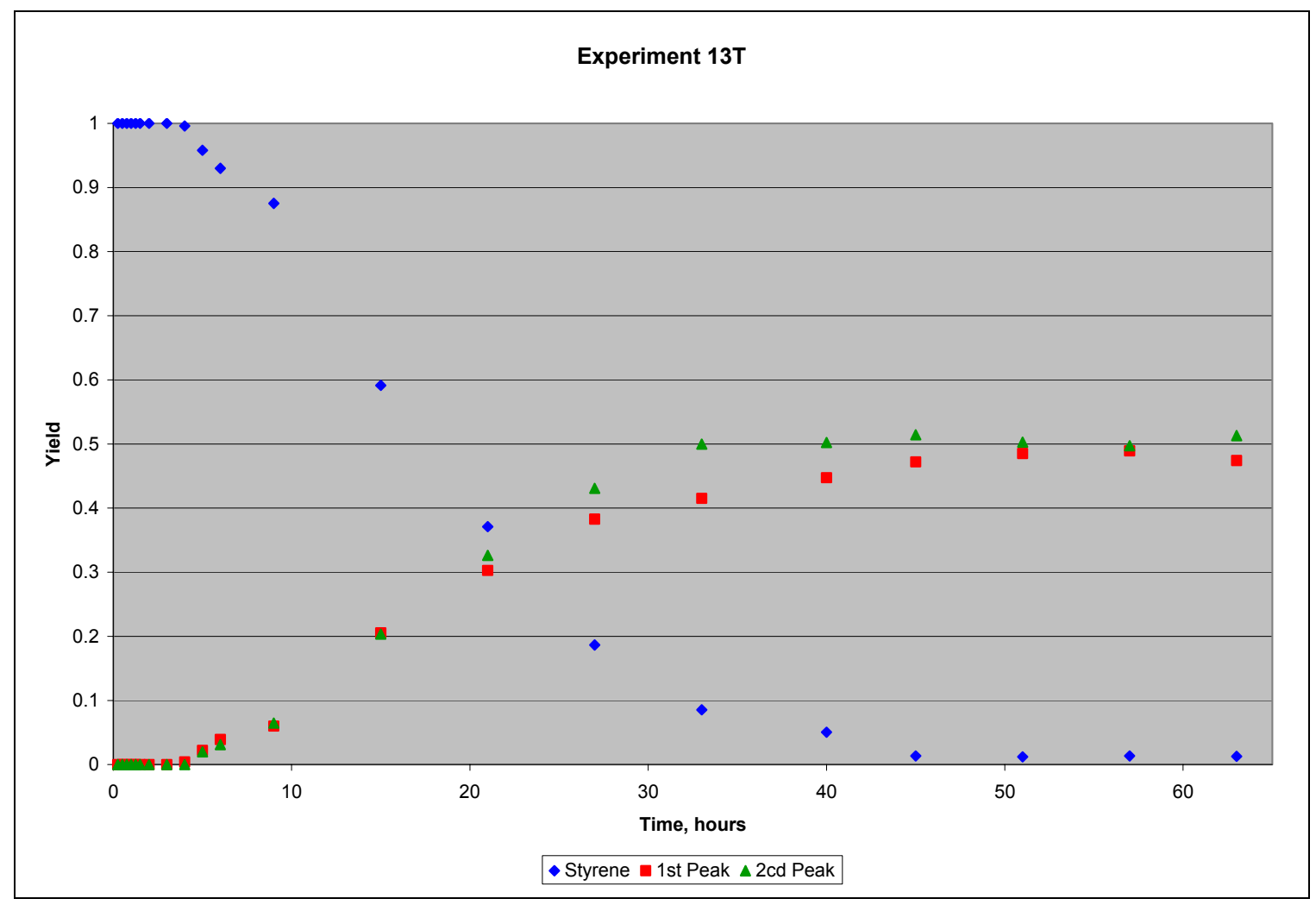


14U - [RhCl(C8H12)]2 \& TPP; Rh:P=1:8; Pre: $90^{\circ} \mathrm{C} \& 2000$ psig; Rxn.: $75^{\circ} \mathrm{C} \& 3000$ psig

\begin{tabular}{|c|c|c|c|c|c|c|c|c|}
\hline \multicolumn{6}{|c|}{ Raw Data } & \multicolumn{3}{|c|}{ Yield, Normalized } \\
\hline time & Sample & Heptane & Styrene & 1st Peak & 2cd Peak & Styrene & 1st Peak & 2cd Peak \\
\hline 0.25 & 1 & 4859176 & 22260064 & 0 & 0 & 1 & 0 & $\overline{0}$ \\
\hline 0.5 & 2 & 5105566 & 23057198 & 0 & 0 & 1 & 0 & 0 \\
\hline 0.75 & 3 & 5851802 & 27506135 & 0 & 0 & 1 & 0 & 0 \\
\hline 1 & 4 & 4620525 & 21596184 & 0 & 0 & 1 & 0 & 0 \\
\hline 1.25 & 5 & 4535804 & 21456363 & 0 & 0 & 1 & 0 & 0 \\
\hline 1.5 & 6 & 4242289 & 20119867 & 0 & 0 & 1 & 0 & 0 \\
\hline 2 & 7 & 4333144 & 20007712 & 0 & 0 & 1 & 0 & 0 \\
\hline 3 & 8 & 4298710 & 20313502 & 0 & 0 & 1 & 0 & 0 \\
\hline 4 & 9 & 4447023 & 20192326 & 0 & 0 & 1 & 0 & 0 \\
\hline 5 & 10 & 4457989 & 21122882 & 0 & 0 & 1 & 0 & 0 \\
\hline 6 & 11 & 4153121 & 19730807 & 0 & 0 & 1 & 0 & 0 \\
\hline 9 & 12 & 4433523 & 19711954 & 0 & 0 & 1 & 0 & 0 \\
\hline 24 & 13 & 3991692 & 18437953 & 0 & 0 & 1 & 0 & 0 \\
\hline 41.25 & 14 & 4290853 & 18102311 & 610817 & 540052 & 1 & 0 & 0 \\
\hline 48 & 15 & 3967036 & 16003522 & 949030 & 816145 & 0.981495 & 0.015551 & 0.002955 \\
\hline 53 & 16 & 4261643 & 17370204 & 1065284 & 945599 & 0.976185 & 0.017423 & 0.006392 \\
\hline 59 & 17 & 3862849 & 14633767 & 942219 & 784041 & 0.979981 & 0.017522 & 0.002497 \\
\hline 72 & 18 & 3861851 & 15437684 & 846428 & 874016 & 0.980834 & 0.011639 & 0.007527 \\
\hline 79.75 & 19 & 3923611 & 14233707 & 1022163 & 1148067 & 0.95483 & 0.021409 & 0.023761 \\
\hline
\end{tabular}

Moles Styrene $=$

Moles Heptane $=$

Wt. of $[\mathrm{RhCl}(\mathrm{C} 8 \mathrm{H} 12)] 2(\mathrm{~g})$

Wt. of Ligand $(\mathrm{g})$
0.02112026

0.00538105

0.0110

0.0908

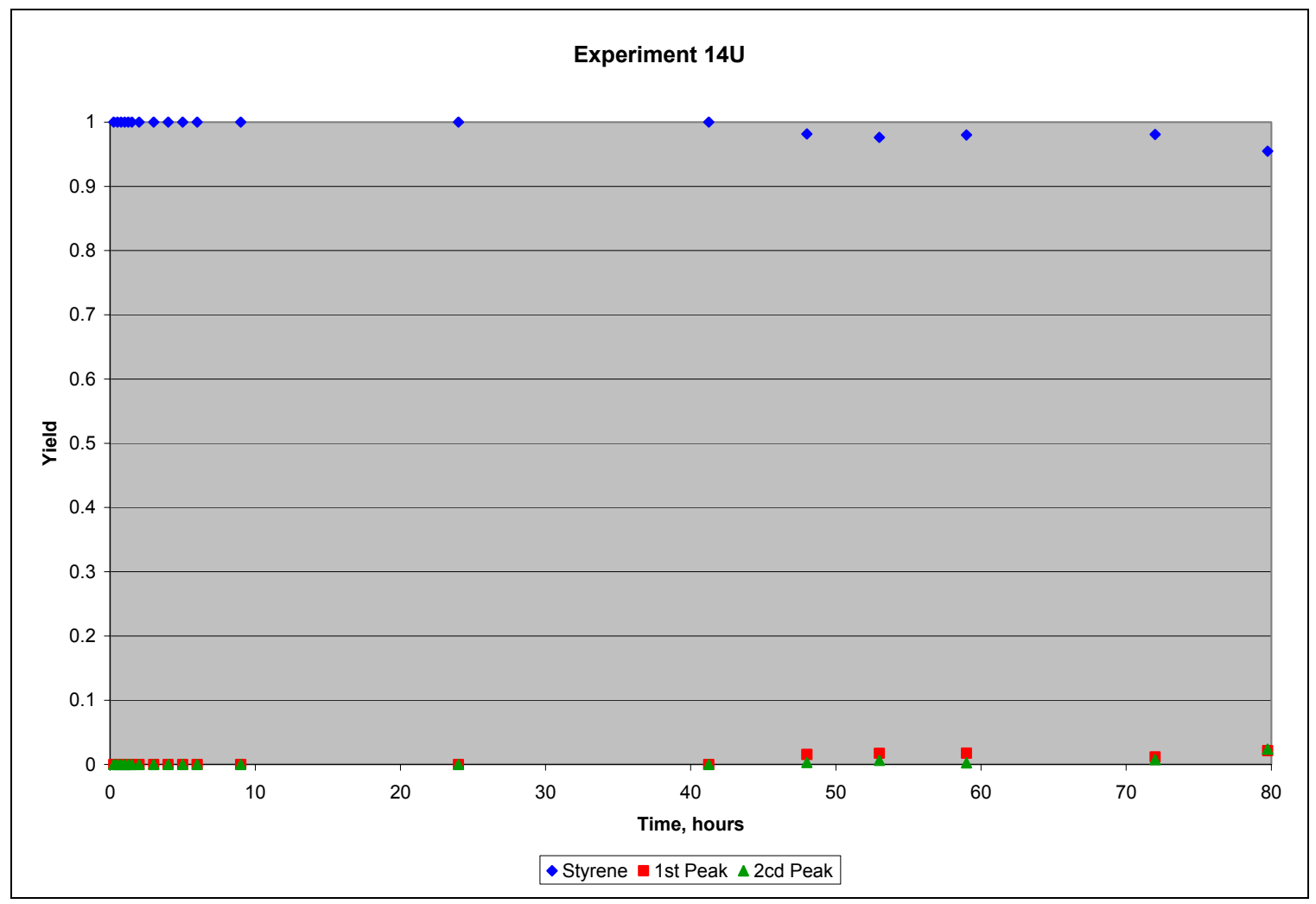

